\title{
Psychosocial moderators in the relation between CD4 count and physical symptoms among African American women with HIV
}

\author{
Cara F. O'Connell \\ West Virginia University
}

Follow this and additional works at: https://researchrepository.wvu.edu/etd

\footnotetext{
Recommended Citation

O'Connell, Cara F., "Psychosocial moderators in the relation between CD4 count and physical symptoms among African American women with HIV" (2005). Graduate Theses, Dissertations, and Problem Reports. 2262.

https://researchrepository.wvu.edu/etd/2262

This Dissertation is protected by copyright and/or related rights. It has been brought to you by the The Research Repository @ WVU with permission from the rights-holder(s). You are free to use this Dissertation in any way that is permitted by the copyright and related rights legislation that applies to your use. For other uses you must obtain permission from the rights-holder(s) directly, unless additional rights are indicated by a Creative Commons license in the record and/ or on the work itself. This Dissertation has been accepted for inclusion in WVU Graduate Theses, Dissertations, and Problem Reports collection by an authorized administrator of The Research Repository @ WVU. For more information, please contact researchrepository@mail.wvu.edu.
} 
Psychosocial Moderators in the Relation between CD4 Count and Physical Symptoms among African American Women with HIV

Cara F. O'Connell, M.A.

Dissertation submitted to the Eberly College of Arts and Sciences at West Virginia University in partial fulfillment of the requirements for the degree of

Doctor of Philosophy

in

Clinical Psychology

Kevin Larkin, Ph.D.

Deborah J. Jones, Ph.D.

Stanley Cohen, Ph.D.

Daniel McNeil, Ph.D.

Lesley Cottrell, Ph.D.

Department of Psychology

Morgantown, West Virginia

2005

Keywords: HIV/AIDS, Depression, Optimism

Copyright 2005 Cara F. O’Connell 


\section{ABSTRACT \\ Psychosocial Moderators in the Relation between CD4 Count and Physical Symptoms among African American Women with HIV}

\section{Cara F. O’Connell}

The current study examined the link between immune functioning (CD4 count) and physical symptoms, as well as the moderating role of optimism and depressive symptoms, in a sample of 99 low income, inner city African American women with HIV. Although there was no main effect of CD4 count on physical symptoms, depressive symptoms moderated the association between CD4 count and physical symptoms. More compromised immune functioning (lower CD4 count) was associated with more physical symptoms under conditions of higher levels of depressive symptoms, but not lower levels of depressive symptoms. This finding was observed using both a self-report measure and a clinician-rating of women's depressive symptoms. There were no main or interactive effects for optimism, suggesting that optimism may not significantly moderate the impact of immune functioning on physical symptoms. The finding that depressive symptoms function to exacerbate the physical impact of CD4 count among African American women has several implications for clinical work among this population. Specifically, the assessment and treatment of depressive symptoms may enhance both emotional and physical functioning among this population. Directions for future research are presented. 
Table of Contents

\begin{tabular}{|c|c|}
\hline Abstract & Page ii \\
\hline Introduction & Page 1 \\
\hline Method & Page 30 \\
\hline Results & Page 38 \\
\hline Discussion & Page 48 \\
\hline References & Page 72 \\
\hline Table 1 & Page 89 \\
\hline Table 2 & Page 91 \\
\hline Table 3 & Page 93 \\
\hline Table 4 & Page 95 \\
\hline Table 5 & Page 97 \\
\hline Table 6 & Page 98 \\
\hline Table 7 & Page 99 \\
\hline Table 8 & Page 100 \\
\hline Table 9 & Page 101 \\
\hline Table 10 & Page 102 \\
\hline Table 11 & Page 103 \\
\hline Table 12 & Page 104 \\
\hline Figure 1 & Page 105 \\
\hline Figure 2 & Page 106 \\
\hline Appendix A & Page 107 \\
\hline Appendix B & Page 109 \\
\hline
\end{tabular}


Appendix C

Appendix D

Appendix E

Appendix F
Page 110

Page 113

Page 115

Page 118 


\section{Acknowledgements}

The author wishes to acknowledge her two mentors, Dr. Deborah Jones and Dr.

Kevin Larkin, for their dedication and support in completing this milestone.

I extend my deepest gratitude to Dr. Deborah Jones for her encouragement, support, and enduring optimism. Her generosity of time, energy, and spirit were fundamental to the completion of this milestone and my development as a professional.

My deepest thanks to Dr. Kevin Larkin for his guidance throughout the past four years. I am grateful for his kindness, unwavering support, and dedication to my development.

It has been a privilege to work with two gifted and dedicated professionals who have demonstrated an unwavering commitment to my personal and professional development.

I am also deeply grateful to my committee members, Dr. Stan Cohen, Dr. Daniel McNeil, and Dr. Lesley Cottrell. I thank each of them for their valuable contribution to the development and completion of this project and their time, effort, and dedication.

Finally, I thank my parents, Joseph and Cynthia O'Connell, for their love and enduring enthusiasm for my academic pursuits. 
Overview

HIV/AIDS is a preventable, but chronic illness that disproportionately affects low-income, African American women of childbearing age (CDC, 1999). A primary immune marker of HIV/AIDS status is CD4 count, with lower CD4 counts indicating more compromised immune functioning. Whether CD4 count is a reliable marker of women's experience of HIV/AIDS has received relatively little empirical attention. The purpose of the current study is to examine the association between CD4 count and physical symptoms among low-income, African American women with HIV/AIDS, as well as two psychosocial moderators of this association, optimism and depressive symptoms.

\section{HIV/AIDS as a Public Health Problem}

Currently, it is believed that between 800,000 and 900,000 individuals are living with HIV in the United States. Additionally, as of the year 2000, there were over 300,000 documented cases of individuals living with AIDS in the United States and it is estimated that nearly 500,000 AIDS-related deaths have occurred since the year 2000 (Centers for Disease Control and Prevention; [CDC], 2003). Despite the devastating impact of HIV/AIDS on public health and the preventability of virus transmission, individuals continue to engage in behaviors that render them vulnerable to contracting the virus, such as unprotected sex and needle sharing. Several routes of transmission of HIV, the virus that causes AIDS, have been identified. HIV may be transmitted through bodily fluids, including blood, semen, vaginal fluid, and breast milk. The most common method of transmitting HIV is through sexual contact with an infected person; however, HIV may also be transmitted through the use of contaminated needles, syringes, and transfusions. 
In addition, the virus may be passed from mother to child during pregnancy, childbirth, or by breastfeeding after birth. Small traces of HIV have also been detected within human saliva and tears; however there are no documented cases of transmission of HIV via contact with these fluids (CDC, 2003).

HIV/AIDS remains a disease without a cure. According to the National Institutes of Health (NIH), there are currently several approved antiretroviral drugs that have been offered to treat HIV. Simply put, these medications target the retrovirus, known as HIV, and inhibit the action of the virus. Combination therapies, including highly active antiretroviral therapy (HAART) are now widely used in the treatment of individuals with HIV/AIDS and have been proven to significantly increase survival time (NIH, 2003). These treatments often involve the combination of antiretroviral drugs, including reverse transcriptase and protease inhibitors. These combinations are believed to counter drug resistance, a common barrier to the treatment of HIV, while effectively targeting the virus.

Despite the medical advances that have been made in the treatment of the virus, issues related to compliance with and availability of the current antiretroviral drugs remain. First, individuals who adhere to the antiretroviral treatment regimen often are required to make dietary changes and undergo periods of fasting. Additionally, they may experience unpleasant side effects, including vomiting, as well as potentially dangerous complications, such as bone loss, heart failure, nerve damage, and muscle wasting (NIH, 2003). Currently, the CDC estimates that between $61-69 \%$ of individuals who meet eligibility receive prescriptions for HAART (2003). Socioeconomic factors, including health insurance status and income, have been shown to impact prescribing trends for 
individuals with HIV/AIDS. Specifically, it has been documented that individuals who have private insurance are more likely to have the treatment prescribed to them and patients who do not have insurance are significantly less likely to receive a prescription (CDC, 2003).

The Progression of HIV/AIDS among African American Women

African American women with HIV/AIDS may experience an illness progression markedly different from that of Caucasian women. First, several factors unique to women with HIV/AIDS exist that may impact the progression of illness and subsequent quality of life. These factors include hormonal fluctuations, immune changes during pregnancy, concerns surrounding becoming pregnant, and issues related to equal access to medical services (Melnick et al., 1995; van Servellen et al., 1998). Additionally, women have been shown to demonstrate more cognitive impairment as a result of HIV, as well as more pronounced declines in functional abilities, relative to men (Bornstein, Nasrallah, Para, Whitacre, \& Fass, 1993). Other issues that may serve as significant stressors for women living with HIV/AIDS include concerns related to child care; in particular, who will care for their children after their death (Harris \& Dennis, 1997)? These issues may present an even greater challenge to African American women who, relative to Caucasian women, are more likely to be living in poverty and heading single-parent households (U.S. Census Bureau, 2004).

Across gender, African Americans in the United States have significantly higher rates of mortality from infectious diseases, including HIV/AIDS, relative to Caucasians (Richardus \& Kunst, 2001; Sorlie, Rogot, Anderson, Johnson, \& Backlund, 1992). These disparities have been found to remain even after controlling for income. Data suggest that 
African American women with HIV/AIDS have significantly decreased survival estimates as well (CDC, 1999; Denenberg, 1997). These differences in survival have been reported for African Americans and Caucasians with HIV/AIDS who endorse similar levels of adherence to medication and treatment regimens (McGinnis et al., 2003). Among individuals who are infected with HIV, half of all HIV-related deaths occur among African Americans (CDC, 1999) and AIDS represents the third most common cause of death among African American women aged 25 to 44 in 1999 (CDC, 2003). In fact, issues related to decreased life expectancy among African American women with HIV have been cited as an obstacle for their inclusion in clinical trials (Adams-Campbell et al., 2004). Given the prevalence of HIV/AIDS among this population, as well as the serious threat that the illness presents to the physical functioning and wellness of African American women, research examining both the physical and psychological factors that impact illness progression is warranted.

Psychosocial Aspects of HIV/AIDS

Although antiretroviral treatments, when used properly, may prolong the lifespan of an infected individual, HIV/AIDS remains a chronic but inevitably fatal illness without a known cure (Revicki, Wu, \& Murray, 1995). Therefore, research that focuses on improving the quality of life for individuals with HIV/AIDS is particularly important for maintaining the well being of a population that potentially confronts a lifetime of physical and psychosocial challenges. In addition to the physical health stressors associated with HIV/AIDS, the stigma attached to the disease has been compared to that of a "social contaminant," (p. 263) where negative attitudes held by the general public towards traditionally marginalized groups are intertwined with belief systems 
surrounding individuals with HIV/AIDS (Pryor \& Reeder, 1993). This social marginalization is particularly evident among African American women infected with HIV/AIDS, who are generally of low socioeconomic status (Armistead \& Forehand, 1995). Moreover, African American women are more likely to have limited access to services (Melnick et al., 1995), are more likely to function as the sole care-taker of their children (Michaels \& Levine, 1992), and appear to be at elevated risk for partner abuse (Stark \& Flitcraft, 1995), relative to women of other ethnicities.

Given the unique social stressors confronted by individuals living with HIV/AIDS, as well as the elevated rates of mental health problems among this population, an understanding of the psychosocial factors that potentially facilitate enhanced functioning, as well as compromised health status and impaired quality of life, is warranted. Currently, extensive research exists related to physical and emotional functioning among gay and bisexual men with HIV/AIDS. However, there is significantly less research that has been dedicated to examining these factors among African American women - a group that, in addition to HIV/AIDS, may confront a variety of stressors associated with variables such as poverty and inadequate health care services.

Women currently represent an understudied yet at-risk group within the literature related to HIV/AIDS. Much attention has been dedicated to gay and bisexual men living with the disease and the psychosocial factors that impact its progression among this population. For gay and bisexual men, it has been well established that psychological factors such as depression and optimism have a substantial impact on functioning and disease progression. For example, Cruess et al. (2000) examined immunological markers 
of physical health and found a significant negative relation between optimism and antibody titers. Specifically, gay and bisexual men with lower levels of optimism were found to have higher viral load, indicating more advanced progression of illness. These findings suggest that optimism may protect against compromised immune functioning among gay and bisexual men and lower levels of optimism may serve as a correlate of disease progression.

Additionally, Holmes and Pace (2002) reported higher CD4 counts for gay men who had higher levels of optimism. Related to depression, gay men with HIV/AIDS have been found endorse higher levels of depressive symptomology, relative to their noninfected counterparts (de Vroome, de Wit, Stroebe, Sandfort, \& van Griensven, 1998) and endorse elevated rates of both suicide and multiple suicide attempts (Paul, Catania, \& Pollack, 2002). Moreover, elevated rates of depressive symptoms have been linked to negative health outcomes among gay men, including higher prevalence of AIDS-related medical conditions (Lesserman, 2002).

The existing research examining psychosocial functioning among African American women with HIV/AIDS has consistently found elevated rates of depression among these individuals (Devine et al., 2000; Jones, Beach, Forehand, \& The Family Health Project Research Group, 2001a; Miles, Gillespie, \& Holditch-Davis, 2001). Research examining potential protective factors in the progression of HIV/AIDS among this population is more limited. Some preliminary findings appear to support the protective role of optimism among African American women with HIV/AIDS (Devine et al., 2000). 
The paucity of research examining potentially protective psychosocial mechanisms among this population is somewhat surprising, particularly given the substantial stressors confronted by African American women with HIV/AIDS. Therefore, the role of psychosocial variables in disease progression and physical functioning among African American women with HIV/AIDS remains unclear. Immune functioning, measured by $\mathrm{T}$ - helper lymphocytes (CD4 cells), as well as physical health symptoms (i.e., fatigue) are important indicators of health status among individuals with HIV/AIDS. Because of the chronic and progressive nature of the illness, it is important to examine the psychosocial variables that may potentially impact physical health to gain an understanding for the potentially modifiable factors that may impact the course of the illness. This study examined the association between immune functioning and physical symptoms, as well as two potential moderators of this link, optimism and depression, among African American women with HIV/AIDS.

\section{Physiological Correlates of HIV/AIDS}

\section{CD4 Count as a Marker of Disease Progression}

HIV is a chronic and progressive illness associated with compromised immune functioning which results from the destruction of T-helper lymphocytes (CD4 cells). CD4 is the abbreviation for the "cluster designation 4" marker, which has been identified as a primary receptor for HIV, the virus responsible for the destruction of T-helper lymphocytes, or CD4, cells (National Institute of Allergy and Infectious Diseases, NIAID; 1996). CD4 cells are responsible for many immune response functions, which include the destruction of foreign disease pathogens. When CD4 cells are destroyed, suppressed immune functioning results. 
The immune response involves both humoral and cellular immunity, which are mediated by B-cells and T-cells, respectively. Humoral immunity relates to the destruction of bacterial cells that promote infection, while cellular immunity combats viral and fungal infection (NIH, 2003). The process by which CD4 cells facilitate the destruction of foreign pathogens is executed through a complex interplay between the B and T cell lineages. In essence, CD4 T-cells regulate the functioning of all other cell lineages within the immune system, thereby coordinating efforts of these cells to destroy the specific pathogen that the body encounters. More specifically, the response to viral and fungal infections is most severely impeded when T-helper cell functioning is suppressed.

In contrast to T-cells, which are derived through the thymus and combat infections by elaborating substances that directly kill the fungus or virally infected cell, B-cells are produced from bone marrow and produce antibodies that target and lead to the destruction of bacteria. The compromised immune response associated with HIV results from the dysfunction of these T-helper cells and B-cells (2003).

HIV is a self-replicating virus marked by distinct periods of replication though the course of the illness. Upon infection, a replication 'burst' occurs, during which time an elevated viral load may be detected. This load decreases following infection and the progression of the virus (i.e., viral load) will vary as a function of several individual and biological factors. Specifically, when a foreign infection is acquired, such as a virus or a fungus, HIV infected cells may replicate more rapidly. This elevated replication results in a more compromised immune response, rendering the individual vulnerable to future infection and subsequent replication of HIV. An additional aspect of HIV-related disease 
progression is the autoimmune response, whereby healthy cells are mistaken for viral pathogens and subsequently destroyed. As a result of these changes in immune response, the total number of T-helper cells is decreased, which results in a decreased CD4 count.

The progression of disease status from HIV to AIDS is marked by the CD4 count, rendering this an important marker of immune functioning. Additionally, the CD4 count is a primary component of the disease staging criteria established by the CDC for tracking disease status among individuals with HIV/AIDS. According to the CDC, an individual with HIV who has a CD4 count of 200 or less meets criteria for a diagnosis of AIDS (1992), whereas a healthy adult would generally have a CD4 count range between 800 to 1200 (Manini, 1996). Although other markers of immune functioning, such as viral load, have emerged as important indicators disease progression, CD4 count remains a robust marker of immune functioning among individuals living with HIV/AIDS. That is, the measurement of CD4 count is used to make decisions regarding decisions to initiate antiretroviral medication and prophylaxis treatments among individuals with HIV/AIDS (CDC, 1992). Subsequently, CD4 count has been shown to as a reliable maker of immune response to pharmacological treatment of HIV across international samples of individuals living with the disease (Monaner, DeMasi, \& Hill, 1998). As a result, it is recommended that CD4 counts are measured between 3 and 6 month intervals among individuals with HIV (CDC, 1994).

\section{Self-reported Physical Symptoms as a Marker of Disease Progression}

Physical symptoms have emerged as an important predictor of health status and physical functioning among individuals with HIV/AIDS. Among the general public, selfreported physical symptoms, such as headaches, fatigue, or muscle pain are the leading 
cause of outpatient physician visits (Ellington \& Wiebe, 1999). Additionally, physical symptoms appear to have a strong link to disability and even mortality, controlling for other health indicators (Idler \& Beyami, 1997; Kroenke, Arrington, \& Mangelsdorff, 1990).

The relation between physical symptoms, health care utilization, and compromised health appears particularly significant among women. Specifically, women have been found to endorse elevated rates of physical symptoms, greater levels of healthrelated occupational impairment, higher use of prescription medications (Fe Caces, Harford, \& Aitken, 1998), and more visits to their physician, relative to men (Kaplan, Sullivan, Spetter et al., 1998; National Center for Health Statistics, 1994). Common physical symptoms experienced by women with HIV/AIDS include fatigue, sleep disturbances, weakness, and gynecological symptoms (Hudson, Lee, \& Portillo, 2003). In particular, women may experience a range of gynecological symptoms as a result of their HIV status ranging from vaginal discharge (Anorlu, Imosemi, Odeunukwe, Abudu, \& Otuonye, 2004) to cervical malignancies (Rojansky \& Anteby, 1996) that may result in discomfort In an investigation of the most common self-reported physical symptoms among a sample of women with HIV, Hudson et al. (2003) found that trouble falling asleep and general weakness were two of the most problematic physical symptoms reported by the majority of their sample. That is, of the 104 women with HIV that were sampled, the majority of the sample (75\%) ranked these two symptoms as most occurring most frequently. The authors also found that the majority of the sample endorsed significant symptoms of depression as well. 
Attention to the role of physical symptoms among individuals with HIV/AIDS has increased in recent years. Specifically, physical symptoms have emerged as a potential predictor of actual physical functioning and health status. Although CD4 count is a common physiological marker which provides a measure of disease status, research exists to suggest that CD4 counts may not consistently or accurately predict survival and may not reflect an individual's quality of life related to perceived wellness (Nott, Vedhara, \& Spickett, 1995). Additionally, interference of physical symptoms has been found to relate to the likelihood that women will seek HIV testing (Sherr et al., 1997).

Physical symptoms may be a more appropriate marker of physical wellness among African American women with HIV/AIDS. Across race and ethnicity, women appear to report more physical symptoms than men and this distinction remains even after controlling for depression (Kroenke \& Spitzer, 1998). Additionally, research suggests that levels of self-reported physical symptoms are consistently higher for African American women, relative to Caucasian women, and that these physical symptoms appear to be more strongly associated with functional impairment and distress among this population (Faucett, Gordon, \& Levine, 1994; McCraken, Matthews, Tang, \& Cuba, 2001). Specifically, a study conducted by Faucett and colleagues (1994) found that African American patients providing self-reports of postoperative pain were significantly more likely to endorse higher levels of pain, relative to patients of European descent. The authors suggest that these differences might be linked to differential learning histories among patients as a function of their ethnicity.

African American women also appear to place significantly greater emphasis upon physical symptoms when rating their health status, relative to Caucasians. A study 
investigating the role of physical symptoms on self-reported ratings of health found that African Americans relied upon physical symptoms when making self reports of their health status (Silverman, Smola, \& Musa, 2000). The impact of physical symptoms on these ratings remained, even after controlling for actual health status (e.g., presence of an identifiable illness). The authors suggested that Caucasians, who generally experience more favorable physical health status, relative to African Americans, may rely on factors related to disruption in functioning and functional status when rating physical health. In contrast, African Americans, who may experience greater illness-related impairment throughout the lifespan, may rely upon 'feeling healthy' as an adequate indicator of physical health.

\section{The Link between CD4 Counts and Self-Reported Physical Symptoms}

There is a current paucity of research examining the potential link between immune functioning and self-reported physical symptoms in the HIV/AIDS literature. Although measures of immune functioning, such as CD4 counts, have received more attention in the HIV/AIDS literature than physical symptoms, both factors appear to have an impact on physical health status and quality of life. It would seem logical that an individual with impaired immune functioning might endorse elevated numbers of physical health complaints (e.g., feel more sick). Conversely, it might also be predicted that an individual who experienced several physical symptoms might more likely have a suppressed immune system.

To date, only a handful of studies have attempted to examine the potential link between CD4 counts and self-reported physical health and findings are equivocal. A promising study involving the examination of immune functioning and physical 
symptoms was conducted using a sample of patients with chronic fatigue syndrome (CFS). Cruess et al. (2000) examined physical symptoms and perceived illness burden as two potential correlates of immune functioning among 27 patients with CFS and 46 healthy controls. Variables of interest included several immune markers, including CD3 and CD8 counts (T-cytotoxic/suppressor cells), activated T-lymphocytes, activated T cytotoxic/suppressor cells, and the ratio of CD4 to CD8 count. Additionally, participants rated the severity and frequency of their physical symptoms, and completed the Sickness Impact Profile and the Cognitive Difficulties Scale. The authors reported a significant link between immune functioning, physical symptoms, and illness severity. Specifically, suppressed immune functioning, as indicated by lower levels of T-suppressor/cytotoxic cells, was significantly and negatively correlated with the severity of physical symptoms. These findings suggest that among individuals with chronic illness, a significant correlation between suppressed immune functioning and elevated physical symptoms exists.

Petrie, Booth, Elder, and Cameron (1999) examined the relation between immune functioning and physical symptoms using a sample of 58 healthy individuals. Perceptions of immune status were measured using a global rating of both immune functioning and physical symptoms were collected from participants over the course of 5 weeks using the 54-item PILL symptom checklist (Pennebaker, 1982). Additionally, actual immune functioning was measured by collecting levels of CD3, CD4, CD8, and CD16 lymphocytes each week. The authors failed to find a relation between perceived and actual immune functioning, however, the two self-report measures of health were correlated. The link between actual immune functioning and physical symptoms was not 
reported, leaving important questions unanswered related to the potential relation between these two correlates of health.

Still other studies have reported rather inconsistent findings related to immune functioning and physical symptoms. Lee and colleagues (2001) examined the relation between fatigue - a physical symptom that has been found to correlate with progression of illness and mortality among individuals with HIV/AIDS — and CD4 counts among individuals with HIV/AIDS. The authors found that CD4 counts were not significantly related to rating of general fatigue, but were associated with increased daytime sleepiness.

Relatively few studies have directly examined the link between CD4 count and physical symptoms among individual with HIV/AIDS; however, those that examined laboratory-based markers of immune functioning have found an association with at least one self-reported physical symptom. Moreover, a related literature suggests that individuals under conditions of high levels of arousal can accurately report changes in other physiological markers of functioning. Studies have found that certain variables increase the accuracy with which individuals can provide reports of physiological variables such as heart rate reactivity, or the change in heart rate that occurs after exposure to a stressor (Goetsch, 1996; Stewart, Buffett-Jerrot, \& Kokaram, 2001). An investigation comparing highly-anxious individuals to those with lower anxiety sensitivity revealed that anxiety was positively related to more accurate self-reports of heart rate reactivity in response to an acute laboratory stressor (mental arithmetic) (Goetsch). These data suggest that individuals in heightened states of arousal may be more accurate reporters of their own physiology. 
Studies to date examining the association of CD4 count and physical symptoms have focused on gay and bisexual men with HIV/AIDS. Although any group with HIV/AIDS must deal with the stress and stigma of the illness, low-income, African American women are also confronting single motherhood, poverty, and concerns about who will raise their children upon their death. The first purpose of the current study was to examine the association between CD4 count and physical symptoms among low-income, African American women with HIV/AIDS. Building on the literature which has examined laboratory-based markers of immune functioning and physical symptoms, as well as the literature suggesting that under high conditions of stress, individuals are better reporters of physiological markers, it was predicted that CD4 count would be associated with physical symptoms both cross-sectionally and longitudinally. Specifically, it was predicted that more compromised immune functioning (lower CD4 count) would be associated with greater physical symptoms.

\section{Psychosocial Correlates of HIV/AIDS}

Overview of Psychosocial Factors Related to HIV/AIDS

Considerable variability exists in clinical symptoms, progression of the illness, and mortality among individuals with HIV/AIDS. Opportunistic infections often present throughout the course of the illness, while individuals may have other periods that are relatively symptom-free. Again, psychosocial variables may impact the course of the illness and the individual's overall quality of life, which underscore the importance of examining these factors among a population confronted by a chronic and progressive illness. 
Two seemingly antithetical psychosocial constructs that have received attention in the literature related to chronic illness are optimism and depression. Both optimism and depression appear to play a role in physical health and adjustment to and progression of chronic illness. Optimism has been linked to favorable outcomes among medical patients undergoing invasive medical procedures (e.g., lower levels of distress, improved quality of life) (Carver \& Scheier, 2003), as well as lower rates of morbidity and mortality, after controlling for medical variables (see Peterson, 2000, for a review). Additionally, in a prospective study examining optimism among individuals with a diagnosis of Type I Diabetes, rheumatoid arthritis, or multiple sclerosis, (ethnicity not reported) optimism was associated with more effective coping strategies, across the sample (Fournier, de Ridder, \& Bensing, 2002). Despite this link, the specific role of optimism related to physical and psychological functioning among individuals with HIV/AIDS is unclear. Conversely, depression has consistently been linked to negative physical and emotional health outcomes, ranging from decreased self-esteem among a sample of predominately Caucasian participants (Shahar \& Davidson, 2003) to early mortality (Romanelli, Fauerbach, Bush, \& Ziegelstein, 2002), suggesting a strong correlation between depression and compromised physical health.

The potential link between immune functioning and self-reported physical symptoms has important implications for understanding physical functioning and quality of life among individuals with HIV/AIDS. First, the extent to which these two distinct markers of wellness relate remains unclear. Second, it is unclear whether psychosocial variables, such as optimism or depression, moderate the link between immune functioning and physical symptoms. The current literature examining these factors among 
individuals with HIV/AIDS is limited and largely inconsistent, leaving important but unanswered questions relating to psychosocial variables and physical health.

In order to examine the moderating role of both optimism and depression in the association between CD4 count and physical symptoms in low-income African American women with HIV/AIDS, it is important to first define the role of any potential moderator variable and provide a clear definition of the psychosocial constructs to be examined. In addition, the existing literature examining both optimism and depression as they relate to physical health and illness generally, and HIV/AIDS specifically, will be reviewed.

Finally, the potential association between optimism and depression - that is, how these two variables may interact to impact both physical symptoms and immune functioning in women with HIV/AIDS--will be explored.

\section{Defining Moderators}

According to Baron and Kenny (1986), moderators are a frequently used but often confused concept in the literature. In their now classic article, the authors attempt to distinguish between mediators and moderators as they relate to the link between independent and dependent variables. For the purposes of the current study, moderators, or variables that either change or enhance the effect of an independent variable on a dependent variable, are of primary interest. In contrast, mediators function as "mechanisms" (p. 1173) that facilitate the relation between the independent and dependent variables (i.e., the independent variable impacts the dependent variable through the presence of a mediator) (Baron \& Kenny). In the current study, both optimism and depressive symptoms will be examined as potential moderators in the relation between CD4 count and physical symptoms. Although the proposed influence of 
these moderators differs (i.e., it is predicted that optimism will function as a buffer while depressive symptoms will function to exacerbate the link between CD4 count and physical symptoms), it is predicted that both variables will function as significant psychosocial moderators.

Optimism and Health

Optimism has long been the subject of both philosophical discussion and psychological theory, serving as a topic of debate for noteworthy philosophers, such as Descartes and Schopenhauer, as well as pioneering psychologists like Freud and James (Domino \& Conway, 2001). Popular expressions in the English language, such as, "look on the bright side of your life" and "it always works out for the best" reflect the continued emphasis on the importance of a positive attitude in our modern culture. The current relevance of the construct of optimism as a psychological variable, however, is multifaceted and not clearly understood. One reason for the inconsistencies in the current optimism literature may relate to the variety of definitions that have been offered to conceptualize this construct.

One of the most widely accepted conceptualizations of optimism is the expectancy-based model of dispositional optimism, which relates to an individual's expectations regarding his/her future (Carver \& Scheier, 2003). Specifically, dispositional optimism is defined in terms of perceptions surrounding the likelihood that either positive or negative outcomes will occur during one's lifetime (2003). Alternatively, optimism has been described as an explanatory style, relating to the causal attributes that an individual assigns to particular events (Buchanan \& Seligman, 1995). An individual with an optimistic explanatory style would therefore attribute successes to more intrinsic 
qualities and failures to external variables. Additionally, the optimism construct may be defined within the context of other variables, as is seen in several of the studies included in the current view. For example, optimism may be examined as it specifically relates to an individual's beliefs surrounding the severity of HIV/AIDS and is therefore described in the literature as "HIV optimism" (e.g., Elford, 2003).

Optimism appears to be related to a variety of important aspects of human functioning, ranging from improved physical health to greater emotional well-being. Research supports the link between optimism and mental health outcomes. For example, Boelen and van den Bout (2002) examined the role of dispositional optimism and positive thinking on symptoms of depression among a sample of 326 bereaved adults ranging in age from 18 to 70 years who had experienced the death of a parent, partner, child, or sibling within the past 3 years. The authors reported lower levels of depressive symptoms among participants who endorsed higher levels of optimism. Positive correlations have also been found between optimism and adaptive psychological strategies, such as approach coping among adolescents (Puskar, Sereika, Lamb, TusaieMumford, \& McGuinness, 1999). Also related to coping, Brisette, Scheier, and Carver (2002) examined depressive symptoms with the Beck Depression Inventory (BDI) short form (Beck, Rial, \& Rickels, 1974) and dispositional optimism with the Life Orientation Test (LOT; Scheier \& Carver, 1985) among a sample of first-year college students. The authors reported that higher levels of optimism were related to lower levels of both selfreported depressive symptoms and stress among these students.

The significance of optimism as a psychological construct is underscored by the current literature suggesting an association between optimism and favorable physical 
health outcomes. Optimism may serve as an important factor in the way that individuals handle stress and cope with hardship associated with illness (Carver et al., 1993; Lauver $\&$ Tak, 1995). Research exploring physical health and optimism to date has examined a range of physical health correlates. Optimism has been linked to favorable outcomes among medical patients undergoing invasive medical procedures (e.g., lower levels of distress, improved quality of life) (Carver \& Scheier, 2003), as well as lower rates of morbidity and mortality, after controlling for medical variables (see Peterson, 2000, for a review). Additionally, in a prospective study examining optimism among individuals with a diagnosis of Type I Diabetes, rheumatoid arthritis, or multiple sclerosis, optimism was associated with more effective coping strategies, across the sample (Fournier, de Ridder, \& Bensing, 2002).

Optimism and HIV/AIDS

Optimism appears to be an important predictor of physical and mental health outcomes. Higher levels of optimism have been linked to improved functioning across a variety of variables, from coping with stress (Carver et al., 1993) to lower morbidity and mortality (See Peterson, 2000, for a review). Various studies have related higher levels of optimism to improved functioning and resiliency among gay and/or homosexually active men with HIV/AIDS. A study by Cruess, Antoni, and Kilbourn et al. (2000) found that optimism was a correlate of improved immune functioning and lower levels of selfreported distress among gay men living with HIV/AIDS. The authors reported a significant negative correlation between optimism and higher levels of antibody titers to three Herpes viruses (indicating lower levels of immune functioning) was detected. Specifically, negative correlations were found between optimism and levels of HHV-6 
and EBV titers, with lower optimism scores associated with higher antibody titer counts. That is, individuals who endorsed less optimism displayed increased physiological signs of compromised health, as higher HHV-6 and EBV antibody titers indicate more advanced illness. Additionally, higher levels of optimism were significantly negatively correlated with fewer depressive symptoms suggesting a potentially protective or buffering role of optimism among this population.

Although optimism appears to function as a protective factor among gay men with HIV/AIDS, much less is known regarding the role of optimism in the functioning of women, particularly African American women, with the disease. Perhaps because African American women with HIV/AIDS are a group that often confront multiple psychosocial stressors, variables such as depression in relation to disease status has received considerably more attention in research conducted with African American women, relative to optimism.

Additionally, Jones, O'Connell, Gound, Heller, and Forehand (2004) examined the relation between optimism and symptoms of depression, as well as the influence of these variables on self-reported physical symptoms, in low income African American with HIV/AIDS, as well as a community comparison group who were not infected. Using hierarchical regression analyses, the authors reported a significant association between depressive symptoms and self-reported physical symptoms in both the HIV positive and non-infected group. Specifically, women with increased levels of depressive symptoms were found to have more elevated levels of physical symptoms, suggesting depressive symptoms may be a risk factor related to health outcomes. Although optimism buffered the association between depressive symptoms and physical symptoms in the non-infected 
group, optimism did not buffer this association in the HIV sample. The authors posited several explanations for this finding, including that higher levels of depressive symptoms in the HIV-infected group weakened the potential role of optimism as a buffer.

\section{Depression and Health}

Depression, in contrast to optimism, has been defined as a cognitive construct characterized by negative perceptions of one's self, the world, and one's future, and is associated with feelings of hopelessness (Beck, 1987). Depression represents a substantial public health problem as it is associated with decreased productivity and increased functional disability, as well as elevated morbidity and mortality (See Katon \& Sullivan, 1990, for a review). Moreover, the link between depression and mortality remains, even when factors such as physical illness, suicide, and accidents are controlled (see Katon \& Sullivan, 1990, for a review).

Rates of both depressive symptoms and depressive disorders are consistently higher among women, relative to men (Nolen-Hoeksema, 1987; 2001). Additionally, research suggests that African American women experience depression at significantly higher rates, relative to both Caucasian women and African American men (Brown, 1990). The link between depression and poor physical health outcomes is clear. Depressive symptoms and disorders are consistently correlated with higher rates of selfreported physical health symptoms (Hahn, Thompson, Wills, Stern, \& Budner, 1994; Kroenke et al., 1994). Additionally, individuals with a diagnosed medical illness appear to demonstrate elevated levels of psychiatric conditions and higher rates of major depression (Cassem, 1995; Wells, Golding, \& Burnham, 1988). Despite the pronounced and consistent link between depression and compromised physical health outcomes 
among the general population, evidence suggests that this link may be more significant for women. For example, factors such as heart rate variability may be more strongly associated with differences in depressive symptoms among women (Landen et al., 2004).

The association between depression and immune functioning has also been wellestablished. Individuals with depression appear to have decreased lymphocyte activity and altered levels of B-cells, T-cells, and helper and suppressor T-cells (Herbert \& Cohen, 1993), as well as altered levels of general immune competence (Weisse, 1992). One theory that has been offered to explain the mechanisms by which depression functions to impact immune responses relates to activity of the hypothalamic-pituitaryadrenal-axis (HPA), as well the sympathetic nervous system (SNS). Specifically, depression is believed to be linked to activation of both the HPA and the SNS, which release cortisol and catecholamines. Immune cells have receptors for both cortisol and catecholamines, which are released when the HPA and SNS are stimulated.

A second theory that has been offered to explain the link between depression and immune functioning relates to life-style patterns and general health behaviors among individuals with depression. Mechanisms for compromised immune functioning among depressed individuals may include alterations in sleep patterns, exercise, and diet. Maladaptive health behaviors, such as inadequate or disturbed sleep schedules, lack of physical activity, and poor eating habits are cornerstone behaviors among individuals with depression and are well-linked to compromised immune status.

A strong link has also been reported between depression and depressive symptomology and physical symptoms (Abbey, Toner, Garfinkel, Kennedy, \& Kaplan, 1990; Hahn et al., 1994; Kiecolt-Glaser, McGuire, Robles, \& Glaser, 2002). Biological, 
behavioral, and cognitive explanations have been offered to explain the relation between these constructs (Kiecolt-Glaser et al., 2002). Specifically, in the biological domain, it has been suggested that immune functioning may impact physical symptoms, while other explanations focus on health behaviors or the interpretation and perception of symptoms as possible mechanisms in this relation (for a review see Cohen \& Rodriguez, 1995).

Considering the strong link between physical symptoms, subjective wellness, and even early mortality (for a review see Strawbridge \& Walhagen, 1999), it is perhaps not surprising that physical symptoms and depressive symptoms appear to be linked, particularly among individuals with HIV/AIDS (Kalichman, Sikkema, \& Simpson, 1995; Rabkin et al., 1991). Debate exists surrounding the extent to which self-reported physical symptoms and the somatic symptoms of depression overlap (Drebing et al., 1994). This question may have particular relevance within the context of HIV/AIDS. Common symptoms of depression, such as weight loss and decreased energy, are also frequently reported physical symptoms among individuals with HIV/AIDS (Strober et al., 1997).

In an attempt to avoid some of the overlap between physical symptoms and somatic symptoms of depression, some studies have examined the unique contributions of each construct by eliminating somatic items on depression-related measures. However, Perkins and colleagues (1994) found that the physical and somatic symptoms measured by a depression scale (e.g., fatigue) correlated with the total depression score, but failed to significantly correlate with HIV disease progression parameters among a sample of individuals with HIV. These findings suggest that HIV-related physical symptoms and the somatic symptoms of depression may in fact relate to different dimensions of physical functioning. 
Depression and HIV/AIDS

Living with HIV/AIDS presents many potential physical, emotional, interpersonal, and financial stressors that may render individuals vulnerable to depressive symptoms and disorders. Estimated prevalence rates for major depression among individuals with HIV/AIDS have been reported to range from 10-15\%, while estimated frequency of depressive symptoms have been reported as high as $80 \%$ (Boccellari, Dilley, \& Shore, 1988; Ciesla \& Roberts, 2001). Research indicates that the rates of depression vary substantially as a function of particular demographic factors. For example, traditionally marginalized groups, including injection drug users and individuals utilizing public health clinics for HIV treatment, may have higher prevalence rates of depression (Lyketsos, Hanson, Fishman, McHugh, \& Treisman, 1994). In addition, African Americans living with HIV/AIDS also appear to have markedly higher prevalence rates of depression (Cochran \& Mays, 1994).

Depression and HIV/AIDS may also vary as a function of gender. Studies conducted examining depressive symptoms among women suggest women living with HIV/AIDS are at an elevated rate for experiencing depressive symptoms, with some estimates suggesting that as many as 50\% of HIV-infected women may endorse clinically significant levels of depression (Atkinson et al., 1988; Perkins et al., 1994). Considering the gender- and illness-related factors confronted by women living with HIV/AIDS, it is not surprising that prevalence of depressive symptoms and disorders among this population is alarmingly high.

Additionally, depression is a serious concern among minority women with HIV/AIDS. Using a sample of predominately African American women (84\%) living 
with HIV/AIDS, Catz, Gore-Felton, and McClure (2002) found that mean scores on the Center for Epidemiological Studies Depression Scale (CES-D) were significantly elevated $(M=24.9)$ and reflected high rates of clinically significant depressive symptoms. Additionally, an investigation of depressive symptoms among low income African American women with HIV demonstrated a higher prevalence of depressive symptoms among women with HIV, relative to demographically matched African American women who were not HIV infected (Jones et al., 2001a). These findings suggest that HIV infection presents an increased risk for depressive symptoms in an already high-risk group.

In their examination of HIV and depressive symptoms, Jones, Beach, and Forehand (2001b) found a significantly higher prevalence of depressive symptoms among an HIV-infected population of African American women, relative to a demographically similar non-infected sample. Additionally, depressive symptoms were found to be a significant predictor of self-reported physical symptoms, as measured with a modified version of the Physical Symptoms Inventory (PSI-modified; Wahler, 1969). Depressive symptoms were not found to correlate significantly with most recent CD4 count, which was gathered from participants' medical charts. The authors suggested that self-reported physical symptoms may function as an important marker of perceived wellness and subjective functioning in low-income African American women with HIV/AIDS.

\section{The link between Optimism and Depression}

The link between optimism and depression is a point of debate within the field. Optimism and depression might appear to be bipolar constructs; that is, two psychological variables at opposite ends of the spectrum. It remains unclear, however, 
whether the presence of one variable determines the absence of the other- that is whether an individual can be both 'optimistic' and 'depressed.' Conversely, it may be argued that optimism and depression pertain to different aspects of functioning, with optimism widely considered a trait or personality variable and depression considered a mood state. That is, although pessimism may be associated with depressive symptoms, one could be pessimistic and not depressed. Similarly, optimists are not necessarily immune to depression or depressive symptoms. Alternative conceptualizations of optimism have also been offered in the literature that suggests that one variable (i.e., optimism or depression) may function to predict the presence or absence of the other variable. Only a handful of studies exist examining the relation of optimism and depression among individuals with HIV/AIDS.

Jones et al. (2004) reported that optimism functioned as a psychological 'buffer' between depressive symptoms and self-reported physical symptoms among a sample of African American women. Specifically, for women experiencing elevated levels of depressive symptoms, those who were also highly optimistic experienced fewer physical symptoms than their less-optimistic counterparts. This finding suggests that optimism and depression may in fact function as two distinct psychosocial constructs that are not mutually exclusive.

van Servellen et al. (1998) examined the relation between optimism, anxiety, depressive symptoms, and physical functioning among a diverse sample, including African American women, with HIV $(n=44)$. The authors defined optimism as: "The tendency to look toward the future with hope and positivity" (p. 179) and measured the construct using a total of seven items derived from the Medical Outcomes Study-HIV 
questionnaire (MOS-HIV; Tarlov et al., 1989). Items were presented as statements (e.g., "I look forward to the future with hope") that participants responded to using a 5-point Likert scale. Symptoms of anxiety and depression were measured with the 14-item Hospital Anxiety and Depression Scale (HADS; Zigmond \& Snaith, 1983) that contained seven items for both anxiety and depression. Finally, physical health was assessed via patient self report of physical symptoms, T-helper/inducer (CD4+) count, and number of hospitalizations over the past year.

Optimism was significantly negatively correlated with symptoms of depression and anxiety, with lower levels of optimism related to elevated levels of depressive symptoms and anxiety. Additionally, the majority of participants endorsed elevated levels of physical symptomology, with $97.6 \%$ reporting fatigue and $66.7 \%$ endorsing pain. The authors concluded that optimism functioned as a protective factor against symptoms of depression and anxiety among women with HIV. The potential relation between optimism and self-reported physical symptoms was not examined.

In summary, the limited research that exists examining both optimism and depression as correlates of mental health has yielded mixed results. This may be in part due to the nature of the questions asked by researchers in the field. Jones et al. (2004) reported that individuals may posses high levels of both depression and optimism and that presence of both variables may have implications for physical health. Additionally, van Servellen et al. (1998) reported that individuals who endorsed lower levels of optimism also described higher levels of depression and anxiety. Accordingly, examination of the link between optimism and depression merits more attention in the field generally and may have particularly important implications for women with HIV. 
Optimism and Depression as Moderators of the Association between Physical Symptoms and Immune Functioning

As highlighted earlier, the literature to date suggests that CD4 count may be associated with how well individuals with HIV/AIDS are feeling, at least in some domains (e.g., daytime sleepiness), but the findings of studies to date which have been conducted almost exclusively with gay and bisexual men are inconsistent. One possibility for the inconsistency in findings was stated previously; that is, the link between CD4 count and physical symptoms is more consistent among groups who are under more chronic and elevated levels of stress. Another possibility for the inconsistency is that the association between CD4 count and physical symptoms is moderated by a third variable. To date, psychosocial moderators between immune functioning (i.e., CD4 count) and physical symptoms have received limited attention in the research.

Based on the literature highlighting the role of depressive symptoms and optimism in health and illness generally and HIV/AIDS in particular, the current study examined their role as moderators of the relation between CD4 count and self-reported physical symptoms in a population of low income inner city HIV-infected African American women. Of particular interest was whether the link between CD4 counts and physical symptoms was strengthened or weakened depending on the level of depression and optimism, respectively. Specifically, it was hypothesized that optimism would function as a buffer for the potentially negative health-related consequences of compromised immune functioning among the sample. That is, women with lower CD4 counts but higher levels of optimism were expected to endorse fewer physical health 
symptoms than those with lower CD4 counts but lower levels of optimism. Conversely, it was hypothesized that depression would strengthen associations between CD4 counts and physical symptoms. That is, a woman with lower CD4 counts but elevated levels of depression might report more physical health symptoms than a woman with lower CD4 counts but less depressive symptoms. These associations were examined both crosssectionally and longitudinally.

Finally, the interrelation of CD4 count, depression, and optimism was also examined as a predictor of physical symptoms, although analyses was considered exploratory, as the sample size precluded adequate power to detect a three-way interaction. It was hypothesized, however, that women with lower CD4 counts and elevated levels of depressive symptoms who are optimistic would demonstrate less physical symptoms, relative to women with low CD4 counts, elevated levels of depressive symptoms, and lower levels of optimism.

\section{Method}

\section{Overview of the Family Health Project}

The Family Health Project was a longitudinal investigation of African American women and their children residing in the inner city of New Orleans, LA (Family Health Project Research Group, 1998). Women living with HIV and residing with at least one biological child, as well as demographically similar women who were not infected, were recruited for this study. The purpose of the investigation was to examine physical and psychological functioning among women and their children, as well as the impact of HIV status on these variables. The project investigated several aspects of physical, psychosocial, and familial functioning. Variables included physical and self-reported 
markers of health status (e.g., immune functioning, physical symptoms), psychosocial variables (e.g., optimism, depression), and familial functioning (e.g., parenting, co-parent conflict). In addition, both internalizing and externalizing behaviors were examined among the children. Additionally, the impact of neighborhood variables (e.g., perceived neighborhood risk) and social support on parenting practices were examined. The present investigation represented secondary analyses of data collected as part of the Family Health Project and only data from the women with HIV were examined.

\section{Participants}

Participants included 99 African American women with HIV residing in the city of New Orleans, LA. The majority of participants (93\%) were recruited from a public HIV clinic and the additional 7\% were recruited from private practices in New Orleans. To be eligible to participate in the study, participants were required to have a CD4 count less than 600 , which reflects a stage of relatively advanced illness. All participants were required to have at least one biological child and no intravenous drug use within the past 6 months to be eligible to participate. Ninety-five percent of the women who were approached regarding participation agreed to enroll in the study. The sample was characterized by low socioeconomic status, with the majority of participants residing in government housing within the inner city of New Orleans. These housing projects were characterized by elevated crime rates, overcrowding, and poverty. Participant age ranged from 18 to 45 years, with a mean participant age of 30.73 (5.11) years. Thirty-three percent of the sample reported having less than a high school education. Additionally, the average monthly income reported for the sample was $\$ 613.22$ (397.98). On average, 
time since diagnosis was 2.9 years at Assessment 1. Additional demographic information for the sample is provided in Table 1.

\section{Interviewer training}

Both a sociological and psychological interview were conducted by members of the Family Health Project team. Sociologists and graduate-level sociology students conducted the sociological/sociodemographic interviews and $\mathrm{Ph}$.D.-level licensed clinical psychologists, as well as clinical psychology doctoral students, conducted the psychological interviews. Interviewers were educated with regards to special issues surrounding populations with HIV, as well as relevant cultural concerns for African American women. Additionally, because of the personal nature of the interview content, all of the interviews with women were conducted by female interviewers. Interviewers were trained in the use of all measures during the initial pilot data collection phase of the study, with training of new staff and continuing interviewers conducted every six months. Interviewers in-training practiced verbal administration of measures to project leaders during training sessions and verbal feedback was provided and interviews were scored for reliability. Interviewers were considered qualified to conduct interviews when $100 \%$ reliability was achieved on identified measures.

\section{Measures}

Focus groups and extensive pilot testing were conducted prior to selecting measures in order to ensure that selected measures were culturally sensitive and appropriate for the sample population (see Family Health Project, 1998).

Demographic information and Medication Status. Information related to age, education, number and age(s) of children, and income was collected from all participants. 
Additionally, information related to current use of antiretroviral medications, including Zidovudine (AZT), Zerit (d4T), Videx (ddI), HIVID (ddC) was obtained from medical records. The demographic questionnaire is shown in Appendix A.

Immune functioning. T-helper cell count (CD4), the independent variable in this study, was derived from the participants' medical records. The CD4 count obtained at each assessment period represented the serum collective in most recent proximity to the interview at Assessment 1 and 2. The contrast flow cytometry procedure was used to obtain a measure of CD4 count. The average amount of time between serum collection and assessment date (i.e., interview) was one month. CD4 counts were examined as a continuous variable and were assessed at Assessment 1 and 2. All laboratory work was conducted at Tulane Medical Center where the Family Health Project was centrally located.

Life Orientation Test (LOT; Scheier \& Carver, 1985). The LOT is an 8-item selfreport instrument developed to measure the construct of dispositional optimism, a moderator variable being tested in the current study. The items are presented as statements to which participants respond by rating their level of agreement with each statement. The LOT has been found to have adequate internal consistency (alpha $=.76$ ) and test-retest reliability (alpha $=.79)(1985)$. Anchors on the scale range from (0) Strongly disagree to (4) strongly agree. Four of the items are positively worded, including: "you always look on the bright side of things" and four of the items are negatively worded and require reverse scoring: "things never work out the way you want them to." Higher scores reflect higher levels of optimism. The LOT was assessed at Assessment 1 and 2. Coefficient alpha obtained for the LOT at Assessment 1 (alpha= 
$.76)$ and Assessment $2($ alpha $=.73)$ indicated adequate internal consistency of the measure. Test-retest reliability $(\mathrm{r}=.41, \mathrm{p}<.001)$ showed stability in the scores over time. The LOT is included in Appendix B.

Depressive Symptoms. Depressive symptoms, a moderator being tested in the current study, were measured using both clinician ratings and participant self report. The Hamilton Rating Scale for Depression (HRSD; Hamilton, 1960) was used to provide a clinician-rated measure of depressive symptoms. The HRSD is a widely used 17-item clinician-rated measure of depressive symptoms and is often used to provide a single 'total' score for depressive symptoms (Marsella, Hirschfeld, \& Katz, 1987). The measure has been found to be effective in the assessment of both depressive symptoms and clinically significant depression (Butcher, 1995). Factor analyses have revealed that the HRSD provides a measure of both cognitive/affective depressive symptoms as well as vegetative symptoms of depression (Rhoades \& Overall, 1983). The distinction between these domains of depression allows for the separate analysis of depressive symptoms including both cognitive/affective and vegetative symptoms, as well as controlling for vegetative symptoms. The HRSD was completed by a clinician during the course of each assessment interview.

Scores were derived by summing item totals for each participant, with higher scores indicating elevated levels of depressive symptoms. Because 7 of the items on the HRSD are structured to assess somatic complaints that may have significant overlap with HIV-related symptoms (e.g., loss of appetite, sleep disturbance), analyses were conducted twice, with and without the 7 somatic items, to determine whether any association of depression with CD4 and/or physical symptoms was maintained after removing 
overlapping items. This step was taken to control for overlap between the somatic domains of depression and HIV/AIDS. This overlap has been demonstrated in previous investigations (e.g., Stober, Schwartz, McDaniel, \& Abrams, 1997). The HRSD, both with and without somatic items, has been demonstrated to have adequate reliability and validity (Hedlund \& Vieweg, 1979). Interrater reliability for the HRSD was 0.77 at Assessments 1 and 2. Test-retest reliability analyses revealed a significant correlation between scores over time, $(r=.52, p<.001)$. The HRSD was examined at Assessment 1 and 2 and is shown in Appendix C.

Self-report of depressive symptoms also were measured using the Depression subscale of the Brief Symptom Inventory (BSI; Derogatis \& Spencer, 1982). The depression subscale is one of 9 subscales of the 53-item BSI and contains a total of 20 items to which participants rate the level that they have been bothered by each during the past 7 days. Items are rated from (0) not at all to (3) extremely and include: "trouble with your mind going blank" and "feelings of guilt." In a previous study with a demographically similar sample, the BSI was found to have adequate reliability and validity (Derogatis, Rickels, \& Rock, 1976). Scores on the depression subscale range from 0 to 60, with higher scores indicating more elevated levels of depressive symptomology. Coefficient alpha for the BSI was 0.82 at Assessment 1 and 0.84 at Assessment 2. Test-retest reliability indicated that scores were stable over time, $(r=.60$, $p<.001)$. The BSI was assessed at Assessment 1 and 2. The depression subscale is depicted in Appendix D.

Physical symptoms. A modified version of the Physical Symptoms Inventory (PSI-modified; Wahler, 1969) was selected to provide a measure of self-reported physical 
symptoms, the dependent variable in the current study. The PSI-modified is structured to assess perceived physical health concerns. Respondents provide a rating of the extent to which they have experienced or have been bothered by a range of physical symptoms. Items are rated on a 4-point Likert scale and range from (0) almost never to (4) nearly everyday and include: "losing weight" and "weakness in your muscles." Higher scores indicate elevated levels of physical symptoms. The PSI-modified was developed to measure physical symptoms among individuals 16 years and older and has been used to measure physical symptoms among African American women with HIV/AIDS in prior investigations (Jones et al., 2004). Moreover, physical symptoms measured with the PSImodified have been demonstrated to significantly relate to overt health behaviors, including higher levels of avoidance-based coping (O’Neil \& Zeichner, 1985) and increased medication use among patients with chronic pain (Daschbach, Lauzon, Caporoso, Houle, \& Remble, 2004). Internal consistency of the PSI-modified has been found to range from 0.88 to 0.94 (Wahler, 1973).

Both directions and items on the PSI-modified were altered to facilitate the oral administration of the measure and address issues related to cultural sensitivity. The PSImodified was subjected to focus groups and using feedback obtained from these groups, four items related to women's health (i.e., vaginal discharge) were added to the PSImodified and seven items were eliminated, rendering a modified version containing 39 items that was administered to all participants. At Assessment 1, a coefficient alpha of 0.91 was obtained, and at Assessment 2, alpha was 0.92. A significant test-retest correlation was obtained for the PSI-modified $(r=.60, p<.001)$. The PSI-modified is depicted in Appendix E. 


\section{Procedures}

African American women with HIV were approached at a public health clinic, as well as private medical practices, regarding their participation in this study. During regularly scheduled checkups, eligible women were approached by a member of the project team and given information regarding the study. Once eligibility was verbally confirmed, interested women were scheduled for an interview with a member of the project staff.

All interviews were conducted in a public medical clinic. Participants who required transportation were provided with free transportation via taxicab. At the start of the interview session, participants reviewed and signed an approved consent form. Upon completion of the consent agreement, participants engaged in a sociological interview during which demographic information was obtained. This interview lasted approximately one hour and participants received $\$ 50$ for their time.

The second interview was generally scheduled within two weeks of the initial sociological interview. This session consisted of a psychological interview and the oral administration of all measures, including the HRSD, the BSI, the LOT, and the PSImodified. Participants were given cue cards with descriptors (e.g., "not true," "sometimes true," and often true"), as well as numeric anchors (e.g., 0, 1, or 2), and illustrated aids (e.g., shaded thermometers) to assist them in responding to the items. In addition to the interview, participants' medical records were reviewed to obtain the most recent CD4 count and current antiretroviral drug regimen. 
Participants were contacted again 12 to 14 months following the first assessment and asked to participate in a follow-up session. The 12-14 month span was selected to track the physiological progression of illness, as well as provide a measure of changes in psychosocial functioning as disease status became more advanced. The same procedure described during assessment one was used during the second assessment period.

Results

\section{Preliminary analyses}

Bivariate associations were examined between all demographic variables, medication management variables, and physical symptoms, the outcome variable of interest in the current study, for both cross-sectional and longitudinal analyses.

Examining the data cross-sectionally at Assessment 1, lifetime history of street drugs, as well as genital ulcers and lymphadenopathy, were positively associated with physical symptoms. Participants who endorsed prior history of drug use $(r=.32, p<.05)$, had a diagnosis of lymphadenopathy $(r=.21, p<.05)$, or a diagnosis of genital ulcers $(r$ $=.32, p<.05)$ were more likely to endorse physical symptoms (see Table 1$)$.

Cross-sectionally at Assessment 2, pneumocytstis carinlipneumonia (PCP) was associated with higher levels of physical symptoms $(r=.38, p<.001)$, with participants having a diagnosis of PCP reporting higher levels of physical symptoms (see Table 2).

Longitudinal analyses revealed that a diagnosis of genital ulcers $(r=-.21, p<$ $.05)$, a diagnosis of human papilloma virus (HPV) $(r=.32, p<.05)$, or a prior history of drug use $(r=.32, p<.001)$ at Assessment 1 were associated with more physical symptoms at Assessment 2 (see Table 3). Demographic and medical variables associated with the outcome of interest were statistically controlled in respective primary analyses. 
Bivariate associations between major study variables and the outcome of interest, physical symptoms were also examined. At Assessment 1 , both the BSI $(r=.60, p<$ $.001)$ and the HRSD $(r=.52, p<.001)$ were significantly associated with PSI-modified. As predicted, higher levels of depressive symptoms were associated with higher levels of physical symptoms. Neither the CD4 $(r=-.09, p=\mathrm{ns})$ nor the LOT $(r=.17, p=\mathrm{ns})$ were significantly associated with PSI-modified at Assessment 1.

At Assessment 2, the pattern of correlations was the same. Both the BSI $(r=.55$, $p<.001)$ and the HRSD $(r=.63, p<.001)$ were significantly associated with PSImodified. Consistent with Assessment 1, women who reported higher levels of depressive symptoms also reported higher levels of physical symptoms. Again, neither CD4 ( $r=-.21, p=\mathrm{ns})$ nor the LOT $(r=.09, p=\mathrm{ns})$ were significantly associated with PSI-modified.

Longitudinally, significant correlations emerged between all major study variables and physical symptoms: BSI $(r=.47, p<.001)$, HRSD $(r=.49, p<.001)$, LOT $(r=.22, p<.05)$, and CD4 $(r=-.19, p<.05)$. Higher levels of depressive symptoms as measured by the BSI or HRSD at Assessment 1 were associated with greater physical symptoms at Assessment 2. Contrary to the proposed hypothesis, higher levels of optimism were associated with higher levels of depressive symptoms as well. Finally, women who had lower CD4 counts reported greater levels of physical symptoms.

A power analysis was conducted using the GPOWER program, a web-based power calculation device (Erdfelder, Faul, \& Buchner, 1996). Six predictors were entered per model, including three demographic variables, the independent variable, the moderator, and the two-way interaction. A medium effect size was selected, based upon 
previous work examining the association between depressive symptoms, optimism, and other health outcomes, and results revealed a power of .81 to detect significant effects using hierchical regression analyses.

\section{Primary Analyses}

Bivariate associations were followed up with hierarchical regression analyses to determine whether significant bivariate associations remained statistically significant after controlling for demographic and medical variables, as well as to examine the proposed interactions. Hierarchical regression analyses were conducted cross-sectionally and longitudinally using either the BSI or the HRSD to measure depressive symptoms, and the LOT to measure optimism. In the cross-sectional analyses at Assessment 1, lifetime history of street-drug use, as well as the diagnoses of genital ulcers and lymphadenopathy, were entered into Block 1. At Assessment 2, PCP was entered into Block 1 and longitudinally, genital ulcers, HPV, and lifetime history of street drugs were entered into Block 1. For cross-sectional analyses, CD4 count was entered into Block 2 and the proposed moderator variables were entered into Block 3 (BSI or HRSD, LOT). In Block 4, the 2-way interactions (LOT x CD4, BSI x CD4, or HRSD x CD4) were entered. In longitudinal analyses, CD4 count at Assessment 1 was entered into Block 2 and the averaged values of the moderator variables (BSI or HRSD and LOT) across Assessment 1 and 2 were entered into Block 3 . The proposed two-way interactions of CD4 x BSI, CD4 x LOT, and CD4 x HRSD, were entered into Block 4 in separate analyses. The outcome variable of interest was the PSI-modified at Assessment 2 for longitudinal analyses. The proposed moderator variables in the longitudinal analyses were averaged 
across time. This was done to provide a representative measure of psychosocial functioning over the time period of interest (i.e., the 12-14 month span).

Given the unexpected positive association between the LOT and the PSI-modified in the longitudinal bivariate analyses (higher levels of optimism were associated with more physical symptoms), as well as the weaker psychometrics for the LOT relative to the HRSD and BSI, hierarchical regression analyses were run separately for the BSI, HRSD, and LOT. Any significant findings using the HRSD were repeated using only the cognitive/affective items subscale to rule out the possibility that significant associations between the HRSD and the PSI-modified were due to women endorsing more physical symptoms on both.

All variables entered into the interaction terms were first centered, according to the recommendations of Aiken and West (1991). This step was taken to control for multicollinearity among the terms.

Cross-sectional analyses at Assessments 1 and 2 Cross-sectional analyses at Assessment 1 using the BSI

As demonstrated in Table 1, CD4 count was not significantly associated with physical symptoms, $\beta=-.02, p=$ ns. Depressive symptoms, $\beta=.54, p<.001$ were associated with physical symptoms. Women who reported higher levels of depressive symptoms reported more physical symptoms.

Although there was no main effect of CD4 count on physical symptoms, a significant BSI x CD4 interaction emerged, $\beta=-.19, p<.05$.

As per Baron and Kenny (1986), the significant interaction between BSI x CD4 was explicated using the recommendations of Aiken and West (1991). Accordingly, two 
regression lines were plotted for low (1 SD below mean) and high (1 SD above mean) values of the moderator (BSI-High and BSI-Low) at low and high values of the independent variable (CD4). The slope and intercept for each line were obtained using the web-based slope calculator for hierarchical multiple regression (Preacher, Curran, \& Bauer, 2004).

As demonstrated by the significant interaction term and evidenced in Table 1, the two plotted regression lines were significantly different from each other. The slopes of each regression line were tested to determine whether they were significantly different from zero at high and low values of depressive symptoms. The slope for the value of the BSI-High line (one standard deviation above the mean) was significantly different from zero $(t=-2.11, p<.05)$ indicating that CD4 significantly predicted physical symptoms among BSI-High women. The slope for the BSI-Low line (one standard deviation below the mean) did not differ significantly from zero $(t=-1.29, p=\mathrm{ns})$ indicating that CD4 did not significantly predict physical symptoms among BSI-Low women. Under conditions of high levels of depressive symptoms, CD4 count was a representative marker of physical symptoms among women with HIV (i.e., how they are feeling), but not under low levels of depressive symptoms (Figure 1).

\section{Cross-sectional analyses at assessment 2 using the BSI}

The hierarchical linear regression analyses were repeated at Assessment 2.

Missing values of the BSI, CD4, and physical symptoms variables were substituted with the mean values for these variables. Of the 17 participants who were lost between Assessments 1 and 2, 10 were deceased, 4 refused to participate, 1 had moved, 1 was 
incarcerated, and 1 had lost custody of her child (excluding her from the Family Health Project study).

As demonstrated in Table 5, depressive symptoms measured with the BSI were significantly associated with physical symptoms at Assessment $2, \beta=.46, p<.001$. These findings indicate that higher levels of depressive symptoms were associated with more physical symptoms at Assessment 2. There were no significant main effects of CD4 count on the PSI-modified at Assessment 2 and the proposed 2-way interaction was not significant.

Cross-Sectional analyses at Assessment 1 with HRSD

Hierarchical linear regression analyses were repeated to examine the impact of immune functioning on physical symptoms and the moderating role of depression, using the HRSD. All items on the HRSD, both vegetative and cognitive, were included in the analyses. As shown in Table 4, higher levels of depressive symptoms measured with the HRSD were again associated with elevated physical symptoms, $\beta=.61, p<.001$. Additionally, a significant 2-way interaction emerged: $\operatorname{HRSD}$ x CD4, $\beta=-.17, p<.05$.

The significant main effect and two-way interaction measured using both the vegetative and cognitive/affective items of the HRSD on physical symptoms were followed up to examine whether the relation would remain significant after controlling for somatic symptoms (vegetative items). The analyses were conducted using the HRSD with cognitive/affective items only, to control for any overlap between somatic symptoms of depression and physical symptoms (Rhoades \& Overall, 1983). Results revealed that the significant main effect of depressive symptoms on physical symptoms remained, $\beta=$ 
$.47, p<.001$. The two-way interaction between depressive symptoms and CD4 count also remained significant, $\beta=-.18, p<.05$ (see Table 6).

The two-way interaction of depressive symptoms and CD4 count was explicated by repeating the procedure described above for testing the slopes of both high and low values of depression. High and low values of the HRSD (HRSD-High and HRSD-Low) were plotted using values of one standard deviation above and below the mean, respectively. The slope calculator revealed that the slope calculated with HRSD-High was significantly different from zero $(t=2.53, p<.05)$, while the slope for HRSD-Low did not differ significantly from zero $(t=1.25, p=\mathrm{ns})$.

As demonstrated in Figure 2, the relation between CD4 count and physical symptoms emerged only at high levels of depressive symptoms. This finding is consistent with the significant interaction obtained using the BSI to measure depressive symptoms. These results suggest that after controlling for potential somatic overlap between symptoms of depression and physical symptoms of HIV/AIDS, clinician-rated depressive symptoms exacerbated the link between immune functioning and physical symptoms, such that women with high levels of clinician-rated depressive symptoms and low CD4 counts endorsed elevated levels of physical symptoms. This relation was not detected at low levels of clinician-rated depressive symptoms (see Figure 2).

Cross-Sectional analyses at Assessment 2 using the HRSD

At Assessment 2, hierarchical linear regression analyses were conducted using the HRSD and including all items to measure depressive symptoms. Again, missing values for all variables at Assessment 2 were replaced with the mean values of these variables. As shown in Table 5, depressive symptoms, measured with the HRSD, were significantly 
associated with physical symptoms, $\beta=.85, p<.001$, with higher levels of depressive symptoms positively associated with higher depressive symptoms. CD4 count did not emerge as a significant main effect, and the proposed 2-way interaction of HRSD x CD4 was not significant. Follow up analyses using only the cognitive/affective symptoms of depression, as measured by the HRSD, were found to significantly positively relate to physical symptoms, $\beta=.64, p<.001$ (see Table 7).

Cross-sectional analyses at Assessment 1 using LOT

Hierarchical linear regression analyses were repeated to examine the impact of optimism on physical symptoms and the moderating role of optimism, using the LOT. As shown in Table 8, optimism did not emerge as a significant predictor of physical symptoms and did not moderate the relation between immune functioning and physical symptoms at Assessment 1 (see Table 8).

Cross-sectional analyses using the LOT at Assessment 2

The predictive role of the LOT, as well as the potentially moderating function of optimism in the relation between CD4 count and physical symptoms, were examined in hierarchical regression analyses at Assessment 2. Again, the LOT did not emerge as a significant predictor of physical symptoms and did not function as a moderator in the relation between CD4 count and physical symptoms (see Table 9).

Longitudinal analyses

\section{Longitudinal analyses using the BSI}

Longitudinal analyses were conducted to examine the predictive role of CD4 count on physical symptoms, as well as the moderating role of depressive symptoms, measured with the BSI, across time. Genital ulcers, HPV, and lifetime history of street 
drug use were entered into Block 1. CD4 count at Assessment 1 was entered into Block 2 and the averaged value of depressive symptoms, measured with the BSI at Assessments 1 and 2, was entered into Block 3. The proposed two-way interaction term of CD4 count at Assessment 1 and the averaged value of the BSI was entered into Block 4.

Results revealed a significant main effect of depressive symptoms on physical symptoms over time, $\beta=.50, p<.001$, with elevated depressive symptoms averaged across time predicting higher levels of physical symptoms at Assessment. 2 This relation did not remain significant, however, after controlling for physical symptoms at Assessment $1, \beta=.19, p=$ ns. None of the remaining analyses were significant (see Table 10).

\section{Longitudinal analyses using HRSD}

Longitudinal analyses were repeated using the HRSD to measure depressive symptoms. The procedure described using the BSI for longitudinal analyses was replicated, substituting the HRSD for the BSI.

A main effect of depressive symptoms, averaged across time, on physical symptoms at Assessment 2 was again significant, $\beta=.69, p<.001$. Higher levels of depressive symptoms averaged across assessments predicted elevated physical symptoms at assessment 2 , and this association remained after controlling for physical symptoms at Assessment $1, \beta=.67, p<.001$.

The analyses were repeated for a third time, using only the cognitive and affective items contained in the HRSD and controlling for physical symptoms at Assessment 1. The direction and significance of the main effects for depressive symptoms, $\beta=.31, p<$ .001 , remained significant over time. CD4 count did not emerge as a longitudinal 
predictor of physical symptoms and did not interact with the HRSD to predict physical symptoms across time (see table 11).

\section{Longitudinal analyses using LOT}

Hierarchical regression analyses were again repeated using the LOT to measure optimism. The moderating role of LOT scores, averaged across Assessments 1 and 2, in the relation between CD4 count at Assessment 1 and physical symptoms at Assessment 2, was examined. The LOT did not emerge as a significant predictor or moderator in longitudinal analyses (see Table 12).

\section{Exploratory Analyses}

The proposed three-way interaction of CD4 x BSI x LOT and CD4 x HRSD x LOT were considered exploratory. Neither of the three-ways interactions was statistically significant in the current analyses when included in a fifth block in the regression analyses. At Assessment 1, neither three-way interaction of BSI x CD4 x LOT, $(\beta=.03$, $p=\mathrm{ns})$ or the HRSD $x$ CD4 $x$ LOT, $(\beta=-.10, p=\mathrm{ns})$ emerged as significant. The proposed 3-way interactions of BSI x CD4 x LOT $(\beta=.02, p=n s)$ and the HRSD x CD4 $\mathrm{x} \operatorname{LOT}(\beta=-.08, p=\mathrm{ns})$ were not significant at Assessment 2 as well. In longitudinal analyses, neither the 3 -way interactions of BSI x CD4 $x$ LOT $(\beta=.17, p=n s)$ or HRSD $\mathrm{x}$ CD4 x LOT $(\beta=-.04, p=n s)$ were significant. A post hoc analysis of power was conducted to examine the probability of rejecting a false null hypothesis. Based upon the inconsistent findings in the literature to date, a small effect size was selected. With the sample size of the current study, the power of the three-way interaction was 0.1274 , suggesting that with the current sample size, the probability of rejecting the null hypothesis was very small. 


\section{Discussion}

The purpose of this study was to examine the impact of immune functioning (CD4 count) on physical symptoms, as well as the potentially moderating role of depressive symptoms and optimism, among low-income, African American women with HIV/AIDS cross-sectionally at two assessments as well as longitudinally between assessments. There was no significant main effect of CD4 count on physical symptoms cross-sectionally or longitudinally. The hypothesized association of depressive symptoms and physical symptoms emerged at both Assessments 1 and 2 using both the HRSD and the BSI; however, the main effects at Assessment 1 must be interpreted within the context of the obtained 2-way interactions. In contrast to expectations, no significant findings were detected using the LOT.

Longitudinally, depressive symptoms (measured with the BSI and the HRSD) predicted physical symptoms over time and the HRSD (but not the BSI) remained statistically significant after controlling for PSI-modified at Assessment 1. Neither CD4 count nor optimism emerged as a significant predictor of physical symptoms longitudinally.

\section{Immune Functioning as a Correlate of Physical Symptoms}

It was hypothesized that CD4 count would emerge as a significant correlate of physical symptoms among African American women with HIV/AIDS at Assessments 1 and 2. Women with lower CD4 count (more suppressed immune functioning) were predicted to report more physical symptoms, relative to women with higher CD4 count. This relation did not emerge in cross-sectional analyses at either Assessment period. That is, CD4 count was not a significant correlate of physical symptoms at Assessments 1 or 2. 
The existing literature surrounding the link between CD4 count and physical symptoms is limited, focused primarily on gay and bisexual men, and largely resulting in inconsistent findings. To date, a handful of studies have examined the link between general markers of immune functioning and physical symptoms. Lee and colleagues (2001) reported some evidence to support the link between CD4 count and physical symptoms among individuals with HIV/AIDS. Specifically, the authors found that CD4 count was significantly associated with increased daytime sleepiness. Interpretation of these findings is complicated by the fact that CD4 count did not relate to general ratings of fatigue, suggesting that the impact of CD4 count on self-reported physical functioning may vary across symptoms. In contrast, other studies have failed to detect any association between CD4 count and fatigue (O’Dell, Meighen, \& Riggs; Phillips, Sowell, \& Rojas et al., 2004).

Phillips et al. (2004) failed to find a relation between CD4 count and the physical symptom of fatigue using an African American sample with HIV. The authors point to the high prevalence of clinical depression among participants in their study, and suggest that psychological factors, rather than CD4 count, may be a more important indicator of physical symptoms and general functioning among individuals with HIV. Further, they underscore the need for a 'multidimensional' understanding of physical symptoms that accounts for both psychological functioning (i.e., depressive symptoms and anxiety) and HIV-related symptoms.

Therefore, CD4 count may not directly relate to physical functioning among African American women with HIV/AIDS. Instead, when immune functioning is considered within the context of psychological factors, such as depressive symptoms, the 
role of CD4 count on physical symptoms may become more apparent. That is, the relation between CD4 count and physical symptoms may be contingent on the level of depressive symptomology.

Consistent with cross-sectional findings, CD4 count did not emerge as a longitudinal correlate of physical symptoms. It is perhaps less surprising that CD4 count did not emerge as a significant predictor of physical symptoms over time. Given the considerable variability that may occur in CD4 count through the course of a single day, it would be less likely that CD4 counts obtained at Assessment 1 would provide a consistent marker of physical functioning at Assessment 2.

Analyses Examining the Association of Depressive Symptoms and Physical Functioning Although a significant association of CD4 count on physical symptoms did not emerge cross-sectionally in the current study, depressive symptoms were found to be a significant correlate of physical symptoms at Assessments 1 and 2. Specifically, both self-reported and clinician-rated depressive symptoms, measured with the BSI and the HRSD, respectively, were found to be significant correlates of elevated levels of physical symptoms.

The consistent association of depressive symptoms and physical symptoms provides strong evidence for the impact of both self-reported and clinician-rated depressive symptoms on physical functioning among African American women with HIV/AIDS. It should be noted that potential overlap between somatic symptoms of HIV/AIDS and vegetative symptoms of depression were controlled for in some of these analyses. These findings are consistent with other studies that have noted a relation 
between depression and physical symptoms among individuals with HIV/AIDS (i.e., Phillips et al., 2004).

The relation between depression and physical symptoms in the literature exploring chronic illness is consistent with the current findings as well. For example, depression was found to be significantly associated with higher levels of physical symptoms, including pain and fatigue, among patients with cancer (Lloyd-Williams, Dennis, \& Taylor, 2004).

There exists a current paucity of studies examining depressive symptoms and physical symptoms among African American women with HIV/AIDS. This disparity in the literature is surprising, particularly given the elevated rates of depressive symptoms among African American women (Bromberger, Harlow, Avis, Kravitz, \& Cordal, 2004; Reed, McLeod, \& Randall, 1996). Research suggests that depressive symptoms may be particularly prevalent among African American women with HIV/AIDS (Moneyham, Sowell, Seals \& Demi, 2000). Jones et al. (2001a) compared a demographically matched sample of HIV-infected and non-infected African American mothers. Relative to their non-infected counterparts, women with HIV/AIDS were found to have significantly greater levels of depressive symptomology, controlling for somatic overlap between depression and disease status.

A significant longitudinal main effect of depressive symptoms (self-reported and clinician-rated) at Assessment 1 on physical symptoms at Assessment 2 also emerged in the current study. Self-reported depressive symptoms (measured with the BSI), as well as clinician-rated depressive symptoms (measured with the HRSD) were related to higher levels of physical symptoms over time. However, after controlling for physical symptoms 
at Assessment 1, only depressive symptoms measured with the HRSD emerged as a significant predictor of physical symptoms. This finding suggests that clinician-rated depressive symptoms may be a more valid predictor of change in physical symptoms over time. It should be noted that, as in the cross-sectional analyses, overlap between vegetative symptoms of depression and somatic symptoms of HIV/AIDS was controlled for in the analyses.

Previous studies comparing self-reported and clinician-rated measures of depression have reported high levels of concurrent validity (e.g., Shain, Naylor, \& Alessi, 1990), suggesting that both methods would provide effective measures of depressive symptoms/depression. One explanation for the differential findings using the HRSD and the BSI is that these assessments are measuring different aspect of depressive symptoms that may account for differential amounts of variability in physical symptoms over time. For example, the HRSD prompts clinicians to rate symptoms related to loss of insight, inability to work, and decreases in social activities, that are not directly measured using the BSI. Admittedly, the variance accounted for in the current model using the BSI and the HRSD was relatively small. Impairment in domains such as occupational and/or social functioning in the current study may have accounted for more variance in predicting change in physical symptoms over time.

Additionally, the BSI prompts respondents to answer questions based upon symptoms they may have experienced within the past seven days. As a result, women in the current study presumably rated their symptoms based upon their most recent level of functioning. Therefore, it might be more likely that women who were experiencing elevated levels of depressive symptoms within a given week might also endorse higher 
levels of physical symptoms during the same assessment period (accounting for crosssectional associations between the BSI and the PSI-modified).

Further evidence to support this hypothesis includes the finding that when physical symptoms at Assessment 1 were controlled for, the predictive role of the BSI at Assessment 1 on physical symptoms at Assessment 2 was rendered non-significant. This suggests substantial overlap between current BSI and PSI-modified scores at each Assessment period. In contrast, the HRSD, which provides a clinician-rated assessment of depressive symptoms, does not impose time constraints in the measurement of depressive symptomatology. In this context, it appears that both the BSI and the HRSD provide a measure of short-term symptoms of depression as correlates of physical symptoms; however, the HRSD may also function as a more appropriate measure for assessment of long-term consequences of depressive symptoms. CD4 Count, Depressive Symptoms, and Physical Symptoms

The association between depressive symptoms and physical symptoms at Assessment 1 must be interpreted within the context of the significant 2-way interaction with CD4 count. That is, when the interaction of depressive symptoms and CD4 count was examined, a significant link to physical symptoms emerged. Specifically, both selfreported depressive symptoms measured with the BSI and clinician-rated depressive symptoms measured with the HRSD moderated the link between CD4 count and physical symptoms at Assessment 1.

Specifically, women with low CD4 count and elevated levels of depressive symptoms (either self-reported or clinician-rated) at Assessment 1 reported higher levels of physical symptoms. The link between CD4 count and physical symptoms emerged 
only at high levels of depressive symptoms and was not significant for women with lower levels of depressive symptomology. Therefore, the anticipated association between lower CD4 count and higher physical symptoms emerged as significant only when depressive symptoms were evident.

Depressive symptoms functioned to exacerbate the physical impact of CD4 count among African American women. That is, suppressed immune functioning may not have served as a consistent marker of how healthy or ill the participants in this sample felt. Instead, CD4 count may be more appropriately understood within the context of the individual's current psychological functioning, (i.e., the presence or absence of depressive symptoms). This finding presents a partial explanation for the current inconsistencies in the literature examining CD4 count and physical symptoms. To date, few studies have examined psychological moderators of immune functioning and physical symptoms, particularly among African American women with HIV/AIDS.

One explanation for the finding that high levels of depressive symptoms moderate the relation between CD4 count and physical symptoms relates to the potential impact of depressive symptoms on the immune response. For example, a study measuring depressive symptoms and immune response to influenza vaccination revealed that the presence of depressive symptoms was associated with elevated IL-6 plasma levels, signifying an elevated immune response following vaccination. This elevated inflammatory response was found to be maintained at 2-week follow up among individuals with higher levels of depressive symptoms, suggesting a relation between symptoms of depression and altered immune functioning over time (Glasser, KiecoltGlaser, Malarkey, \& Sheridan, 1998) 
In the current study, women who were at a relatively more advanced stage of their disease (i.e., demonstrated lower CD4 counts) may have experienced additional suppression and alteration of immune functioning as a result of their depressive symptoms, which may have in turn resulted in elevated levels of self-reported physical symptoms.

Evidence to support this hypothesis is routed in the fact that the characteristic alterations in immune functioning and immune response that are associated with depressive symptoms extend beyond the immune markers examined in the current study. Women with elevated depressive symptoms and suppressed immune functioning may have experienced additional immune dysregulation linked to their depressive symptoms that were not reflected by CD4 count. These alterations may have in turn resulted in elevated levels of physical symptoms among women who were already immunocompromised (i.e., had low CD4 counts).

In a review of the literature examining immune functioning and major depression, Kronfol (2002) highlighted consistent abnormalities in immune functioning among individuals with major depression. Specifically, depression was linked to elevated neutrophils, which are the cells that respond to acute infection by bacterial pathogens, suggesting an exaggerated immune response. In addition, major depression was linked to suppressed numbers of lymphocytes, which produce antibodies and respond to bacterial, viral, fungal, or parasitic infections, as well as decreased number of Natural Killer (NK) cells. NK cells are a type of lymphocyte (white blood cell) that function to destroy foreign bacteria, as well as viral-infected cells (e.g., herpes), lymphomas, and other tumors (Linnemeyer, 1993). 
Kronfol (2002) discussed evidence supporting a link between depression and alterations in NK-cell numbers, as well as some support for elevated mortality rates among individuals with AIDS who endorsed chronic depression. Therefore, immunocompromised women in the current sample (i.e., women with lower CD4 counts) with lower levels of NK cells (perhaps related to elevated levels of depressive symptoms), may have been rendered vulnerable to a variety of viral and bacterial infections that resulted in elevated levels of physical symptoms.

These findings underscore the complexity of the immune response and the range of the potential impact of depression and depressive symptoms on immune functioning. The exacerbating effect of depressive symptoms in the link between CD4 count and physical symptoms could relate to a wider range of immunological markers, extending beyond the scope of the current investigation. Some of these other immunological actions may have demonstrated characteristic variations as a function of depressive symptoms, had they been measured in the current study. In conjunction with low CD4 count, these changes in the immune functioning associated with depressive symptoms may have resulted in a vulnerability to greater severity of physical symptoms.

An alternative explanation to the exacerbating role of depressive symptoms in the link between immune functioning and CD4 count relates to the role of behavior. Antoni (2003) suggests that among individuals with HIV/AIDS, the role of psychosocial variables should be considered when examining the physiological progression of HIV/AIDS. He suggests that potentially protective psychosocial factors, such as positive coping strategies, as well as psychosocial risk variables, such as risk-taking behaviors and 
emotional distress, may significantly impact immune markers, including NK cells and CD4 count.

Women with higher levels of depressive symptoms may have been less likely to engage in physical exercise, select healthful food choices, seek out positive social support persons, and engage in pleasant activities. A large body of evidence supports the link between depressive symptoms and poor health behaviors, such as smoking (Brown, Madden, Palenchar, \& Cooper-Patrick, 2000; McCaffery, Niaura, Swan, \& Carmelli, 2003), alcohol abuse/dependency (Hasin \& Glick, 1993), and decreased health care utilization (ten Have, de Graaf, Vollebergh, \& Beekman, 2004).

One possibility is that women with suppressed CD4 count (i.e., compromised immune functioning), may have possessed a greater vulnerability to the negative physical consequences associated with such negative health behaviors as smoking, abusing alcohol, or not maintaining an active role in their health care. In contrast, women with higher CD4 counts may not have demonstrated the same vulnerability to physical effects of poor health behaviors. Specifically, higher levels of immunocompetence may have buffered the potentially negative impact of high-risk health behaviors associated with depressive symptoms and physical symptoms. Alternatively, women who were not experiencing significant symptoms of depression may not have been as likely to engage in negative health behaviors such as smoking or abusing alcohol and may have experienced less physical symptoms as a result.

One final explanation for the interaction between CD4 count and depressive symptoms might relate to knowledge regarded current CD4 count. Many of the women in the study may have had knowledge of their most recent CD4 counts. If the CD4 count 
was low, it would be predicted that the women may have experienced increased distress as a result of this knowledge and their appraisal of the subsequent implications of a low CD4 count (i.e., declining health status). That is, learning that one's CD4 count had decreased would have functioned as a personally relevant indicator of the participant's disease progression and immune functioning. Emotional responses to information related to their disease status may have resulted in a decline in emotional well-being (i.e., more depressive symptoms) as well as an increase in self-reported physical symptoms. Women who believed they were more ill and subsequently experienced higher levels of emotional distress may have reported more physical symptoms, relative to women who did not appraise their current CD4 count to be an indicator of advancing disease status. Although testing these hypotheses is beyond the scope of the current investigation, several directions for future research exist.

One possibility for the failure to replicate the interaction at Assessment 2 is that depressive symptoms may function differently among women at different stages of their disease. At Assessment 2, women were at a more advanced time point in their illness, with mean CD4 count significantly lower at Assessment 2, relative to Assessment 1. In an investigation examining the relation between CD4 count and depression, Vedhara and colleagues (1999) suggested that depression may have a less significant impact on disease progression among women at a more advanced stage of illness. That is, as women reach later stages of HIV/AIDS, depression does not appear to interact with immune functioning to predict physical functioning.

One final potential explanation for the failure to detect an interaction between depressive symptoms and CD4 count may have related to changes in sample size over 
time. As noted earlier, 17 participants were lost between Assessments 1 and 2. Instead of excluding these participants from analyses at Assessment 2, imputed values derived from mean values of scores were used to replace missing data. Although both approaches have some merit, the non-significant findings could be due to the destruction of the natural variability that occurred by entering mean scores for these participants.

Finally, the predicted longitudinal two-way interaction of CD4 count at Assessment 1 and depressive symptoms, measured with either the HRSD or the BSI, and averaged across Assessments 1 and 2, did not emerge as significant. That is, neither clinician-rated nor self-reported symptoms of depression moderated the impact of CD4 count at Assessment 1 on physical symptoms at Assessment 2. Both clinician-rated and self-reported depressive symptoms (measured with the HRSD and the BSI, respectively) were significant moderators of CD4 count in cross-sectional analyses at Assessment 1, only.

The finding that depressive symptoms did not moderate the link between immune functioning and physical symptoms over time suggests that psychological variables may be a less significant moderator of immune functioning over time among African American women with HIV/AIDS. That is, while depressive symptoms may significantly impact physical symptoms both cross-sectionally and longitudinally, these symptoms appear to operate independently of immune functioning over the long term. Thus, regardless of immune status, women who experienced significant depressive symptoms were more likely to report elevated physical symptoms.

It is interesting to contrast the significant interaction detected at Assessment 1 between depressive symptoms and CD4 count with the failure to detect this interaction at 
either Assessment 2 or in longitudinal analyses. These findings suggest that the impact of depressive symptoms in relation to immune functioning may vary at different time points during the progression of illness. That is, the potentially exacerbating role of depressive symptoms in the relation between CD4 count and physical symptoms may be more significant in earlier stages of the disease, and this impact may decrease over time.

\section{Analyses Examining the Association of Optimism and Physical Functioning}

Optimism did not emerge as a significant correlate of physical symptoms at either Assessment 1 or 2. One possibility for the failure to support our hypotheses regarding the moderating role of optimism is that depressive symptoms overshadowed the impact of optimism on physical symptoms such that women who were experiencing significant depressive symptomology may not have experienced the potentially protective benefits of optimism as it might relate to physical functioning.

That is, although optimism has been shown to function as a protective factor related to positive health outcomes (see Peterson, 2001, for a review), when the impact of optimism on physical functioning is examined among African American women at high risk for depressive symptomology, the potentially protective impact of the construct was overshadowed by the role of depressive symptoms. The current study lends support to this hypothesis, as depressive symptoms emerged as a significant predictor of physical symptoms among African American women, both cross-sectionally and longitudinally, while optimism failed to produce any significant effects.

In a review of the literature related to optimism and HIV/AIDS, O'Connell and Jones (in submission) underscore the current inconsistencies among existing studies examining optimism as it relates to mental and physical health outcomes among 
individuals living with HIV/AIDS. The authors note that findings are largely inconsistent, with studies reporting associations between optimism and both negative as well as favorable outcomes among individuals with HIV/AIDS. For example, while some studies have associated lower levels of distress related to optimism among individuals with HIV/AIDS (Johnson \& Endler, 2002), other studies have linked optimism to elevated sexually risk taking and medication nonadherence (i.e., Holmes \& Pace, 2002).

Another possible explanation for the failure to detect consistent findings among the current studies may relate to methodological problems. Optimism is perhaps most commonly measured using the LOT; however the construct has also been measured by assessing expectations specific to HIV/AIDS and labeled 'HIV optimism' (Van de Ven, Kippax, Knox, Prestage, \& Crawford, 1999), or with word lists containing positive descriptors (Holmes \& Pace, 2002). In the current study, the LOT was selected to assess optimism among participants. Careful attention (i.e., focus groups, reliability analyses) was given to the selection of all instruments in an attempt to ensure that they were appropriate for use with African American women. It should be noted that the alpha for the LOT among the current sample was significantly lower than the other measures used in the study. It is possible that the LOT was not the most appropriate measure for use with the targeted population.

LOT scores also did not significantly interact with CD4 count to predict physical symptoms. Specifically, optimism did not provide the anticipated buffering effect between immune functioning and physical symptoms. A review of the literature revealed no studies that examined optimism as a potential moderator in the relation between CD4 count and physical symptoms, rendering the current investigation somewhat preliminary. 
However, a handful of studies have examined the impact of optimism on CD4 count and report rather inconsistent findings. An investigation of the relation between dispositional optimism and CD4 count over time found no relation between the two variables among gay men with HIV/AIDS (Tomakowsky, Lumley, \& Markowitz, 2001). In contrast, another longitudinal investigation revealed that moderate levels of optimism predicted higher CD4 counts over time (Milam, Richardson, Marks, Kepmer, \& McCutchan, 2004).

Finally, Segerstrom (2001) found that environmental circumstances impacted the role of optimism on CD4 counts among a healthy sample. That is, in periods of high stress, optimism was linked to lower CD4 counts. In contrast, optimism was associated with higher CD4 counts in relatively lower-stress periods. The authors suggested that optimists, as a function of their increased likelihood to engage in more goal-related activities, and consequently experience more stress over the short-term, were vulnerable to decreased immune functioning in times of higher stress.

Women in the current study confronted multiple environmental stressors on a daily basis, including poverty, crime, and chronic illness. The finding that environmental stress may perhaps moderate the role of optimism and CD4 count (Segerstrom, 2001) provides a potential explanation for the failure to detect consistent findings related to the moderating role of optimism in the relation between CD4 count and physical symptoms. That is, the failure to measure current stressors or perhaps levels of perceived stress in the current study may partially explain the lack of findings.

In addition to cross-sectional findings, optimism did not emerge as a significant predictor of physical symptoms over time. This finding was consistent with the failure to detect a significant effect of optimism on physical symptoms at Assessments 1 or 2. As 
noted earlier, the impact of optimism on psychological and physical functioning among individuals with HIV/AIDS has been largely inconsistent. Again, one possibility is that optimism did not emerge as a significant predictor of physical symptoms because it was perhaps overshadowed by the impact of depressive symptoms in this population over time. A previous investigation examining the prevalence of depressive symptoms among this sample, relative to demographically similar non-infected African American women found that the women with HIV/AIDS endorsed significantly higher levels of depressive symptoms (Jones et al., 2001b). As discussed earlier, depressive symptoms, relative to optimism, may function as a more powerful predictor of physical functioning. The finding that depressive symptoms emerged as the only significant psychosocial predictor of physical symptoms over time supports this hypothesis.

Similar to the findings that emerged when examining depressive symptoms, optimism, averaged over Assessments 1 and 2, did not emerge as a significant moderator in the link between CD4 count at Assessment 1 and physical symptoms at Assessment 2. The failure to detect a significant interaction is perhaps less surprising, given the inconsistent impact of optimism in the relation between CD4 count and physical symptoms. Again, these findings suggest that optimism did not function to buffer the impact of immune functioning on physical symptoms over time.

\section{Exploratory Analyses}

The proposed exploratory three-way interaction of depressive symptoms, optimism, and CD4 count on physical symptoms at either Assessments 1 or 2 did not emerge as significant. That is, optimism and depressive symptoms (self-reported or 
clinician-rated), did not interact with the predictor variable, immune functioning, to significantly impact physical symptoms among the sample.

This proposed three-way interaction was considered exploratory, as no prior studies have supported the potentially interactive role of these variables among individuals with HIV. As discussed earlier, Jones and her colleagues (2004) found that optimism and depressive symptoms did not interact to predict physical symptoms among African American women with HIV. In the current study, it was hypothesized that when the role of immune functioning (CD4 count) was accounted for, women with higher levels of CD4 count and less depressive symptoms who also reported higher levels of optimism would report less physical symptoms, relative to their more immunocompromised counterparts who reported higher depressive symptoms and less optimism.

Although Jones et al. (2004) reported that optimism functioned as a buffer for physical symptoms among healthy women, this does not appear to occur among women with HIV/AIDS. The pathway through which depressive symptoms impacted CD4 count and physical symptoms among the current sample may differ from the mechanism by which optimism moderates (or fails to moderate) the relation between CD4 count and physical symptoms. For example, it is well established that depressive symptoms impact health behaviors, particularly high-risk health behaviors, among both healthy individuals (Kobau, Safran, Zack, Moriarty, \& Chapman, 2004) and individuals with HIV/AIDS (Valente, Saunders, \& Uman, 1993). Conversely, evidence suggests that optimism may also relate to health behaviors among individuals with HIV; however, studies have linked higher optimism to both adaptive health correlates, such as health-specific coping 
(Johnson \& Endler, 2002), and high-risk health behaviors, such as unprotected casual sex and medication non-adherence (Holmes \& Pace, 2001) among this population.

Among the current sample, women with lower CD4 counts who engaged in highrisk health behaviors (presumably related to their elevated levels of depressive symptoms) may have been at risk for elevated physical symptoms. Among these women, those who also reported higher levels of optimism may have fallen into one of two categories: (1) women who, as a result of their higher level so optimism, engaged in unprotected sexual intercourse with unfamiliar partners and were less adherent with their antiretroviral medications; and (2) women who, as a result of optimism, were more likely to engage in adaptive health behaviors. Both pathways would have presumably demonstrated a differential impact on physical symptoms. Surprisingly, mean levels of optimism for the current study were somewhat higher than would be expected, relative to normative data derived from samples of college students (Scheier, Carver, \& Bridges, 1994). These findings suggest that optimism alone does not function to buffer the relation between depressive symptoms and immune functioning.

Therefore, the relation between immune functioning, optimism, and depressive symptoms among women with HIV/AIDS in the current sample may have been inconsistent as a function of the potentially differential effect of optimism. As noted elsewhere (e.g., O'Connell \& Jones, in submission), the role of optimism on HIV-related health behaviors may be protective and adaptive, or may render individuals more vulnerable to negative health consequences.

A second possibility for the failure to obtain a significant three-way interaction using the current sample may have related to insufficient power. Issues related to power 
may have precluded the detection of a significant interaction in the analyses of moderators (Cohen, 1988). Therefore, future studies might investigate the proposed twoand three-way interactions among larger sample sizes.

\section{Limitations and Strengths}

All findings discussed in the current study must be considered within the context of the limitations of the investigation. First, it is important to note that the current findings may not be generalized beyond low-income, African-American women with HIV/AIDS. Conclusions made related to the role of psychosocial moderators in the relation between immune functioning and physical symptoms may not apply to other groups or populations living with HIV/AIDS.

The sample examined in the current study consisted of low-income women who resided within inner-city regions of New Orleans. Many of the women were unemployed and all had at least one child. Given the lack of tangible resources, as well as the environmental stressors confronted by these women, the progression of their disease and the impact of variables such as depressive symptoms and optimism may have operated differently, relative to populations with fewer risk factors for impaired functioning.

An additional limitation that must be recognized is the failure to collect other markers of immune functioning, beyond CD4 count. As noted earlier, markers such as viral load and NK cells contribute to the determination of disease status and immune functioning. These markers represent additional parameters of immune functioning and may have accounted for additional variance in physical symptoms, above and beyond CD4 count. Future investigations might target additional immune markers in examining the relation between physical symptoms and the psychosocial moderators associated with 
this relation. As noted earlier, immune markers, including viral load and NK cells have been identified as potentially important determinants of immunocompetence. It would be interesting to investigate whether these markers potentially predict physical symptoms and interact with psychosocial moderators, as was observed when examining CD4 count.

A final limitation to be considered in the current study relates to the measurement of optimism. O'Connell and Jones (in submission) discuss the various methods for measuring the construct of optimism among individuals with HIV/AIDS. These methods included the standard use of instruments such as the LOT (used in the current study), as well as the measurement of 'HIV optimism.' Issues related to the measurement of optimism among this population are critical when considering the current inconsistencies within this literature.

Despite the limitations of the current study, several strengths should be recognized as well. The longitudinal design employed in the current study facilitated the examination of the stability of physical and psychological factors in a population confronted by a chronic and progressive illness. As noted earlier, African American women with HIV/AIDS are a largely understudied population within the psychosocial literature examining individuals with HIV/AIDS. Much of what is currently known regarding the impact of variables such as depressive symptoms and optimism has been derived from samples using gay and bisexual men with HIV/AIDS.

A primary objective of the current study was to extend the understanding of psychosocial variables in the relation between immune functioning and physical symptoms. Within the context of the multiple stressors confronted by participants in the current study, variables that are generally conceptualized as either risk or resiliency 
factors (i.e., depressive symptoms or optimism) may operate differently. Although depressive symptoms functioned to exacerbate physical symptoms and moderated the link between CD4 count and physical symptoms, optimism did not operate as expected.

\section{Directions for Future Research}

The failure to detect a relation between optimism and physical functioning among African American women with HIV/AIDS reveals pathways for future research. One possibility is that the potentially protective function of optimism may have been overshadowed by the multiple stressors confronted by this population. That is, the potential benefit of dispositional optimism did not operate under circumstances where individuals were confronted by multiple stressors and reported high levels of depressive symptomology. One possibility for future investigation might be to measure perceived stress and/or daily hassles and compare the potentially protective role of optimism among women who endorse high and low levels of stress.

An additional issue to be addressed relates to the measurement of the construct of optimism. In the current study, the alpha level obtained for the LOT, a commonly used measure of dispositional optimism, was low, relative to the other measures selected. One possibility is that the items included in the LOT may have been less applicable to African American women with HIV/AIDS. Given the limited number of studies examining optimism among this population, the current investigation, as it relates to the role of optimism, should be considered preliminary. Future studies are needed to investigate appropriate measures for measuring optimism in this population before the role of optimism as it relates to physical and emotional health can be more accurately understood. An important first step in this process would be to examine optimism among 
African Americans, relative to Caucasians, to determine differences in levels of optimism as a function of race and/or ethnicity.

Issues related to measurement of optimism extend to the examination of optimism across various populations. Various methods for the measurement of optimism, ranging from use of the LOT to the measurement of optimism within the context of HIV have been employed and conclusions have been made about the impact of optimism as it relates to health. Before the construct of optimism can be fully understood, it is first important to establish whether the variable is more appropriately measured as a dispositional quality or a context-specific variable.

Finally, as noted above, issues of power may have contributed to the failure to detect significant two- and three-way interactions as they related to immune functioning and psychosocial variables and the impact on physical functioning. Larger sample sizes may provide the power required to gain a more accurate understanding of these variables among African American women with HIV/AIDS. Of course, longitudinal studies are complicated when working with chronically ill populations who confront multiple risk factors. This fact is reflected in the current study, where participants were lost to due to incarceration, relocation to other areas, and death.

\section{Clinical Implications}

The findings from the current study have several implications for both assessment and intervention among African American women with HIV/AIDS. First, given the prevalence of depression among this population and the subsequent impact on physical functioning, assessment of psychological variables such as depressive symptoms should be routinely conducted. Second, the consistent link between depressive symptoms and 
immune functioning on physical symptoms, particularly in earlier stages of the disease, contributes to the understanding of variables related to disease progression.

The knowledge that depressive symptoms render immunocompromised women more vulnerable to physical symptoms provides an important opportunity for primary care providers and mental health practitioners to intervene. Addressing depressive symptoms with appropriate treatment interventions, whether they are behavioral or pharmacological, provides a potential opportunity to modify the impact of immune functioning on physical symptoms. These interventions will presumably result in improving both physical and mental health functioning and improved quality of life.

Additionally, it should be noted that in the current study, an effort was made to control for the potential overlap between physical symptoms of HIV/AIDS and vegetative symptoms of depression. Even after controlling for this overlap, depressive symptoms remained a significant predictor of physical functioning. However, in clinical practice, providers may fail to recognize or diagnose depression among African American women with HIV/AIDS who demonstrate or endorse primarily vegetative symptoms. Instead, these changes in physical functioning may be attributed to the impact of HIV/AIDS, rather than depression. Therefore, women may be at risk for misdiagnosis and may subsequently not receive appropriate services to address both physical and mental health problems.

Finally, although optimism did not emerge as a significant moderator of physical functioning among the current population, this finding should not detract from the importance of potentially protective factors that may promote resiliency among a population at significant risk for psychological distress and impaired functioning. Living 
with a chronic, often stigmatizing illness presents daily challenges that potentially impact every aspect of interpersonal and occupational functioning. Because there is currently no cure for HIV, attention must be focused on adaptive coping strategies that improve quality of life and promote optimal functioning. Therefore, clinicians must focus not only on the treatment of pathology among African American women with HIV/AIDS, but also on promoting coping skills, such as problem-solving, emotional regulation, and the nurturing of social support networks.

Interventions focused on developing skills that build upon human strength and resilience are a tenant of the Positive Psychology movement, whereby clinicians deemphasize psychopathology and move toward models of psychological wellness (Seligman, 2002). Although optimism did not emerge as a protective factor in the current sample, researchers and clinicians should assume an active role in developing culturally relevant models of resilience among African American women with HIV/AIDS. Such a focus would move past traditional deficit models in the understanding of mental health problems among vulnerable populations to an appreciation of factors that may serve to protect individuals from impairment physical and psychological functioning. 


\section{References}

Abbey, S. E., Toner, B. B., Garfinkel, P. E., Kennedy, S. H., \& Kaplan, A. S. (1990). Self-report symptoms that predict major depression in patients with prominent physical symptoms. International Journal of Psychiatry in Medicine, 20, 247-258.

Adams-Campbell, L. L., Ahaghotu, C., Gaskins, M., Dawkins, F. W., Smoot, D., Polk, O. D., et al. (2004). Enrollment of African Americans onto clinical treatment trials: Study design barriers. Journal of Clinical Oncology, 22, 730-734.

Aiken, L. S., \& West, S. G. (1991). Multiple regression: Testing and interpreting interactions. Thousand Oaks: Sage.

Anorlu, R., Imosemi, D., Odunukwe, N., Abudu, O., \& Otuonye, M. (2004). Prevalence of HIV among women with vaginal discharge in a gynecological clinic. Journal of the National Medical Association, 96, 367-371.

Antoni, M. H. (2003). Stress management and Psychoneuroimmunology in HIV infection. CNS Spectrums, 8, 40-50.

Armistead, L. \& Forehand, R. (1995). For whom the bell tolls: Parenting decisions and challenges faced by women who are HIV seropositive. Clinical Psychology: Science and Practice, 2, 239-250.

Atkinson, J. H., Grant, I., Kennedy, C. J., Richman, D. D., Spector, S. A., \& McCutchan, J. A. (1988). Prevalence of psychiatric disorders among men infected with human immunodeficiency virus: A controlled study. Archives of General Psychiatry, 45, 859-864.

Baron, R. M., \& Kenny, D. A. (1986). The moderator-mediator variable distinction in social psychological research: Conceptual, strategic, and statistical 
considerations. Journal of Personality and Social Psychology, 51, 11731182.

Beck, A. T. (1987). Cognitive models of depression. Journal of Cognitive Psychotherapy, $1,5-37$.

Beck, A. T., Rial, W. Y. \& Rickels, K. (1974). Short form of depression inventory: Cross-validation. Psychological Reports, 34, 1184-1186.

Boccellari, A., Dilley, J., \& Shore, M. (1988). Neuropsychiatric aspects of AIDS dementia complex: A report on a clinical series. Neurotoxicology, 9, 381-390.

Boelen, P. A., \& van den Bout, J. (2002). Positive thinking in bereavement: Is it related to depression, anxiety, or grief symptomatology? Psychological Reports, 91, 957863.

Bornstein, R. A., Nasrallah, H. A., Para, M. F., Whitacre, C. C., \& Fass, R. J. (1993). Change in neuropsychological performance in asymptomatic HIV infection: 1year follow-up. AIDS, 12, 1607-1611.

Brissette, I., Scheier, M. F., \& Carver, C. S. (2002). The role of optimism in social network development, coping, and psychological adjustment during a life transition. Journal of Personality and Social Psychology, 82, 102-111.

Bromberger, J. T., Harlow, S., Avis, N., Kravitz, H. M., \& Cordal, A. (2004). Racial/Ethnic differences in the prevalence of depressive symptoms among middle-aged women: The Study of Women's Health Across the Nation (SWAN). American Journal of Public Health, 94, 1378-1385.

Brown, D. R. (1990). Depression among blacks. In D. S. Ruiz (Ed.), Handbook of mental health and mental disorders among black Americans (pp. 71-93). New York. 
Brown, C., Madden, P. A., Palenchar, D. R., \& Cooper-Patrick, L. (2000). The association between depressive symptoms and cigarette smoking in an urban primary care sample. International journal of psychiatry in medicine, 1, 15-26.

Buchanon, G. M., \& Seligman, M. E. (1995). Explanatory style. Hillsdale, NJ: Erlbaum.

Butcher, J. N. (1995). Clinical personality assessment practical approaches. New York: Oxford University Press.

Carver, C. S., Pozo, C., Harris, S. D., Noriega, V., Scheier, M., \& Robinson, D. S., et al. (1993). How coping mediates the effect of optimism on distress: A study of women with early stage breast cancer. Journal of Personality and Social Psychology, 65, 375-390.

Carver, C. S., \& Scheier, M. F. (2003). Optimism. In S. J. Lopez, \& C. R. Snyder (Eds.) Positive psychological assessment: A handbook of models and measures, (pp. 7589). Washington, D.C.: American Psychological Association.

Cassem, E. H. (1995). Depressive disorders in the medically ill. Psychosomatics, 36, $2-10$.

Catz, S. L., Gore-Felton, C., \& McClure, J. B. (2002). Psychological distress among minority and low-income women living with HIV. Behavioral Medicine, 28, 5360.

Centers for Disease Control and Prevention. (1992). 1993 revised classification system for HIV infection and expanded surveillance case definition for AIDS among adolescents and adults. Retrieved February 4, 2004, from http://www.cdc.gov. 
Centers for Disease Control and Prevention. (1994). 1994 revised classification system for human immunodeficiency virus infection in children less than 12 years of age. Retrieved May 1, 2005, from http://www.cdc.gov.

Centers for Disease Control and Prevention (1999). Leading causes of death reports for 1999. Retrieved March 2004, from http://www.cdc.gov

Centers for Disease Control and Prevention (2001). HIV prevalence trends in selected populations in the United States: Results from National Serosurveillance, 19931997. Retrieved July 20, 2003, from http://www.cdc.gov.

Centers for Disease Control and Prevention. (2003). A glance at the HIV epidemic. Retrieved July 20, 2003, from http://www.cdc.gov.

Ciesla, J. A., \& Roberts, J. E. (2001). Meta-analysis of the relationship between HIV infection and risk for depressive disorders. American Journal of Psychiatry, 158, 725-730.

Cochran, S. D., \& Mays, V. M. (1994). Depressive distress among homosexually active African American men and women. American Journal of Psychiatry, 151, 524529.

Cohen, J. (1988). Statistical power analysis for the behavioral sciences $\left(2^{\text {nd }}\right.$ ed.). Hillsdale, NJ: Erlbaum.

Cohen, S., \& Rodriquez, M. A. (1995). Pathways linking affective disturbance and physical disorders. Health Psychology, 14, 374-380.

Cruess, S., Antoni, M., Kilbourn, K., Ironson, G., Klimas, N., \& Fletcher, M., et al. (2000). Optimism, distress, and immunologic status in HIV-infected gay men following Hurricane Andrew. Behavioral Medicine, 7, 160-182. 
Denenberg, R. (1997). HIV infection in women: Still untreated, still deadly. Treatment Issues, 11, 7-8.

Derogatis, L. R., Rickels, K., \& Rock, A. F. (1976). The SCL-90 and the MMPI: A step in the validation of a new self-report scale. British Journal of Psychiatry, 128, 280-289.

Derogatis, L.R., \& Spencer, P.M. (1982). The Brief Symptom Inventory (BSI) administration, score, procedures manual - I. Baltimore: Johns Hopkins University School of Medicine, Clinical Psychometrics Research Unit.

de Vroome, E. M., de Wit, J. B., Stroebe, W., Sandfort, T. G., \& van Griensven, G. J. (1998). Sexual behavior and depression among HIV-positive gay men. AIDS \& Behavior, 2, 137-149.

Devine, D., Forehand, R., \& Morse, E. (2001). HIV infection in inner-city African American women: The role of optimism in predicting depressive symptomatology. International Journal of Rehabilitation Health, 53, 141-156.

Domino, B., \& Conway, D. W. (2001). Optimism and pessimism from a historical perspective. In E. C. Chang (Ed.) Optimism \& Pessimism: Implications for Theory, Research, and Practice. 13-30.

Drebing, C. E., Van Gorp, W. G., HInkin, C., Miller, E. N., Satz, P., \& Kim, D. S., et al., (1994). Confounding factors in the measurement of depression in HIV. Journal of Personality Assessment, 62, 63-83.

Elford, J. (2003). HIV treatments optimism among gay men: An international perspective. JAIDS: Journal of Acquired Immune Deficiency Syndromes, 32, $545-$ 550. 
Ellington, L., \& Wiebe, D. J. (1999). Neuroticism, symptom presentation, and medial decision making. Health Psychology, 18, 634-643.

Erdfelder, E., Faul, F., \& Buchner, A. (1996). GPOWER: A general power analysis program. Behavior Research Methods, Instruments, \& Computers, 28, 1-11.

Family Health Project Research Group (1998). A multidisciplinary longitudinal investigation of children whose mothers are HIV infected. Clinical Psychology Review, 18, 839-856.

Faucett, J., Gordon, N., \& Levine, J. (1994). Differences in post-operative pain severity among four ethnic groups. Journal of Pain Symptom Management, 9, 383-389.

Fe Caces, M. J. (1998). Prescription and non-prescription drug use: A longitudinal study. Substance Abuse, 10, 115-126.

Fournier, M., de Ridder, D., \& Bensing, J. (2002). Optimism and adaptation to chronic disease: The role of optimism in relation to self-care options of type 1 diabetes mellitus, rheumatoid arthritis and multiple sclerosis. British Journal of Health Psychology, 7, 409-432.

Glaser, R., Kiecolt-Glaser, J. K., Malarkey, W. B., \& Sheridan, J. F. (1998). The influence of psychological stress on the immune response to vaccines. Annals of the New York Academy of Sciences, 840, 649-655.

Goetsch, V. L. (1996). Psychophysiological reactivity and heartbeat awareness in anxiety sensitivity. Journal of Anxiety Disorders, 10, 283-294.

Hahn, S. R., Thompson, K. S., Wills, T. A., Stern, V., \& Budner, N. S. (1994). The difficult doctor-patient relationship: Somatization, personality, and psychopathology. Journal of Clinical Epidemiology, 47, 647-657. 
Harris, R. M., \& Dennis, K. E. (1997). Where reality meets methodology in conducting nursing intervention research with women. Nursing Research, 46, 240-243.

Hasin, D. S., \& Glick, H. (1993). Depressive symptoms and DSM-III-R alcohol dependence: General population results. Addiction, 88, 1431-1436.

Hedlund, J. L., \& Vieweg, B. W. (1979). The Hamilton rating scale for depression: A comprehensive review. Journal of Operational Psychiatry, 10, 149-165.

Herbert, T. B., \& Cohen, S. (1993). Depression and immunity: A meta-analytic review. Psychological Bulletin, 113, 472-486.

Holmes, W. C., \& Pace, J. L. (2002). HIV-seropositive individuals' optimistic beliefs about prognosis and relation to medication and safe sex adherence. Journal of General Internal Medicine, 17, 677-683.

Hudson, A. L., Lee, K. A., \& Portillo, C. J. (2003). Symptom experience and functional status among HIV-infected women. AIDS Care, 15, 483-492.

Idler, E. L., \& Beyami, Y. (1997). Self-rated health and mortality: A review of twentyseven community studies. Journal of Health and Social Behavior, 38, 21-37.

Johnson, J. M., \& Endler, N. S. (2002). Coping with human immunodeficiency virus: Do optimists fare better? Current Psychology, 21, 3-16.

Jones, Beach, Forehand, \& The Family Research Group. (2001a). HIV infection and depressive symptoms: An investigation of African American single-mothers. AIDS Care, 13, 343-350.

Jones, D. J., Beach, S. R. H., \& Forehand, R. (2001b). Disease status in African American single mothers with HIV: The role of depressive symptoms. Health Psychology, 20, 417-423. 
Jones, D. J., O’Connell, C., Gound, M., Heller, L., \& Forehand, R. (2004). Predictors of self-reported physical symptoms in low-income, inner-city African American women: The role of optimism, depressive symptoms, and chronic illness. Psychology of Women Quarterly, 28, 112-121.

Kalichman, S. C., Sikkema, K. J., \& Simpson, D. D. (1991). Depression and decisionmaking among intravenous drug users. Psychological Reports, 68, 339-347.

Kaplan, S. H., Sullivan, L. M., Spetter, D., Dukes, K. A., Khan, A., \& Greenfield, S. (1996). Gender and patterns of physician-patient communication. In M. M. Falik, \& K. S. Collins (Eds.), Women's health: The Commonwealth Fund Survey, (pp. 76-95). Baltimore, MD: Johns Hopkins University Press.

Katon, W., \& Sullivan, M. D. (1990). Depression and chronic medical illness. Journal of Clinical Psychiatry, 51, 3-11.

Kiecolt-Glasser, J. K., McGuire, L., Robles, T. F., \& Glaser, R. (2002). Emotions, morbidity, and mortality: New perspectives from psychoneuroimmunology. Annual Review of Psychology, 53, 83-107.

Kobau, R. (2004). Sad, blue, or depressed days, health behaviors and health-related quality of life. Health Quality of Life Outcomes, 2, 40.

Kroenke, K., Arrington, M. E., \& Mangelsdorff, A. D. (1990). The prevalence of symptoms in medical outpatients and the adequacy of therapy. Archives of Internal Medicine, 150, 1685-1689.

Kroenke, K. \& Spitzer, R. L. (1998). Gender differences in the reporting of physical and somatoform symptoms. Psychosomatic Medicine, 60, 150-155.

Kroenke, K., Spitzer, R. L., Williams, J. B., Linzer, M., Hahn, S. R., \& deGruy, F. V, et 
al. (1994). Physical symptoms in primary care: Predictors of psychiatric disorders and functional impairment. Archives of Family Medicine, 3, 774-779.

Kronfol, Z. (2002). Immune dysregulation in major depression: A critical review of existing evidence. The International Journal of Neuropsychopharmacology, 5, $333-343$.

Landen, M., Wennerblom, B., Tygesen, H., Modigh, K., Sorvik, K., \& Ysander, C. (2004). Heart rate variability in premenstrual dysphoric disorder. Psychoneuroendocrinology, 29, 733-740.

Lauver, D., \& Tak, Y. (1995). Optimism and coping with a breast cancer symptom. Nursing Research, 44, 202-207.

Lee, K. A., Portillo, C. J., \& Miramontes, H. (2001). The influence of sleep and activity patterns on fatigue in women with HIV/AIDS. Journal of the Association of Nurses in AIDS Care, 12, 19-27.

Lesserman, J. (2002). Progression to AIDS, a clinical AIDS condition and mortality: Psychosocial and physiological predictors. Journal of Psychological Medicine, $32,1059-1073$.

Linnemeyer, P. A. (1993). The Immune System-An Overview. Retrieved from: http://www.thebody.com/step/immune.html, October 1, 2004.

Lyketsos, C. G., Hanson, A. O., Fishman, M., McHugh, P. R., \& Treisman, G. J. (1994). Screening for psychiatric disorders in an HIV medical clinic: The importance of a psychiatric presence. International Journal of Psychiatry in Medicine, 24, 103113.

Manini M. K. (1996). Reference ranges and sources of variability of CD4 counts in HIV- 
seronegative women and men. Genitourinary Medicine, 72, 27-31.

Marsella, A. J., Hirschfeld, R. M., \& Katz, M. (1987). The Measurement of Depression. New York: Guilford Press.

Melnick, S. L., Wertheimer, W. J., \& Pinn V. W. (1995). Women and HIV/AIDS research in the United States. Journal of the American Medical Women Association, 50, 137-138.

McCaffery, J. M., Niaura, R., Swan, G. E., \& Carmelli, D. (2003). A study of depressive symptoms and smoking behavior in adult male twins from the NHLBI Twin Study. Nicotine \& Tobacco Research, 5, 77-83.

McCraken, L. M., Matthews, A. K., Tang, T. S., \& Cuba, S. L. (2001). A comparison of blacks and whites seeking treatment for chronic pain. Clinical Journal of Pain, $17,249-255$.

McGinnis, K. A., Fine, M. J., Sharma, R. K., Skanderson, M., Wagner, J. H., \& Rodriguez-Barradas, M. C., et al. (2003). Understanding racial disparities in HIV using data from the veterans aging cohort 3-site study and VA administrative data. American Journal of Public Health, 93, 1728-1733.

Michaels, D., \& Levine, C. (1992). Estimates of the number of motherless youth orphaned by AIDS in the United States. JAMA, 24, 3456-3461.

Milam, J. E., Richardson, J. L., Marks, G. K., Kemper, C. A., \& McCutchan, A. J. (2004). The roles of dispositional optimism and pessimism in HIV disease progression. Psychology \& Health, 19, 167-182.

Miles, M. S., Gillespie, J. V., \& Holditch-Davis, D. (2001). Physical and mental health in African American mothers with HIV. Journal of the Association of Nurses in 
AIDS Care, 12, 42-50.

Moneyham, L. (2000). Depressive symptoms among African American women with HIV disease. Scholarly Inquiries in Nursing Practice, 14, 9-39.

Montaner, J. S., DeMasi, R., \& Hill, A. M. (1998). The effects of lamivudine treatment on HIV-1 disease progression are highly correlated with plasma HIV-1 RNA and CD4 cell count. AIDS, 12, 23-28.

Mosley, T., Perrin, S. G., Neral, S. M., \& Dubbert, P. M. (1994). Stress, coping, and well-being among third-year medical students. Academic Medicine, 69, 765-767.

National Institute of Allergy and Infectious Diseases (NIAID; 1996). NIAID researcher identify cofactors for entry of HIV into cells. Retrieved October 7, 2004, from: http://www.niaid.nih.gov.

National Institutes of Health (NIH; 2003). HIV infection and AIDS: An overview. Retrieved March 8, 2004, from: http://www.niaid.nih.gov.

National Institutes of Health (NIH; 2003). Immune response. Retrieved October 8, 2004, from: http://www.nlm.nih.gov.

National Center for Health Statistics. (1994). Vital and health statistics: Current estimates from the National Interview Survey, 1992 (Series 10, Number 189). Washington, DC: U. A. Government Printing Office.

Nolen-Hoeksema, S. (1987). Sex differences in unipolar depression: Evidence and theory. Psychological Bulletin, 101, 259-282.

Nolen-Hoeksema, S. (2001). Gender differences in depression. Current Directions in Psychological Science, 10, 173-176. 
Nott, K. H., Vedhara, K., \& Spickett, G. P. (1995). Psychology, immunology, and HIV. Psychoneuroendocrinology, 20, 451-474.

O’Connell, C. F., \& Jones, D. J. (in submission). The Role of Optimism in Physical Health and Emotional Adjustment among Individuals with HIV/AIDS: A Critical Review.

O’Dell, M. W., Meighen, M., Riggs, R. V. (1996). Correlates of fatigue in HIV infection prior to AIDS: A pilot study. Disability Rehabilitation, 28, 249-254.

Paul, J. P., Catania, J., \& Pollack, L. (2002). Suicide attempts among gay and bisexual men: Lifetime prevalence and antecedents. American Journal of Public Health, 92-1344.

Pennebaker, J. W. (1982). Physical symptoms associated with blood pressure. Psychophysiology, 19, 201-210.

Perkins, D. O., Stern, R. A., Golden, R. N., et al., (1994). Mood disorders in HIV infection: Prevalence and risk factors in a nonepicenter of the AIDS epidemic. American Journal of Psychiatry, 151, 233-236.

Peterson, C. (2000). The future of optimism. American Psychologist, 55, 44-55.

Petrie, K. J., Booth, R. J., Elder, H., \& Cameron, L. D. (1999). Psychosocial influences on the perception of immune function. Psychological Medicine, 29, 391-397.

Phillips, K. D., Sowell, R. L., Rojas, M., Ravakoli, A., Fulk, L. J., \& Hand, G. A. (2004). Physiological and psychological correlates of fatigue in HIV disease. Biological Research for Nursing, 6, 59-74. 
Preacher, K. J., Curran, P. J., \& Bauer, D. J. (2004). Simple intercepts, simple slopes, and regions of significance in 2-way interactions. Retrieved August 1, 2004, from: http://www.unc.edu/ preacher/interact.

Pryor, J. B., \& Reeder, G. D. (1993). Collective and individual representations of HIV/AIDS stigma. In J. B. Pryor, \& G. D. Reeder (Eds.), The social psychology of HIV Infection, (pp. 263-286). Hillsdale, New Jersey: Lawrence Erlbaum Associates.

Puskar, K. R., Sereika, S. M., Lamb, J., Tusaie-Mumford, K., \& McGuinness, T. (1999). Optimism and its relationship to depression, coping, anger, and life events in rural adolescents. Issues in Mental Health Nursing, 20, 115-130.

Rabkin, J. G., Williams, J. B., Remien, R. H., Goetz, R., Kertzner, R., \& Gorman, J. M. (1991). Depression, distress, lymphocyte subsets, and human immunodeficiency virus symptoms on two occasions in HIV-positive homosexual men. Archives of General Psychiatry, 48, 111-119.

Raszka, W. V., Meyer, G. A., Waecker, N. J., et al. (1994). Variability of serial absolute and percent CD4+ lymphocyte counts in healthy children born to human immunodeficiency virus 1-infected parents. Pediatric Infectious Diseases Journal, 13, 70-72.

Reed, M. K., McLeod, S., \& Randal, Y. (1996). Depressive symptoms in AfricanAmerican women. Journal of Multicultural Counseling \& Development, 24, 6-14.

Revicki, D. A., Wu, A. W., \& Murray, M. I. (1995). Change in clinical status, health status, and health utility outcomes in HIV-infected patients. Medical Care, 33, 173-182. 
Richardus, J. H., \& Kunst, A. E. (2001). Black-white differences in infectious disease mortality in the United States. American Journal of Public Health, 91, 1251-1254.

Romanelli, J., Fauerbach, J. A., Bush, D. E., \& Ziegelstein, R. C. (2002). The significance of depression in older patients after myocardial infarction. Journal of American Geriatrics Society, 50, 817-822.

Rojansky, N. \& Anteby, S. O. (1996) Gynecological neoplasias in the patient with HIV infection. Obstetrical \& Gynecological Surgery, 51, 697-683.

Segerstrom, S. C. (2001). Optimism, goal conflict, and stressor-related immune change. Journal of Behavioral Medicine, 24, 441-467.

Scheier, M., \& Carver, C. S. (1985). Optimism, coping and health: Assessment and implications of generalized outcome expectancies. Health Psychology, 4, $219-$ 247.

Scheier, M. F., Carver, C. S., \& Bridges, M. W. (1994). Distinguishing optimism from neuroticism (and trait anxiety, self-mastery, and self-esteem): A reevaluation of the Life Orientation Test. Journal of Personality and Social Psychology, 67, 10631078.

Shahar, G., \& Davidson, L. (2003). Depressive symptoms erode self-esteem in severe mental illness: A three-wave, cross-lagged study. Journal of Consulting and Clinical Psychology, 71, 890-900.

Shain, B. N., Naylor, M., \& Alessi, N. (1990). Comparison of self-rated and clinicianrated measures of depression in adolescents. American Journal of Psychiatry, 14, $793-795$. 
Sherr, L., Barnes, J., Elford, J., Olaitan, A., Miller, R., \& Johnson, M. (1997). Women with HIV disease attending a London clinic. Genitourinary Medicine, 73, 274279.

Silverman, M., Smola, S., \& Musa, D. (2000). The meaning of healthy and not healthy: Older African Americans and whites with chronic illness. Journal of CrossCultural Gerontology, 15, 139-156.

Sorlie, P., Rogot, E., Anderson, R., Johnson, N.J., \& Backlund, E. (1992). Black-white mortality differences by family income. Lancet, 340, 346-350.

Stansell, J.D. (1997). Predictors of Pneumocystis carinii pneumonia in HIV-infected persons. American Journal of Respiratory and Critical Care Medicine, 155, 6066.

Stark, E., \& Flitcraft, A. (1995). Killing the beast within: Woman battering and female suicidality. International Journal of Health Services, 25, 43-64.

Stewart, S. H., Buffett-Jerrott, S. E., \& Kokaram, R. (2001). Heartbeat awareness and heart rate reactivity in anxiety sensitivity: A further investigation. Journal of Anxiety Disorders, 15, 535-553.

Strawbridge, W. J., \& Wallhagen, M. I. (1999). Self-rated health and mortality over three decades: Results from a time-dependent covariate analysis. Research on Aging, $21,402-416$.

Strober, D. R., Schwartz, J. A., McDaniel, J. S., \& Abrams, R. F. (1997). Depression and HIV disease: Prevalence, correlates, and treatment. Psychiatric Annals, 27, 372377.

Tarlov, A. R., Ware, J. E., Greenfield, S., Nelson, E. C., Perrin, E., \& Zubkoff, M. 
(1989). The medical outcomes study: An application of methods for monitoring the results of medical care. Journal of the American Medical Association, 262, 925-930.

ten Have, M., de Graaf, R., Vollebergh, W., \& Beekman, A. (2004). What depressive symptoms are associated with the use of care services? Results from the Netherlands Mental Health Survey and Incidence Study (NEMESIS). Journal of Affective Disorders, 80, 239-248.

Tomakowsky, J. (2001). Optimistic explanatory style and dispositional optimism in HIVinfected men. Journal of Psychosomatic Research, 51, 577-587.

U.S. Bureau of the Census. (2004). Current population reports, Poverty in the United States: 2002. Retrieved March 2004 from: www.census.gov.

Valente, S. M. (1993). Self-care, psychological distress, and HIV disease. AIDS Care, 4, $15-25$.

Van de Ven, P., Kippax, S., Knox, S., Prestage, G., \& Crawford, J. (1999). HIV treatments optimism and sexual behavior among gay men in Sydney and Melbourne. AIDS, 13, 2289-2294.

van Servellen, G., Sarna, L., Nyamathi, A., Padilla, G., Brecht, M. L., \& Jablonski, K. J. (1998). Emotional distress in women with symptomatic HIV disease. Issues in Mental Health Nursing, 19, 173-189.

Vedhara, K., Schifitto, G., McDermott, M., \& the Dana Consortium on Therapy for HIV Dementia \& Related Cognitive Disorders. (1999). Disease progression in HIVpositive women with moderate to severe immunosuppression: The role of depression. Behavioral Medicine, 25, 43-47. 
Wahler, H. J., (1969). The Physical Symptoms Inventory: Measuring levels of somatic complaining behavior. Journal of Clinical Psychology, 24, 207-211.

Wahler, H. J. (1973). Wahler Physical Symptoms Inventory Manual. Western Psychology Services, Los Angeles.

Weisse, C. S. (1992). Depression and immunocompetence: A review of the literature. Psychological Bulletin, 111, 475-489.

Wells, K. B., Golding, J. M., \& Burnham, M. A. (1988). Psychiatric disorder in a sample of a general population with and without chronic medical conditions. American Journal of Psychiatry, 145, 976-981.

Zigmond, A. S., \& Snaith, R. P. (1983). The Hospital Anxiety and Depression Scale. Acta Psychiatrica Scandinavica, 67, 361-370. 
Table 1

Correlations between physical symptoms at Assessment 1, demographics, and major study variables

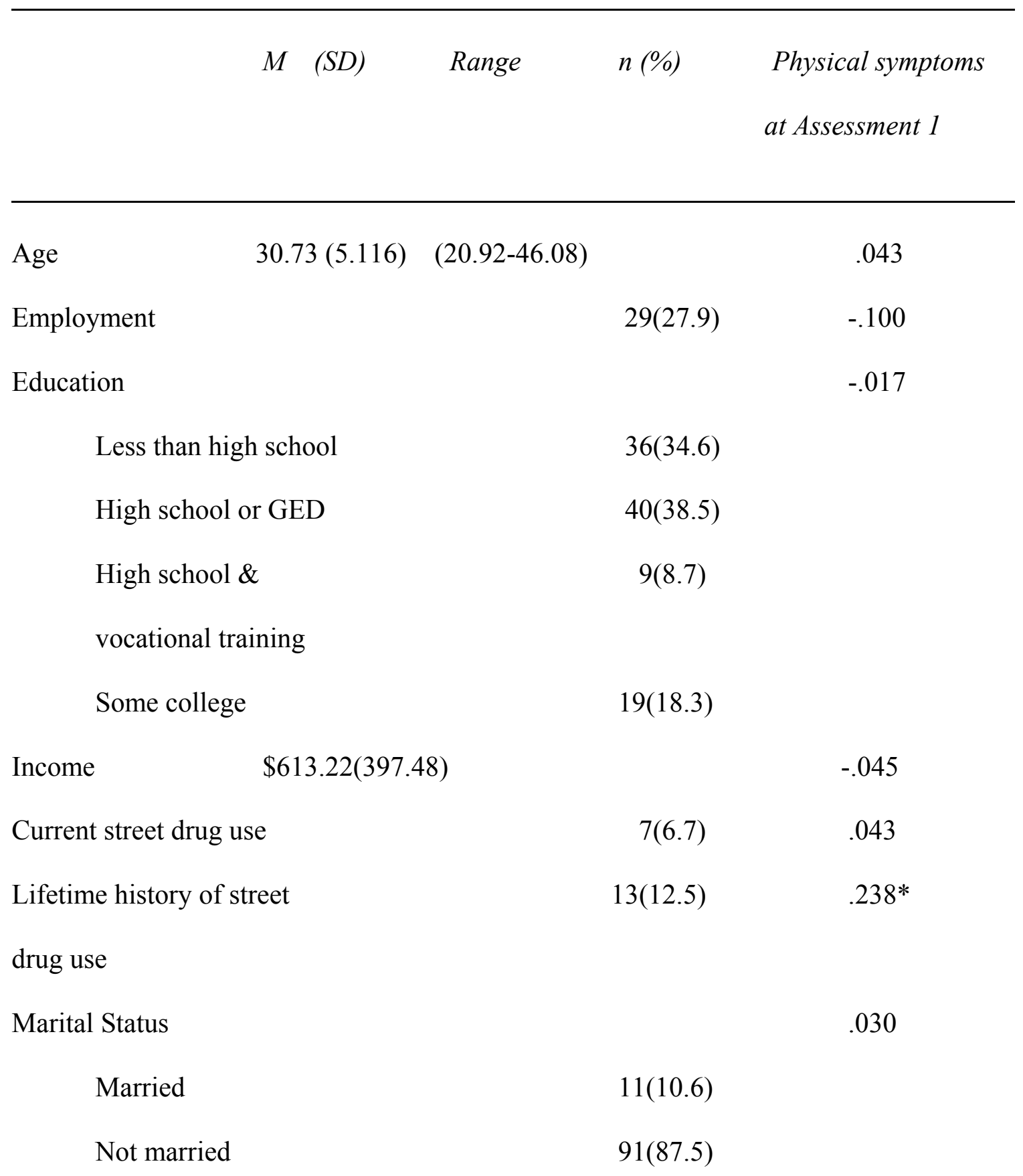

AIDS-related conditions 
Psychosocial Moderators 90

Genital ulcers

Humanpapilloma virus

Lymphadenopathy

Pneumocystis carinii pneumonia (PCP)

Medication management (AZT)

$\begin{aligned} & 4(3.8) .318^{* *} \\ & 11(10.6) .136 \\ & 7(6.7) .208^{*} \\ & 7(6.7)-.054 \\ &\end{aligned}$

62(59.6)

$-.171$

Study Variables

$\begin{array}{lcll}\text { Time 1 BSI } & 3.93(4.06) & (0-17) & .596^{* *} \\ \text { Time 1 CD4 } & 316.18(211.06)(1-1167) & -.091 \\ \text { Time 1 HRSD } & 4.8(4.26) & (0-19) & .522^{* *} \\ \text { Time 1 LOT } & 19.26(4.49) & (4-31) & .173 \\ \text { Time 1 PSI } & 35.50(24.19) & (0-126) & 1\end{array}$

$* * \mathrm{p}<.001 * \mathrm{p}<.05$ 
Table 2

Correlations between Physical symptoms at Assessment 2 and demographics, and major study variables

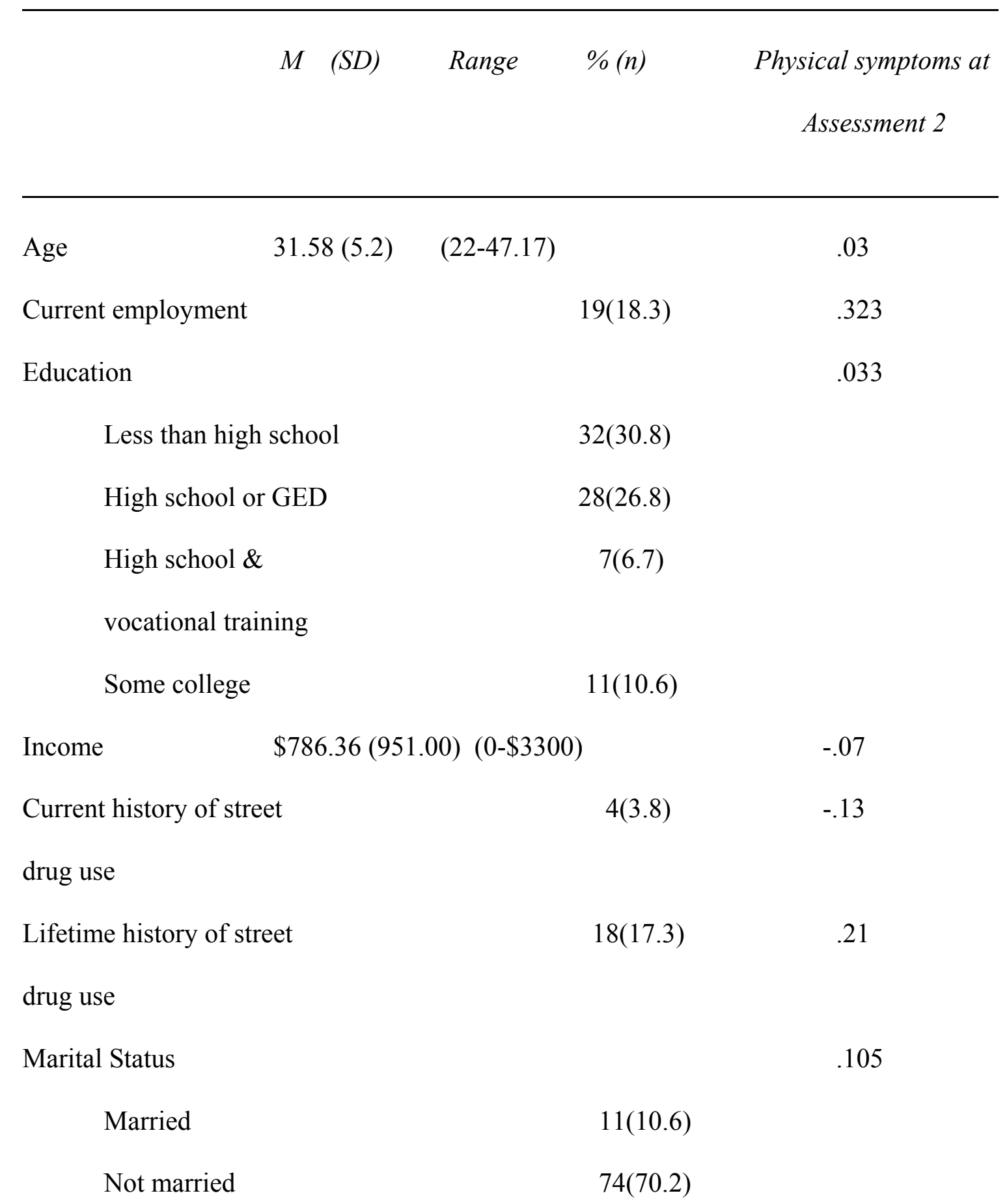




\begin{tabular}{|c|c|c|c|}
\hline \multicolumn{4}{|l|}{ AIDS-related conditions } \\
\hline \multicolumn{2}{|l|}{ Genital ulcers } & $0(0)$ & \\
\hline \multicolumn{2}{|c|}{ Humanpapilloma virus } & $4(3.8)$ & -.012 \\
\hline \multicolumn{2}{|c|}{ Lymphadenopathy (PGL) } & $0(0)$ & \\
\hline \multicolumn{2}{|c|}{ Pneumocystis carinii pneumonia } & $5(4.8)$ & $.380^{* *}$ \\
\hline \multicolumn{4}{|l|}{$(\mathrm{PCP})$} \\
\hline \multicolumn{2}{|c|}{ Medication management (AZT) } & $42(40.4)$ & -.127 \\
\hline \multicolumn{4}{|l|}{ Study Variables } \\
\hline Time 2 BSI & $3.43(3.50)$ & $(0-17)$ & $.550 * *$ \\
\hline Time 2 CD4 & \multicolumn{2}{|c|}{$308.27(214.48)(1-1110)$} & -.206 \\
\hline Time 2 HRSD & $4.91(3.33)$ & $(0-15)$ & $.634 * *$ \\
\hline Time 2 LOT & $19.73(3.43)$ & $(11-29)$ & .090 \\
\hline Time 2 PSI & $33.63(22.38)$ & $(1-108)$ & 1 \\
\hline
\end{tabular}


Table 3

Longitudinal correlations between physical symptoms at Assessment 2, demographics, and major study variables at Assessment 1

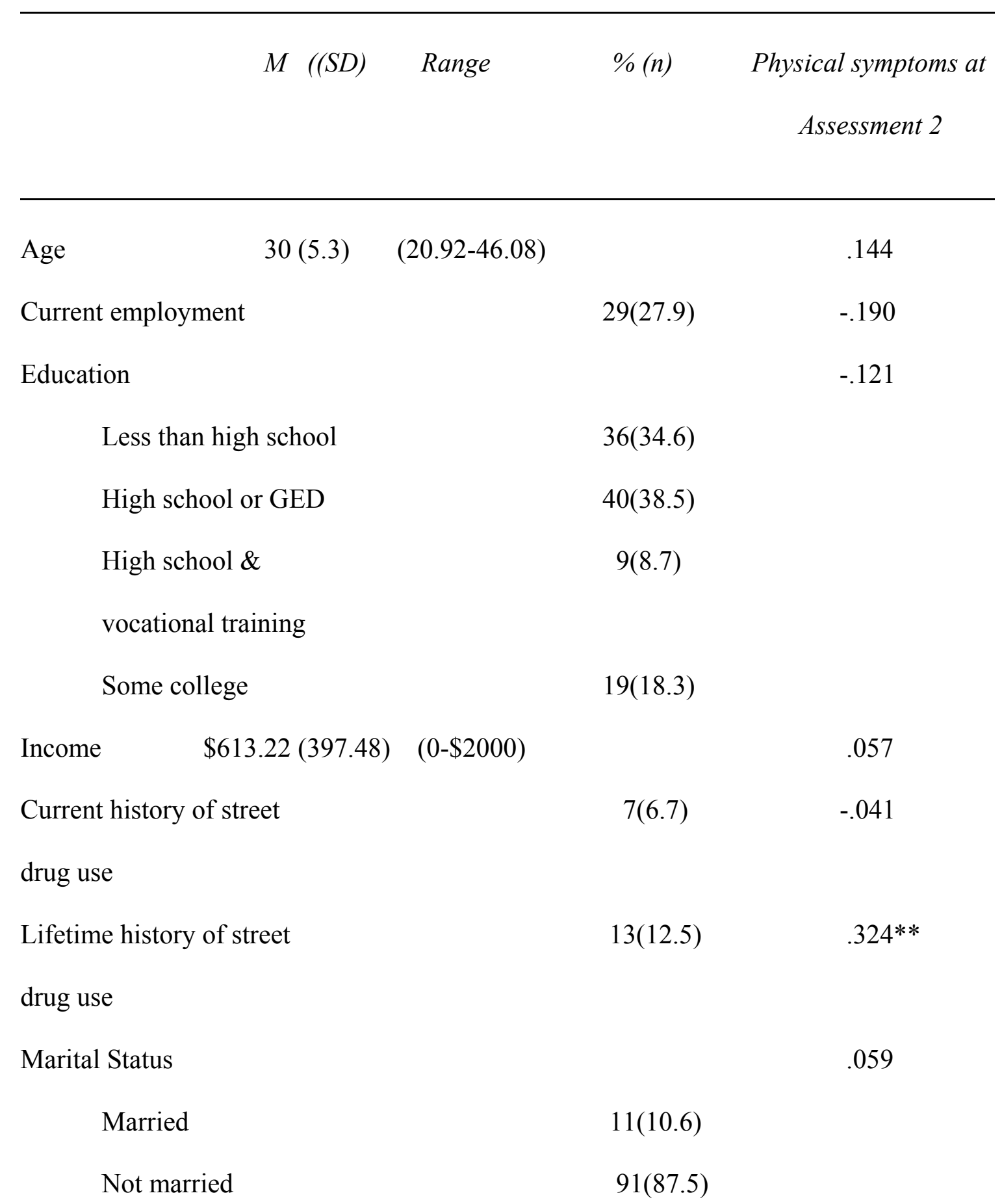




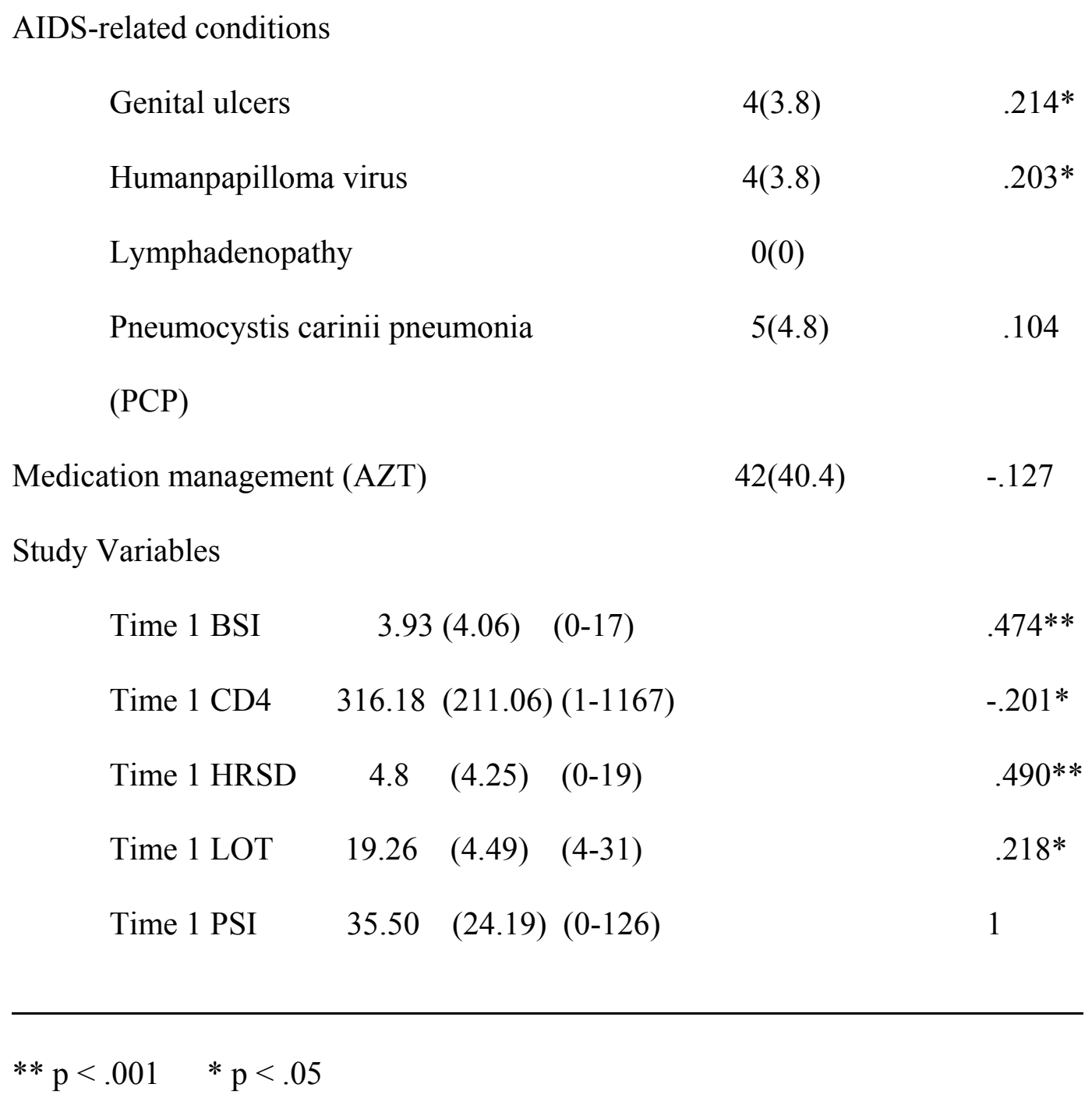


Table 4

Cross-sectional analyses at Assessment 1 using the BSI

\begin{tabular}{|c|c|c|c|c|}
\hline Variable & $F$ & $R^{2} \Delta$ & $B$ & $t$ \\
\hline Covariates & 5.90 & .15 & & \\
\hline \multicolumn{5}{|l|}{ Block 1} \\
\hline Genital ulcers & & & .33 & $3.56^{* *}$ \\
\hline Lymphadenopathy & & & .22 & $2.38^{*}$ \\
\hline Current history of street & & & .25 & $2.64^{*}$ \\
\hline
\end{tabular}

Immune $\quad 4.40 \quad 000$

Block 2

CD4

$\begin{array}{ll}-.02 & -.23\end{array}$

Psychological

13.99

.27

Block 3

BSI

.54

$6.33^{* *}$

2-Way Interactions

13.14

.03

Block 4

CD4 x BSI

$-.19 \quad-2.36^{*}$ 
Psychosocial Moderators 96

\section{$* * \mathrm{p}<.001 \quad * \mathrm{p}<.05$}


Table 5

Cross-sectional Analyses at Assessment 2 using the BSI

\begin{tabular}{|c|c|c|c|c|}
\hline & $F$ & $R^{2} \Delta$ & $B$ & $t$ \\
\hline \multicolumn{5}{|l|}{ Covariates } \\
\hline PCP & 12.67 & .15 & .38 & $3.56^{* *}$ \\
\hline \multicolumn{5}{|l|}{ Immune } \\
\hline $\mathrm{CD} 4$ & 6.76 & .01 & -.10 & -.94 \\
\hline Psychological & 9.92 & .20 & & \\
\hline BSI & & & .46 & $4.61 * *$ \\
\hline 2-Way Interactions & 6.46 & .001 & & \\
\hline CD4 x BSI & & & -.03 & -.32 \\
\hline
\end{tabular}

$* * \mathrm{p}<.001 \quad * \mathrm{p}<.05$ 
Table 6

Cross-sectional analyses at Assessment 1 using the HRSD and controlling for vegetative symptoms of depression

\begin{tabular}{|c|c|c|c|c|}
\hline & $F$ & $R^{2} \Delta$ & $B$ & $t$ \\
\hline Covariates & 5.94 & .16 & & \\
\hline Genital ulcers & & & .34 & $3.56^{* *}$ \\
\hline Lymphadenopathy & & & .25 & $2.39 *$ \\
\hline Lifetime history of street & & & .25 & $2.64^{*}$ \\
\hline drugs & & & & \\
\hline Immune & & & & \\
\hline CD4 & 4.43 & .001 & -.03 & -.30 \\
\hline Psychological & 11.17 & .215 & & \\
\hline HRSD & & & .47 & $5.68 * *$ \\
\hline 2-Way Interactions & 10.41 & .029 & & \\
\hline CD4 x HRSD & & & -.18 & $-2.13^{*}$ \\
\hline
\end{tabular}


Table 7

Cross-sectional analyses at Assessment 2 using the HRSD and controlling for vegetative symptoms and physical symptoms at Assessment 1

\begin{tabular}{ccccc}
\hline & $F$ & $R^{2} \Delta$ & $B$ & $t$ \\
\hline Covariates & 12.48 & .14 & & $3.56^{* *}$ \\
PCP & & & .38 & \\
Immune & & & & \\
CD4 & 6.68 & .01 & -.10 & \\
Psychological & 16.70 & .33 & & \\
HRSD & & & .64 & \\
2-Way Interactions & 12.18 & .030 & & -.65 \\
CD4 x HRSD & & & -.05 & \\
\end{tabular}

$* * \mathrm{p}<.001 \quad * \mathrm{p}<.05$ 
Table 8

Cross-sectional analyses at Assessment 1 using the LOT.

\begin{tabular}{|c|c|c|c|c|}
\hline & $F$ & $R^{2} \Delta$ & $B$ & $t$ \\
\hline Covariates & 4.50 & .12 & & \\
\hline Genital ulcers & & & .28 & $2.89 *$ \\
\hline Lymphadenopathy & & & .23 & $2.34^{*}$ \\
\hline Lifetime history of street & & & .25 & $2.64 *$ \\
\hline drugs & & & & \\
\hline Immune & & & & \\
\hline CD4 & 3.37 & .001 & -.03 & -.31 \\
\hline Psychological & 2.92 & .010 & & \\
\hline LOT & & & .11 & 1.05 \\
\hline 2-Way Interactions & 2.68 & .013 & & \\
\hline CD4 x LOT & & & -.12 & -1.18 \\
\hline
\end{tabular}

$* * \mathrm{p}<.001 \quad * \mathrm{p}<.05$ 
Table 9

Cross-sectional analyses at Assessment 2 using LOT

\begin{tabular}{|c|c|c|c|c|}
\hline & $F$ & $R^{2} \Delta$ & $B$ & $t$ \\
\hline Covariates & 1.11 & .011 & & \\
\hline PCP & & & .10 & 1.05 \\
\hline \multicolumn{5}{|l|}{ Immune } \\
\hline CD4 & 2.31 & .033 & -.18 & -1.87 \\
\hline Psychological & 1.80 & .007 & & \\
\hline LOT & & & .09 & .89 \\
\hline 2-Way Interactions & 1.35 & .001 & & \\
\hline CD4 x LOT & & & -.02 & .24 \\
\hline
\end{tabular}


Table 10

Longitudinal analyses using BSI and controlling for physical symptoms at Assessment 1

\begin{tabular}{|c|c|c|c|c|}
\hline & $F$ & $R^{2} \Delta$ & $B$ & $t$ \\
\hline Covariates & 23.22 & .547 & & \\
\hline HPV & & & -.01 & -.10 \\
\hline Genital ulcers & & & .15 & 1.94 \\
\hline Lifetime history of & & & .27 & $3.45^{* *}$ \\
\hline \multicolumn{5}{|l|}{ Street drugs } \\
\hline Physical Symptoms at A1 & & & .61 & $7.38 * *$ \\
\hline \multicolumn{5}{|l|}{ Immune } \\
\hline $\mathrm{CD} 4$ & 20.00 & .021 & -.15 & -1.94 \\
\hline Psychological & 18.13 & .024 & & \\
\hline BSI & & & .19 & 1.99 \\
\hline 2-Way Interactions & 19.63 & .009 & & \\
\hline CD4 x BSI & & & -.28 & -1.46 \\
\hline
\end{tabular}

$$
* * \mathrm{p}<.001 \quad * \mathrm{p}<.05
$$


Table 11

Longitudinal analyses using HRSD and controlling for physical symptoms at Assessment 1

\begin{tabular}{|c|c|c|c|c|}
\hline & $F$ & $R^{2} \Delta$ & $B$ & $t$ \\
\hline Covariates & 14.49 & .376 & & \\
\hline HPV & & & .13 & 1.66 \\
\hline Genital ulcers & & & .03 & -.08 \\
\hline Lifetime history of & & & .20 & $2.36^{*}$ \\
\hline \multicolumn{5}{|l|}{ Street drugs } \\
\hline Physical symptoms at A1 & & & .49 & $5.62 * *$ \\
\hline \multicolumn{5}{|l|}{ Immune } \\
\hline $\mathrm{CD} 4$ & 12.18 & .014 & -.12 & -1.48 \\
\hline Psychological & 24.35 & .218 & & \\
\hline HRSD & & & .31 & $5.23 * *$ \\
\hline \multicolumn{5}{|l|}{ 2-Way Interactions } \\
\hline CD4 x HRSD & 19.20 & .003 & .23 & 1.20 \\
\hline
\end{tabular}


Table 12

Longitudinal analyses using the LOT and controlling for physical symptoms at Assessment 1

\begin{tabular}{|c|c|c|c|c|}
\hline & $F$ & $R^{2} \Delta$ & $B$ & $t$ \\
\hline Covariates & 14.01 & .37 & & \\
\hline HPV & & & .14 & 1.66 \\
\hline Genital ulcers & & & -.01 & -.08 \\
\hline Lifetime history of & & & .21 & $2.44^{*}$ \\
\hline \multicolumn{5}{|l|}{ Street drugs } \\
\hline Physical symptoms & & & .49 & $5.62 * *$ \\
\hline \multicolumn{5}{|l|}{ Immune } \\
\hline $\mathrm{CD} 4$ & 11.86 & .016 & -.13 & -1.56 \\
\hline Psychological & 11.17 & .013 & & \\
\hline LOT & & & .12 & 1.44 \\
\hline \multicolumn{5}{|l|}{ 2-Way Interactions } \\
\hline CD4 x LOT & 10.89 & .002 & -.13 & -1.79 \\
\hline
\end{tabular}


Psychosocial Moderators 105

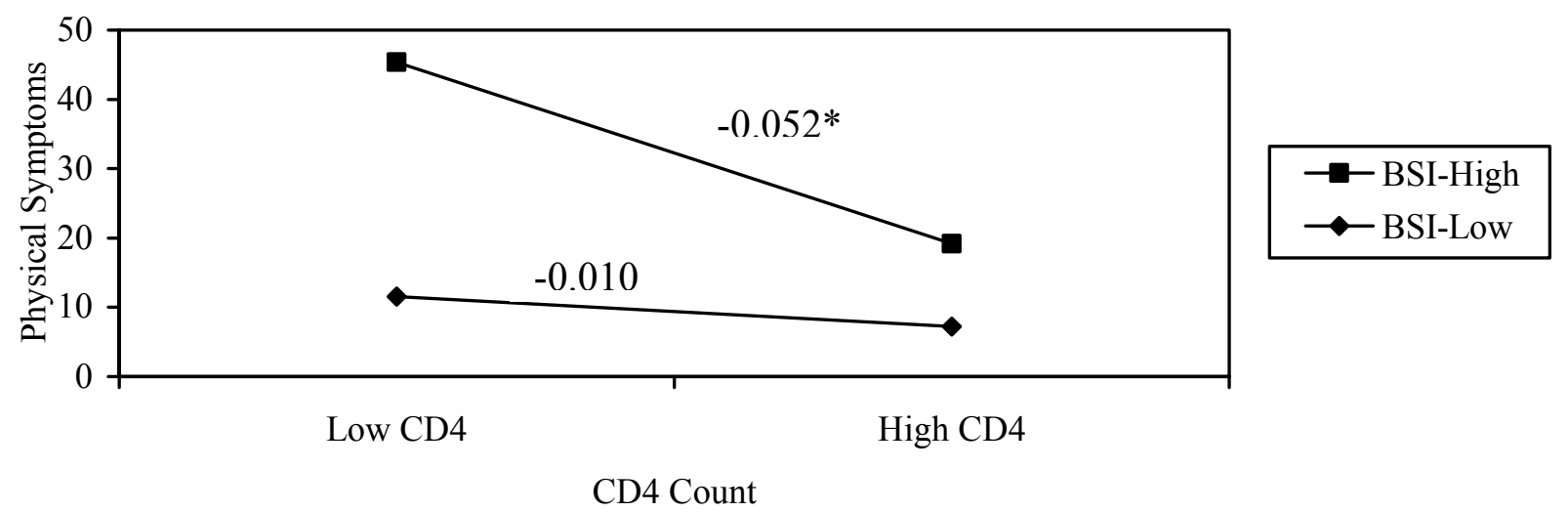

Figure 1. Interaction of depressive symptoms measured with the BSI and CD4 count on physical symptoms at Assessment One. 


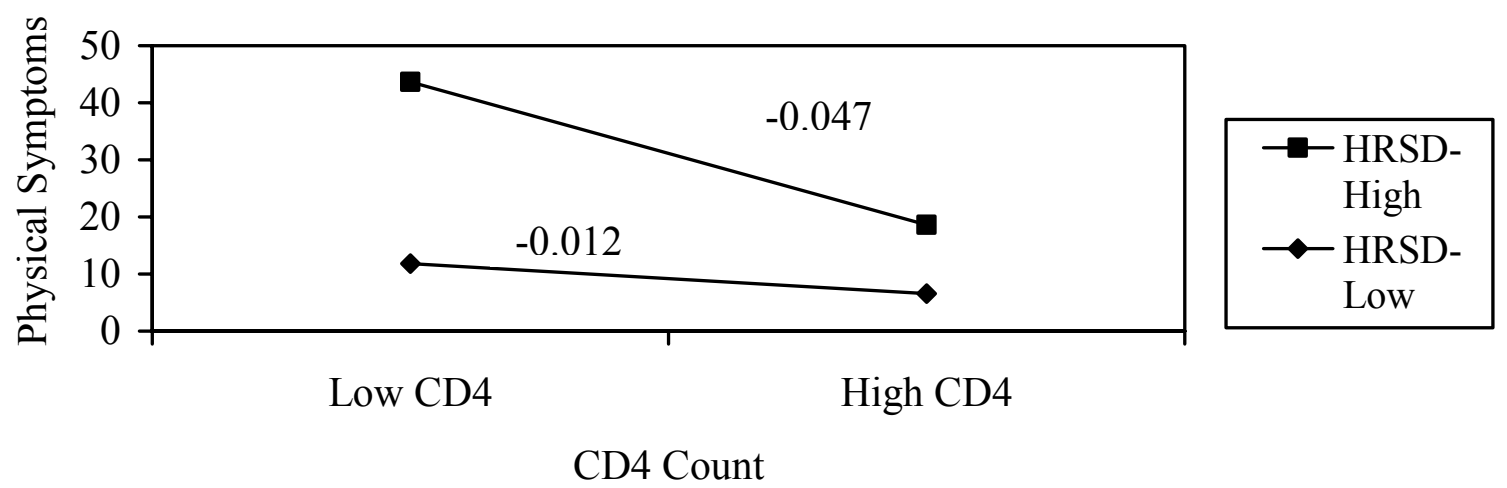

Figure 2 . Interaction of depressive symptoms measured with the HRSD and CD4 count on physical symptoms at Assessment One. 


\section{Appendix A}

\section{Brief Demographic Assessment}

1. How much schooling have you completed?

(Record highest level)

$$
\begin{aligned}
& 1=\text { less than high school } \\
& 2=\text { H.S. or GED } \\
& 3=\text { H.S. }+ \text { Voc. Ed. } \\
& 4=\text { Some college }
\end{aligned}
$$

2. What is your marital status?

$$
\begin{aligned}
& 1=\text { Never married } \\
& 2=\text { Married } \\
& 3=\text { Common law } \\
& 4=\text { Separated } \\
& 5=\text { Divorced } \\
& 6=\text { Widowed } \\
& 7=\text { Engaged }
\end{aligned}
$$

3. How much money do you live on each month?

4. Think back over the past year and tell me how much difficulty

You had with paying your bills. Would you say you had:

$$
\begin{aligned}
& 4=\text { A great deal of difficulty } \\
& 3=\text { Quite a bit of difficulty } \\
& 2=\text { A little bit of difficulty } \\
& 1=\text { No difficulty at all }
\end{aligned}
$$


5. Are you employed outside the home?

$$
\begin{aligned}
& \text { Yes }=1 \\
& \text { No }=0
\end{aligned}
$$

a. If yes,

$$
\begin{aligned}
& 2 \text { = Part-time } \\
& \text { (less than } 32 \text { hours/week) } \\
& 1 \text { = Full-time }
\end{aligned}
$$

6. How many people live in your household?

7. Of those, how many are under age 18 ? 


\section{Appendix B}

\section{Life Orientation Test (LOT)}

Tell me how much you agree with each of these items, using these categories:

\section{SHOW AND EXPLAIN CUE CARD}

$0=$ strongly disagree

$1=$ disagree

$2=$ neutral or in the middle

$3=$ agree

$4=$ strongly agree

1. In uncertain or bad times, you usually expect the best.

2. If something can go wrong for you, it will.

3. You always look on the bright side of things.

4. You're always optimistic or positive about your future.

5. You hardly ever expect things to go your way.

6. Things never work out the way you want them to.

7. You're a believer in the idea that "every cloud has a silver lining" or "something good will come out of everything."

8. You rarely count on good things happening to you. 


\section{Appendix C}

\section{Hamilton Depression Rating Scale}

To be completed by interviewer at the end of the interview. This rating is based on clinical impressions forming from the participants' responses to specific items, as well as behavioral observations. Please see scoring guidelines.

\begin{tabular}{|c|c|c|}
\hline \multirow[t]{5}{*}{5 point ratings: } & $0=\mathrm{absent}$ & 3 point ratings: \\
\hline & $1=$ mild & $0=$ absent \\
\hline & $2=$ moderate & $1=$ slight \\
\hline & $3=$ high moderate & $1=$ slight \\
\hline & $4=$ severe & $2=$ clearly present \\
\hline
\end{tabular}

Depressed Mood

$\begin{array}{lllllll}\text { Sad, pessimistic, tendency to weep } & 0 & 1 & 2 & 3 & 4\end{array}$

Guilt

Feels let other down, illness is a $\quad \begin{array}{llllll}0 & 1 & 2 & 3 & 4\end{array}$

Punishment, delusions of guilt

Suicide

$\begin{array}{lllll}0 & 1 & 2 & 3 & 4\end{array}$

Life isn't worth living, wishes she

Initial-difficulty falling asleep

0

1 
Middle-disturbed during the night

Delayed-early morning awakening

Work and Interests

Anhedonia, indecision, decrease in

Social activities, unable to work

Psychomotor Retardation

Slowness of thought, speech, and activity

Apathy

Agitation

Restless or fidgety

Anxiety

Psychic

worrying, apprehensive, fears

Somatic

GI distress, headaches, racing heart
0

0
2

2

4 
Psychosocial Moderators112

General

Weak muscles, backache, fatigue

Genital Symptoms

Loss of libido, menstrual disturbances

Hypochondriasis

Bodily or health preoccupation, delusions

Loss of weight

Loss of insight

Denies emotional pain or difficulty in face

Of evidence to the contrary

0

1 2

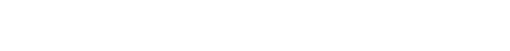

\section{Psychosocial Moderators112}

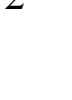




\section{Appendix D}

Brief Symptoms Inventory (Depression Subscale)

I am going to read a list of problems people sometimes have. Please listen to each one carefully, and tell me the number (SHOW CUE CARD AND DESCRIBE) that best describes HOW MUCH YOU HAVE HAD THIS PROBLEM DURING THE PAST

7 DAYS INCLUDING TODAY. If you have any questions about any of the items that I read, please ask about them.

Let's do an example first: In the last week, how much have you had body aches?

$0 \quad$ Not at all

1 A little bit

2 Moderately

3 Extremely

\section{IN THE LAST WEEK, HOW MUCH HAVE YOU HAD:}

1. Nervousness or shakiness inside

2. Trouble remembering things

3. Thoughts of ending your life

4. A poor appetite or not felt hungry very often

5. Feelings like you can't get things done

6. Feelings of loneliness

7. Feelings of being blue

8. Feelings of no interest in things

9. Feelings of fearfulness

10. Feelings that you are inferior to others 
or that others are better than you

11. Trouble falling asleep

12. Difficulty making decisions

13. Trouble with your mind going blank

14. Feelings of hopelessness about the future

15. Feelings of being tense or keyed up

16. Thoughts of death or dying

17. Feelings of nervousness when you are left alone

18. Feelings of being so restless that you couldn't sit still

19. Feelings of worthlessness or being no good

20. Feelings of guilt 
Appendix E

Physical Symptoms Inventory

I am going to read a list of physical troubles. Please tell me how often each of these bothers you. Do this by telling me the number which shows how often you are bothered by that trouble. Keep in mind that the LARGER the number the MORE OFTEN the trouble bothers you.

\section{HAND MOTHER CUE CARD AND EXPLAIN RESPONSE CATEGORIES}

Almost never $=0 \quad$ About once a month $=1 \quad$ About once a week $=2 \quad$ More

than once a week $=3 \quad$ Nearly every day $=4$

1. Nausea (Feeling like throwing up)

2. Headaches

3. Trouble with ears or hearing

4. Neck aches or pains

5. Arm or leg aches or pains

6. Shakiness

7. Swelling of arms, hands, legs or feet

8. Trouble sleeping (initial, middle, or delayed?)

9. Losing weight

10. Backaches

11. Irregular or loss of menstruation (if past menopause, N/A)

12. Difficulty with urination (passing water)

13. Heart trouble 
14. Numbness, or lack of feeling in any part of the body

15. Aches or pains in hands or feet

16. Fainting spells

17. Excessive perspiration (sweating)

18. Abnormal blood pressure

19. Trouble with eyes or vision

20. Burning, tingling or crawling feelings in the skin

21. Skin trouble (Rashes, boils, or itching)

22. Feeling tired

23. Weakness in your muscles

24. Dizzy spells

25. Tension or tightness in your muscles

26. Difficulty breathing (Short of breath, asthma, etc.)

27. Twitching muscles

28. Poor health in general

29. Passing gas a lot

30. More severe menstrual cramps than usual

31. Seizures (Convulsions or fits)

32. Gaining weight

33. Trouble with not feeling hungry

34. Trouble going to the bathroom (constipation or loose bowels)

35. Vomiting

36. Chest pains 
37. Sinus problems

38. Vaginal itching

39. Vaginal discharge 
Psychosocial Moderators118

\section{Appendix F}

Correlation Table for Demographic Variables and Major Study Variables at Time One

\begin{tabular}{|c|c|c|c|c|c|c|c|c|c|c|c|c|c|}
\hline & & Age & $\begin{array}{l}\text { Marital } \\
\text { Status }\end{array}$ & Schooling & Employment & Income & $\begin{array}{l}\text { Number } \\
\text { of } \\
\text { Children } \\
\text { given } \\
\text { birth to }\end{array}$ & $\begin{array}{l}\text { Lifetime } \\
\text { History } \\
\text { of } \\
\text { Street } \\
\text { drug } \\
\text { use }\end{array}$ & $\begin{array}{l}\text { Current } \\
\text { Use of } \\
\text { Street } \\
\text { drugs }\end{array}$ & $\begin{array}{l}\text { LOT } \\
\text { Time } 1\end{array}$ & $\begin{array}{c}\text { PSI } \\
\text { Time } 1\end{array}$ & $\begin{array}{l}\text { HAM } \\
\text { (COG) } \\
\text { Time } 1\end{array}$ & $\begin{array}{c}\text { BSI } \\
\text { (DEP) } \\
\text { Time } 1\end{array}$ \\
\hline \multirow[t]{2}{*}{ Age } & $\begin{array}{l}\text { Pearson } \\
\text { Correlation }\end{array}$ & 1 & $.377(* \star)$ & .066 & .160 & .037 & .025 & .127 & .017 & .062 & .043 & -.065 & .025 \\
\hline & $\begin{array}{l}\text { Sig. (2- } \\
\text { tailed) }\end{array}$ & & .000 & .507 & .132 & .706 & .803 & .201 & .868 & .543 & .668 & .517 & .806 \\
\hline \multirow[t]{2}{*}{$\begin{array}{l}\text { Marital } \\
\text { Status }\end{array}$} & $\begin{array}{l}\text { Pearson } \\
\text { Correlation }\end{array}$ & $.377\left(^{\star \star}\right)$ & 1 & .148 & .174 & $.208\left(^{\star}\right)$ & -.034 & .160 & -.091 & -.018 & .030 & -.082 & -.048 \\
\hline & $\begin{array}{l}\text { Sig. (2- } \\
\text { tailed) }\end{array}$ & .000 & & .134 & .102 & .034 & .732 & .104 & .356 & .856 & .765 & .419 & .633 \\
\hline \multirow[t]{2}{*}{$\begin{array}{l}\text { Years of } \\
\text { Schooling }\end{array}$} & $\begin{array}{l}\text { Pearson } \\
\text { Correlation }\end{array}$ & .066 & .148 & 1 & .112 & .035 & -.192 & -.086 & -.158 & -.035 & -.017 & -.082 & -.057 \\
\hline & $\begin{array}{l}\text { Sig. (2- } \\
\text { tailed) }\end{array}$ & .507 & .134 & & .295 & .724 & .050 & .383 & .110 & .730 & .869 & .416 & .570 \\
\hline \multirow[t]{2}{*}{ Employment } & $\begin{array}{l}\text { Pearson } \\
\text { Correlation }\end{array}$ & .160 & .174 & .112 & 1 & $.310(* \star)$ & -.114 & -.168 & .040 & $.303^{* \star}{ }^{*}$ & -.100 & $-.261\left({ }^{*}\right)$ & -.116 \\
\hline & $\begin{array}{l}\text { Sig. (2- } \\
\text { tailed) }\end{array}$ & .132 & .102 & .295 & & .003 & .286 & .113 & .706 & .004 & .356 & .015 & .282 \\
\hline \multirow[t]{2}{*}{ Income } & $\begin{array}{l}\text { Pearson } \\
\text { Correlation }\end{array}$ & .037 & $.208\left(^{*}\right)$ & .035 & $.310(* *)$ & 1 & .035 & .033 & .005 & .052 & -.045 & -.148 & .007 \\
\hline & $\begin{array}{l}\text { Sig. (2- } \\
\text { tailed) }\end{array}$ & .706 & .034 & .724 & .003 & & .721 & .737 & .961 & .609 & .652 & .143 & .942 \\
\hline \multirow{2}{*}{$\begin{array}{l}\text { Number of } \\
\text { Children } \\
\text { given } \\
\text { birth to }\end{array}$} & $\begin{array}{l}\text { Pearson } \\
\text { Correlation }\end{array}$ & .025 & -.034 & -.192 & -.114 & .035 & 1 & $.226\left(^{*}\right)$ & .047 & .081 & .046 & $.210\left(^{*}\right)$ & .188 \\
\hline & $\begin{array}{l}\text { Sig. (2- } \\
\text { tailed) }\end{array}$ & .803 & .732 & .050 & .286 & .721 & & .021 & .638 & .424 & .649 & .036 & .058 \\
\hline \multirow{2}{*}{$\begin{array}{l}\text { Lifetime } \\
\text { History of } \\
\text { Street drug } \\
\text { use }\end{array}$} & $\begin{array}{l}\text { Pearson } \\
\text { Correlation }\end{array}$ & .127 & .160 & -.086 & -.168 & .033 & $.226\left(^{*}\right)$ & 1 & .015 & -.003 & $.238\left(^{\star}\right)$ & .180 & .189 \\
\hline & $\begin{array}{l}\text { Sig. (2- } \\
\text { tailed) }\end{array}$ & .201 & .104 & .383 & .113 & .737 & .021 & & .884 & .980 & .017 & .074 & .058 \\
\hline \multirow[t]{2}{*}{$\begin{array}{l}\text { Current Use } \\
\text { of Street } \\
\text { drugs }\end{array}$} & $\begin{array}{l}\text { Pearson } \\
\text { Correlation }\end{array}$ & .017 & -.091 & -.158 & .040 & .005 & .047 & .015 & 1 & -.191 & .043 & .041 & .043 \\
\hline & $\begin{array}{l}\text { Sig. (2- } \\
\text { tailed) }\end{array}$ & .868 & .356 & .110 & .706 & .961 & .638 & .884 & & .056 & .670 & .688 & .667 \\
\hline \multirow[t]{2}{*}{ LOT Time 1} & Pearson & .062 & -.018 & -.035 & $-.303\left({ }^{\star *}\right)$ & .052 & .081 & -.003 & -.191 & 1 & .173 & .052 & .137 \\
\hline & $\begin{array}{l}\text { Sig. (2- } \\
\text { tailed) }\end{array}$ & .543 & .856 & .730 & .004 & .609 & .424 & .980 & .056 & & .087 & .611 & .175 \\
\hline \multirow[t]{2}{*}{ PSI Time 1} & $\begin{array}{l}\text { Pearson } \\
\text { Correlation }\end{array}$ & .043 & .030 & -.017 & -.100 & -.045 & .046 & $.238\left(^{*}\right)$ & .043 & .173 & 1 & $.522\left({ }^{\star *}\right)$ & $.596(* *)$ \\
\hline & Sig. (2- & .668 & .765 & .869 & .356 & .652 & .649 & .017 & .670 & .087 & & .000 & .000 \\
\hline
\end{tabular}


Psychosocial Moderators119

\begin{tabular}{|c|c|c|c|c|c|c|c|c|c|c|c|c|c|}
\hline & tailed) & & & & & & & & & & & & \\
\hline \multirow[t]{2}{*}{$\begin{array}{l}\text { HAM (COG) } \\
\text { Time } 1\end{array}$} & $\begin{array}{l}\text { Pearson } \\
\text { Correlation }\end{array}$ & -.065 & -.082 & -.082 & $-.261\left(^{*}\right)$ & -.148 & $.210\left(^{*}\right)$ & .180 & .041 & .052 & $.522\left({ }^{\star \star}\right)$ & 1 & $\left..810^{(* \star}\right)$ \\
\hline & $\begin{array}{l}\text { Sig. (2- } \\
\text { tailed) }\end{array}$ & .517 & .419 & .416 & .015 & .143 & .036 & .074 & .688 & .611 & .000 & & .000 \\
\hline \multirow[t]{2}{*}{$\begin{array}{l}\text { BSI (DEP) } \\
\text { Time } 1\end{array}$} & $\begin{array}{l}\text { Pearson } \\
\text { Correlation }\end{array}$ & .025 & -.048 & -.057 & -.116 & .007 & .188 & .189 & .043 & .137 & $.596\left(^{* \star}\right)$ & $\left..810^{(* *}\right)$ & 1 \\
\hline & $\begin{array}{l}\text { Sig. (2- } \\
\text { tailed) }\end{array}$ & .806 & .633 & .570 & .282 & .942 & .058 & .058 & .667 & .175 & .000 & .000 & \\
\hline
\end{tabular}


Psychosocial Moderators120

\begin{tabular}{|c|c|c|c|c|c|c|c|c|c|c|c|c|c|c|c|c|c|c|}
\hline \multicolumn{19}{|c|}{ Correlation Table for Immune Functioning, AIDS-Related Conditions, and Major Study Variables at Time One } \\
\hline & & CD4 & $\begin{array}{l}\text { Candidiasis } \\
\text { Esophagus }\end{array}$ & $\begin{array}{l}\text { Cryptococ- } \\
\text { cosis }\end{array}$ & CMV & $\begin{array}{l}\text { Cervical } \\
\text { Cancer }\end{array}$ & $\begin{array}{l}\text { Genital } \\
\text { ulcers }\end{array}$ & $\begin{array}{l}\text { HIV } \\
\text { Encephal- } \\
\text { opathy }\end{array}$ & HPV & PGL & PID & PCP & $\begin{array}{l}\text { Recurrent } \\
\text { bacterial } \\
\text { pneumonia }\end{array}$ & $\begin{array}{l}\text { Squamous } \\
\text { intraepithelial } \\
\text { neoplasm }\end{array}$ & PSI & LOT & HAM & BSI \\
\hline \multirow[t]{2}{*}{ CD4 } & $\begin{array}{l}\text { Pearson } \\
\text { Correlation }\end{array}$ & 1 & $-.327(* \star)$ & -.147 & $\begin{array}{r}.253( \\
* *)\end{array}$ & -.147 & -.132 & -.090 & $\begin{array}{r}.207( \\
\star)\end{array}$ & -.073 & -.172 & -.135 & .023 & .070 & -.091 & .008 & .051 & .050 \\
\hline & $\begin{array}{l}\text { Sig. (2- } \\
\text { tailed) }\end{array}$ & & .001 & .135 & .010 & .136 & .183 & .363 & .035 & .464 & .081 & .173 & .816 & .478 & .367 & .936 & .617 & .619 \\
\hline \multirow{2}{*}{$\begin{array}{l}\text { Candidiasis } \\
\text { Esophagus }\end{array}$} & $\begin{array}{l}\text { Pearson } \\
\text { Correlation }\end{array}$ & $\begin{array}{r}.327( \\
* \star)\end{array}$ & 1 & $.215\left(^{*}\right)$ & .041 & -.064 & .173 & -.045 & $\begin{array}{r}.339( \\
* \star\end{array}$ & .080 & $.283(* *)$ & -.021 & .016 & -.045 & .051 & -.003 & -.073 & .008 \\
\hline & $\begin{array}{l}\text { Sig. (2- } \\
\text { tailed) }\end{array}$ & .001 & & .028 & .682 & .518 & .079 & .650 & .000 & .420 & .004 & .829 & .872 & .650 & .612 & .980 & .471 & .940 \\
\hline \multirow{2}{*}{ Cryptococcosis } & $\begin{array}{l}\text { Pearson } \\
\text { Correlation }\end{array}$ & -.147 & $.215\left(^{*}\right)$ & 1 & -.020 & -.014 & -.020 & -.010 & .287( & .367( & $.367(* \star)$ & -.026 & -.022 & -.010 & .039 & .062 & -.090 & -.048 \\
\hline & $\begin{array}{l}\text { Sig. (2- } \\
\text { tailed) }\end{array}$ & .135 & .028 & & .843 & .889 & .843 & .922 & .003 & .000 & .000 & .790 & .823 & .922 & .695 & .542 & .372 & .635 \\
\hline \multirow[t]{2}{*}{ CMV } & $\begin{array}{l}\text { Pearson } \\
\text { Correlation }\end{array}$ & $\begin{array}{r}.253( \\
* *)\end{array}$ & .041 & -.020 & 1 & -.028 & -.040 & $.493\left({ }^{* \star}\right)$ & .094 & -.054 & .146 & .146 & .189 & -.020 & .008 & .000 & -.102 & .028 \\
\hline & $\begin{array}{l}\text { Sig. (2- } \\
\text { tailed) }\end{array}$ & .010 & .682 & .843 & & .778 & .687 & .000 & .344 & .588 & .140 & .140 & .055 & .843 & .933 & .996 & .311 & .776 \\
\hline \multirow{2}{*}{ Cervical Cancer } & $\begin{array}{l}\text { Pearson } \\
\text { Correlation }\end{array}$ & -.147 & -.064 & -.014 & -.028 & 1 & -.028 & -.014 & -.048 & -.038 & -.038 & -.038 & -.031 & -.014 & -.148 & .072 & -.078 & -.120 \\
\hline & $\begin{array}{l}\text { Sig. (2- } \\
\text { tailed) }\end{array}$ & .136 & .518 & .889 & .778 & & .778 & .889 & .627 & .705 & .705 & .705 & .751 & .889 & .141 & .479 & .443 & .229 \\
\hline \multirow{2}{*}{ Genital ulcers } & $\begin{array}{l}\text { Pearson } \\
\text { Correlation }\end{array}$ & -.132 & .173 & -.020 & -.040 & -.028 & 1 & -.020 & .094 & -.054 & .146 & -.054 & -.045 & -.020 & $.318^{* *}$ & .095 & .154 & $\begin{array}{r}.254( \\
*)\end{array}$ \\
\hline & $\begin{array}{l}\text { Sig. (2- } \\
\text { tailed) }\end{array}$ & .183 & .079 & .843 & .687 & .778 & & .843 & .344 & .588 & .140 & .588 & .651 & .843 & .001 & .348 & .126 & .010 \\
\hline HIV & Pearson & -.090 & -.045 & -.010 & .493 & -.014 & -.020 & 1 & -.034 & -.026 & -.026 & -.026 & $\left..4388^{* \star}\right)$ & -.010 & -.035 & -.118 & .028 & .026 \\
\hline
\end{tabular}




\section{Psychosocial Moderators121}

\begin{tabular}{|c|c|c|c|c|c|c|c|c|c|c|c|c|c|c|c|c|c|c|}
\hline \multirow{2}{*}{ Encephalopathy } & Correlation & & & & $\star \star)$ & & & & & & & & & & & & & \\
\hline & $\begin{array}{l}\text { Sig. (2- } \\
\text { tailed) }\end{array}$ & .363 & .650 & .922 & .000 & .889 & .843 & & .733 & .790 & .790 & .790 & .000 & .922 & .726 & .241 & .779 & .793 \\
\hline \multirow{2}{*}{ HPV } & $\begin{array}{l}\text { Pearson } \\
\text { Correlation }\end{array}$ & $.207^{-}$ & $.339\left(^{\star \star}\right)$ & $.287\left(^{\star \star}\right)$ & .094 & -.048 & .094 & -.034 & 1 & .157 & $.282(* *)$ & .032 & -.077 & -.034 & .136 & .093 & $\begin{array}{r}.212( \\
*)\end{array}$ & $\begin{array}{r}.202( \\
*)\end{array}$ \\
\hline & $\begin{array}{l}\text { Sig. (2- } \\
\text { tailed) }\end{array}$ & .035 & .000 & .003 & .344 & .627 & .344 & .733 & & .111 & .004 & .744 & .435 & .733 & .174 & .360 & .034 & .042 \\
\hline \multirow[b]{2}{*}{$\begin{array}{l}\text { Lymphaden- } \\
\text { opathy }\end{array}$} & $\begin{array}{l}\text { Pearson } \\
\text { Correlation }\end{array}$ & -.073 & .080 & $.367\left(^{\star \star}\right)$ & -.054 & -.038 & -.054 & -.026 & .157 & 1 & .081 & .081 & -.060 & -.026 & $.208\left(^{*}\right)$ & $\begin{array}{r}.274( \\
* *)\end{array}$ & .068 & .062 \\
\hline & $\begin{array}{l}\text { Sig. (2- } \\
\text { tailed) }\end{array}$ & .464 & .420 & .000 & .588 & .705 & .588 & .790 & .111 & & .414 & .414 & .543 & .790 & .037 & .006 & .498 & .534 \\
\hline \multirow{2}{*}{ PID } & $\begin{array}{l}\text { Pearson } \\
\text { Correlation }\end{array}$ & -.172 & $\left..283^{(*}\right)$ & $.367\left(^{\star \star}\right)$ & .146 & -.038 & .146 & -.026 & $\begin{array}{r}.282( \\
* *)\end{array}$ & .081 & 1 & .081 & .119 & -.026 & .066 & .151 & -.052 & .072 \\
\hline & $\begin{array}{l}\text { Sig. (2- } \\
\text { tailed) }\end{array}$ & .081 & .004 & .000 & .140 & .705 & .140 & .790 & .004 & .414 & & .414 & .229 & .790 & .515 & .134 & .609 & .473 \\
\hline \multirow[t]{2}{*}{ PCP } & $\begin{array}{l}\text { Pearson } \\
\text { Correlation }\end{array}$ & -.135 & -.021 & -.026 & .146 & -.038 & -.054 & -.026 & .032 & .081 & .081 & 1 & -.060 & -.026 & -.054 & .081 & -.144 & $\begin{array}{r}. \\
.197( \\
*)\end{array}$ \\
\hline & $\begin{array}{l}\text { Sig. (2- } \\
\text { tailed) }\end{array}$ & .173 & .829 & .790 & .140 & .705 & .588 & .790 & .744 & .414 & .414 & & .543 & .790 & .590 & .426 & .152 & .047 \\
\hline \multirow{2}{*}{$\begin{array}{l}\text { Recurrent } \\
\text { bacterial } \\
\text { pneumonia }\end{array}$} & $\begin{array}{l}\text { Pearson } \\
\text { Correlation }\end{array}$ & .023 & .016 & -.022 & .189 & -.031 & -.045 & $.438\left(^{* \star}\right)$ & -.077 & -.060 & .119 & -.060 & 1 & -.022 & -.010 & -.058 & -.087 & -.019 \\
\hline & $\begin{array}{l}\text { Sig. (2- } \\
\text { tailed) }\end{array}$ & .816 & .872 & .823 & .055 & .751 & .651 & .000 & .435 & .543 & .229 & .543 & & .823 & .917 & .569 & .391 & .852 \\
\hline \multirow{2}{*}{$\begin{array}{l}\text { Squamous } \\
\text { intraepithelial } \\
\text { neoplasm }\end{array}$} & $\begin{array}{l}\text { Pearson } \\
\text { Correlation }\end{array}$ & .070 & -.045 & -.010 & -.020 & -.014 & -.020 & -.010 & -.034 & -.026 & -.026 & -.026 & -.022 & 1 & -.118 & .084 & -.066 & -.072 \\
\hline & $\begin{array}{l}\text { Sig. (2- } \\
\text { tailed) }\end{array}$ & .478 & .650 & .922 & .843 & .889 & .843 & .922 & .733 & .790 & .790 & .790 & .823 & & .238 & .405 & .511 & .470 \\
\hline \multirow{2}{*}{ PSI } & $\begin{array}{l}\text { Pearson } \\
\text { Correlation }\end{array}$ & -.091 & .051 & .039 & .008 & -.148 & $.318\left(^{* \star}\right)$ & -.035 & .136 & $\begin{array}{r}.208( \\
*)\end{array}$ & .066 & -.054 & -.010 & -.118 & 1 & .173 & $\begin{array}{r}.522( \\
\star \star)\end{array}$ & $\begin{array}{r}.596( \\
* *)\end{array}$ \\
\hline & $\begin{array}{l}\text { Sig. (2- } \\
\text { tailed) }\end{array}$ & .367 & .612 & .695 & .933 & .141 & .001 & .726 & .174 & .037 & .515 & .590 & .917 & .238 & & .087 & .000 & .000 \\
\hline LOT & $\begin{array}{l}\text { Pearson } \\
\text { Correlation }\end{array}$ & .008 & -.003 & .062 & .000 & .072 & .095 & -.118 & .093 & $\begin{array}{r}.274( \\
\star \star)\end{array}$ & .151 & .081 & -.058 & .084 & .173 & 1 & .052 & .137 \\
\hline
\end{tabular}




\section{Psychosocial Moderators122}

\begin{tabular}{|c|c|c|c|c|c|c|c|c|c|c|c|c|c|c|c|c|c|c|}
\hline & $\begin{array}{l}\text { Sig. (2- } \\
\text { tailed) }\end{array}$ & .936 & .980 & .542 & .996 & .479 & .348 & .241 & .360 & .006 & .134 & .426 & .569 & .405 & .087 & & .611 & .175 \\
\hline \multirow{2}{*}{ HAM } & $\begin{array}{l}\text { Pearson } \\
\text { Correlation }\end{array}$ & .051 & -.073 & -.090 & -.102 & -.078 & .154 & .028 & $\begin{array}{r}.212( \\
*)\end{array}$ & .068 & -.052 & -.144 & -.087 & -.066 & $\begin{array}{r}.522(* * \\
)\end{array}$ & .052 & 1 & $\underset{* \star}{.810(}$ \\
\hline & $\begin{array}{l}\text { Sig. (2- } \\
\text { tailed) }\end{array}$ & .617 & .471 & .372 & .311 & .443 & .126 & .779 & .034 & .498 & .609 & .152 & .391 & .511 & .000 & .611 & & .000 \\
\hline \multirow[t]{2}{*}{ BSI } & $\begin{array}{l}\text { Pearson } \\
\text { Correlation }\end{array}$ & .050 & .008 & -.048 & .028 & -.120 & $.254\left(^{*}\right)$ & .026 & $\begin{array}{r}.202( \\
*)\end{array}$ & .062 & .072 & $\begin{array}{r}.197( \\
*)\end{array}$ & -.019 & -.072 & $\begin{array}{r}.5966^{\star \star} \\
)\end{array}$ & .137 & $\left.\begin{array}{r}.810( \\
\star \star\end{array}\right)$ & 1 \\
\hline & $\begin{array}{l}\text { Sig. (2- } \\
\text { tailed) }\end{array}$ & .619 & .940 & .635 & .776 & .229 & .010 & .793 & .042 & .534 & .473 & .047 & .852 & .470 & .000 & .175 & .000 & \\
\hline
\end{tabular}


Psychosocial Moderators123

Correlation Table for Demographic Variables and Major Study Variables at Time Two

\begin{tabular}{|c|c|c|c|c|c|c|c|c|c|c|c|c|}
\hline & & $\begin{array}{l}\text { Marital } \\
\text { Status }\end{array}$ & Schooling & Employment & Income & $\begin{array}{l}\text { Number of } \\
\text { Children given } \\
\text { birth to }\end{array}$ & $\begin{array}{l}\text { Lifetime History of } \\
\text { Street drug use }\end{array}$ & $\begin{array}{l}\text { Current Street } \\
\text { drug use }\end{array}$ & PSI & LOT & HAM & BSI \\
\hline \multirow{2}{*}{ Marital Status } & Pearson Correlation & 1 & .048 & -.129 & $\left..298{ }^{(* *}\right)$ & .063 & .029 & -.039 & .105 & -.102 & .189 & $.251\left(^{*}\right)$ \\
\hline & Sig. (2-tailed) & & .675 & .296 & .008 & .583 & .804 & .734 & .360 & .375 & .097 & .026 \\
\hline \multirow{2}{*}{ Schooling } & Pearson Correlation & .048 & 1 & .012 & .173 & -.146 & -.141 & -.006 & .033 & .083 & .168 & .069 \\
\hline & Sig. (2-tailed) & .675 & & .920 & .129 & .202 & .219 & .957 & .776 & .469 & .141 & .549 \\
\hline \multirow{2}{*}{ Income } & Pearson Correlation & $.298(\star \star)$ & .173 & .024 & 1 & .010 & -.152 & -.149 & -.066 & -.061 & -.029 & .033 \\
\hline & Sig. (2-tailed) & .008 & .129 & .846 & & .932 & .185 & .193 & .568 & .597 & .803 & .776 \\
\hline \multirow{2}{*}{$\begin{array}{l}\text { Number of } \\
\text { Children given } \\
\text { birth to }\end{array}$} & Pearson Correlation & .063 & -.146 & .046 & .010 & 1 & .096 & .100 & -.068 & -.080 & -.067 & -.133 \\
\hline & Sig. (2-tailed) & .583 & .202 & .710 & .932 & & .402 & .386 & .553 & .484 & .561 & .247 \\
\hline \multirow{2}{*}{$\begin{array}{l}\text { Lifetime History } \\
\text { of Street drug } \\
\text { use }\end{array}$} & Pearson Correlation & .029 & -.141 & -.079 & -.152 & .096 & 1 & .011 & .212 & -.094 & .010 & .088 \\
\hline & Sig. (2-tailed) & .804 & .219 & .525 & .185 & .402 & & .927 & .063 & .414 & .929 & .443 \\
\hline \multirow{2}{*}{$\begin{array}{l}\text { Current Street } \\
\text { drug use }\end{array}$} & Pearson Correlation & -.039 & -.006 & -.110 & -.149 & .100 & .011 & 1 & -.131 & -.076 & .141 & .000 \\
\hline & Sig. (2-tailed) & .734 & .957 & .374 & .193 & .386 & .927 & & .253 & .508 & .218 & .997 \\
\hline \multirow{2}{*}{ PSI } & Pearson Correlation & .105 & .033 & $-.323(\star \star)$ & -.066 & -.068 & .212 & -.131 & 1 & .090 & $.634(\star \star)$ & $.550(* *)$ \\
\hline & Sig. (2-tailed) & .360 & .776 & .008 & .568 & .553 & .063 & .253 & & .364 & .000 & .000 \\
\hline \multirow{2}{*}{ LOT } & Pearson Correlation & -.102 & .083 & -.139 & -.061 & -.080 & -.094 & -.076 & .090 & 1 & $.196\left(^{*}\right)$ & .096 \\
\hline & Sig. (2-tailed) & .375 & .469 & .262 & .597 & .484 & .414 & .508 & .364 & & .046 & .334 \\
\hline \multirow{2}{*}{ HAM } & Pearson Correlation & .189 & .168 & -.122 & -.029 & -.067 & .010 & .141 & $.634\left({ }^{\star \star}\right)$ & $.196\left(^{*}\right)$ & 1 & $.750(* *)$ \\
\hline & Sig. (2-tailed) & .097 & .141 & .326 & .803 & .561 & .929 & .218 & .000 & .046 & & .000 \\
\hline \multirow{2}{*}{ BSI } & Pearson Correlation & $.251\left(^{*}\right)$ & .069 & -.108 & .033 & -.133 & .088 & .000 & $.550(* \star)$ & .096 & $.750(\star \star)$ & 1 \\
\hline & Sig. (2-tailed) & .026 & .549 & .383 & .776 & .247 & .443 & .997 & .000 & .334 & .000 & \\
\hline
\end{tabular}


Psychosocial Moderators124

Correlation Table for Immune Functioning, AIDS-Related Conditions, and Major Study Variables at Time Two

\begin{tabular}{|c|c|c|c|c|c|c|c|c|c|c|c|c|c|}
\hline & & CD4 & $\begin{array}{c}\text { Candidiasis of } \\
\text { Esophagus }\end{array}$ & CMV & HPV & PID & PCP & $\begin{array}{l}\text { Recurrent } \\
\text { bacterial } \\
\text { pneumonia }\end{array}$ & $\begin{array}{l}\text { Squamous } \\
\text { intraepithelial } \\
\text { neoplasm }\end{array}$ & HAM & BSI & LOT & PSI \\
\hline \multirow[t]{2}{*}{ CD4 } & $\begin{array}{l}\text { Pearson } \\
\text { Correlation }\end{array}$ & 1 & $-.248\left({ }^{\star}\right)$ & -.052 & -.109 & -.128 & -.207 & -.128 & -.017 & -.101 & -.080 & -.141 & -.206 \\
\hline & Sig. (2-tailed) & & .030 & .652 & .347 & .266 & .071 & .266 & .885 & .381 & .484 & .218 & .070 \\
\hline \multirow{2}{*}{$\begin{array}{l}\text { Candidiasis of } \\
\text { Esophagus }\end{array}$} & $\begin{array}{l}\text { Pearson } \\
\text { Correlation }\end{array}$ & $-.248\left(^{*}\right)$ & 1 & $.363(\star \star)$ & .130 & $.232\left(^{\star}\right)$ & $.467\left(^{\star \star}\right)$ & -.052 & -.064 & $.226\left(^{*}\right)$ & .138 & .173 & .206 \\
\hline & Sig. (2-tailed) & .030 & & .001 & .261 & .042 & .000 & .656 & .582 & .049 & .233 & .133 & .073 \\
\hline \multirow[t]{2}{*}{ CMV } & $\begin{array}{l}\text { Pearson } \\
\text { Correlation }\end{array}$ & -.052 & $.363(* *)$ & 1 & -.027 & -.019 & -.030 & -.019 & -.023 & .064 & .130 & .040 & .129 \\
\hline & Sig. (2-tailed) & .652 & .001 & & .817 & .872 & .794 & .872 & .842 & .581 & .260 & .727 & .263 \\
\hline \multirow[t]{2}{*}{ HPV } & $\begin{array}{l}\text { Pearson } \\
\text { Correlation }\end{array}$ & -.109 & .130 & -.027 & 1 & -.038 & .176 & -.038 & $.558\left(^{* *}\right)$ & .114 & .025 & -.044 & -.012 \\
\hline & Sig. (2-tailed) & .347 & .261 & .817 & & .741 & .126 & .741 & .000 & .323 & .832 & .701 & .916 \\
\hline \multirow[t]{2}{*}{ PID } & $\begin{array}{l}\text { Pearson } \\
\text { Correlation }\end{array}$ & -.128 & $.232\left(^{*}\right)$ & -.019 & -.038 & 1 & -.043 & -.027 & -.033 & .180 & $.248\left(^{*}\right)$ & .102 & -.020 \\
\hline & Sig. (2-tailed) & .266 & .042 & .872 & .741 & & .710 & .818 & .777 & .116 & .030 & .378 & .864 \\
\hline \multirow[t]{2}{*}{ PCP } & $\begin{array}{l}\text { Pearson } \\
\text { Correlation }\end{array}$ & -.207 & $.467(* *)$ & -.030 & .176 & -.043 & 1 & -.043 & -.053 & $.306(* *)$ & $.258\left(^{*}\right)$ & -.021 & $.380(* *)$ \\
\hline & Sig. (2-tailed) & .071 & .000 & .794 & .126 & .710 & & .710 & .647 & .007 & .024 & .853 & .001 \\
\hline \multirow{2}{*}{$\begin{array}{l}\text { Recurrent } \\
\text { bacterial } \\
\text { pneumonia }\end{array}$} & $\begin{array}{l}\text { Pearson } \\
\text { Correlation }\end{array}$ & -.128 & -.052 & -.019 & -.038 & -.027 & -.043 & 1 & -.033 & .024 & .017 & -.075 & .158 \\
\hline & Sig. (2-tailed) & .266 & .656 & .872 & .741 & .818 & .710 & & .777 & .838 & .882 & .515 & .170 \\
\hline \multirow{2}{*}{$\begin{array}{l}\text { Squamous } \\
\text { intraepithelial } \\
\text { neoplasm }\end{array}$} & $\begin{array}{l}\text { Pearson } \\
\text { Correlation }\end{array}$ & -.017 & -.064 & -.023 & $.558(* \star)$ & -.033 & -.053 & -.033 & 1 & .018 & .063 & .011 & -.064 \\
\hline & Sig. (2-tailed) & .885 & .582 & .842 & .000 & .777 & .647 & .777 & & .874 & .587 & .922 & .580 \\
\hline \multirow[t]{2}{*}{ HAM } & $\begin{array}{l}\text { Pearson } \\
\text { Correlation }\end{array}$ & -.101 & $.226\left(^{*}\right)$ & .064 & .114 & .180 & $.306(* *)$ & .024 & .018 & 1 & $.750\left(^{\star \star}\right)$ & $.196\left(^{*}\right)$ & $.634(* *)$ \\
\hline & Sig. (2-tailed) & .381 & .049 & .581 & .323 & .116 & .007 & .838 & .874 & & .000 & .046 & .000 \\
\hline BSI & Pearson & -.080 & .138 & .130 & .025 & $.248\left(^{*}\right)$ & $.258\left(^{*}\right)$ & .017 & .063 & $.750^{(* *)}$ & 1 & .096 & $.550(* *)$ \\
\hline
\end{tabular}


Psychosocial Moderators 125

\begin{tabular}{|c|c|c|c|c|c|c|c|c|c|c|c|c|c|}
\hline & Correlation & & & & & & & & & & & & \\
\hline & Sig. (2-tailed) & .484 & .233 & .260 & .832 & .030 & .024 & .882 & .587 & .000 & & .334 & .000 \\
\hline \multirow[t]{2}{*}{ LOT } & $\begin{array}{l}\text { Pearson } \\
\text { Correlation }\end{array}$ & -.141 & .173 & .040 & -.044 & .102 & -.021 & -.075 & .011 & $.196\left(^{*}\right)$ & .096 & 1 & .090 \\
\hline & Sig. (2-tailed) & .218 & .133 & .727 & .701 & .378 & .853 & .515 & .922 & .046 & .334 & & .364 \\
\hline \multirow[t]{2}{*}{ PSI } & $\begin{array}{l}\text { Pearson } \\
\text { Correlation }\end{array}$ & -.206 & .206 & .129 & -.012 & -.020 & $\left..3800^{* \star}\right)$ & .158 & -.064 & $.634(* \star)$ & $.550(* \star)$ & .090 & 1 \\
\hline & Sig. (2-tailed) & .070 & .073 & .263 & .916 & .864 & .001 & .170 & .580 & .000 & .000 & .364 & \\
\hline
\end{tabular}

\begin{tabular}{|c|c|c|c|c|c|c|c|c|c|c|c|c|c|c|c|}
\hline \multicolumn{16}{|c|}{ Longitudinal Correlations for Demographic Variables and AIDS-Related Conditions at Time One and Major Study Variables at Time Two } \\
\hline & & $\begin{array}{l}\text { PSI } \\
\text { Tim } \\
\text { e } 2\end{array}$ & $\begin{array}{l}\text { Most } \\
\text { Recent } \\
\text { CD4\# }\end{array}$ & $\begin{array}{c}\text { PSI } \\
\text { Time } 1\end{array}$ & $\begin{array}{l}\text { LOT } \\
\text { Time } 1\end{array}$ & $\begin{array}{l}\text { HAM (COG) } \\
\text { Time } 1\end{array}$ & $\begin{array}{l}\text { BSI (DEP) } \\
\text { Time } 1\end{array}$ & $\begin{array}{l}\text { Marital } \\
\text { Status }\end{array}$ & $\begin{array}{l}\text { Years of } \\
\text { Schooling }\end{array}$ & Age & Employment & Income & $\begin{array}{l}\text { Number } \\
\text { of } \\
\text { Children } \\
\text { given } \\
\text { birth to }\end{array}$ & $\begin{array}{l}\text { Lifetime } \\
\text { History } \\
\text { of Street } \\
\text { drug } \\
\text { use }\end{array}$ & $\begin{array}{l}\text { Current } \\
\text { Use of } \\
\text { Street } \\
\text { drugs }\end{array}$ \\
\hline \multirow{2}{*}{ PSI Time 2} & $\begin{array}{l}\text { Pearson } \\
\text { Correlation }\end{array}$ & 1 & $.194\left(^{*}\right)^{-}$ & $.567\left(^{\star \star}\right)$ & $.218(*)$ & $.490(* *)$ & $.474(* *)$ & .059 & -.121 & .144 & -.190 & .057 & .037 & $.324(* \star)$ & -.043 \\
\hline & Sig. (2-tailed) & & .049 & .000 & .029 & .000 & .000 & .552 & .219 & .144 & .073 & .565 & .706 & .001 & .667 \\
\hline \multirow[t]{2}{*}{$\begin{array}{l}\text { Most Recent } \\
\text { CD4\# }\end{array}$} & $\begin{array}{l}\text { Pearson } \\
\text { Correlation }\end{array}$ & $\begin{array}{r}- \\
.194 \\
\left(^{*}\right)\end{array}$ & 1 & -.091 & .008 & .051 & .050 & -.023 & .070 & -.045 & $.246\left(^{*}\right)$ & -.081 & .045 & -.021 & -.078 \\
\hline & Sig. (2-tailed) & .09 & & .367 & .936 & .617 & .619 & .814 & .478 & .651 & .019 & .416 & .652 & .836 & .432 \\
\hline \multirow[t]{2}{*}{ PSI Time 1} & $\begin{array}{l}\text { Pearson } \\
\text { Correlation }\end{array}$ & $\begin{array}{r}.567 \\
(\star \star)\end{array}$ & -.091 & 1 & .173 & $.522(* \star)$ & $\left..596{ }^{(\star *}\right)$ & .030 & -.017 & .043 & -.100 & -.045 & .046 & $.238\left(^{*}\right)$ & .043 \\
\hline & Sig. (2-tailed) & .000 & .367 & & .087 & .000 & .000 & .765 & .869 & .668 & .356 & .652 & .649 & .017 & .670 \\
\hline \multirow[t]{2}{*}{ LOT Time 1} & $\begin{array}{l}\text { Pearson } \\
\text { Correlation }\end{array}$ & $\begin{array}{r}.218 \\
\left({ }^{*}\right)\end{array}$ & .008 & .173 & 1 & .052 & .137 & -.018 & -.035 & .062 & $-.303(* *)$ & .052 & .081 & -.003 & -.191 \\
\hline & Sig. (2-tailed) & $\mid 029$ & .936 & .087 & & .611 & .175 & .856 & .730 & .543 & .004 & .609 & .424 & .980 & .056 \\
\hline \multirow[t]{2}{*}{ HAM Time 1} & $\begin{array}{l}\text { Pearson } \\
\text { Correlation }\end{array}$ & $\begin{array}{r}.490 \\
(* *)\end{array}$ & .051 & $.522(* *)$ & .052 & 1 & $\left..810^{(* \star}\right)$ & -.082 & -.082 & -.065 & $-.261\left(^{\star}\right)$ & -.148 & $.210\left(^{*}\right)$ & .180 & .041 \\
\hline & Sig. (2-tailed) & .000 & .617 & .000 & .611 & & .000 & .419 & .416 & .517 & .015 & .143 & .036 & .074 & .688 \\
\hline BSI Time 1 & $\begin{array}{l}\text { Pearson } \\
\text { Correlation }\end{array}$ & $\begin{array}{r}.474 \\
(\star \star)\end{array}$ & .050 & $.596\left(^{* \star}\right)$ & .137 & $\left..810^{(* *}\right)$ & 1 & -.048 & -.057 & .025 & -.116 & .007 & .188 & .189 & .043 \\
\hline
\end{tabular}




\begin{tabular}{|c|c|c|c|c|c|c|c|c|c|c|c|c|c|c|c|}
\hline & Sig. (2-tailed) & .000 & .619 & .000 & .175 & .000 & & .633 & .570 & .806 & .282 & .942 & .058 & .058 & .667 \\
\hline \multirow[t]{2}{*}{ Marital Status } & $\begin{array}{l}\text { Pearson } \\
\text { Correlation }\end{array}$ & .059 & -.023 & .030 & -.018 & -.082 & -.048 & 1 & .148 & $.377\left(^{\star \star}\right)$ & .174 & $.208\left(^{*}\right)$ & -.034 & .160 & -.091 \\
\hline & Sig. (2-tailed) & .552 & .814 & .765 & .856 & .419 & .633 & & .134 & .000 & .102 & .034 & .732 & .104 & .356 \\
\hline \multirow[t]{2}{*}{ Schooling } & $\begin{array}{l}\text { Pearson } \\
\text { Correlation }\end{array}$ & $.121^{-}$ & .070 & -.017 & -.035 & -.082 & -.057 & .148 & 1 & .066 & .112 & .035 & -.192 & -.086 & -.158 \\
\hline & Sig. (2-tailed) & .219 & .478 & .869 & .730 & .416 & .570 & .134 & & .507 & .295 & .724 & .050 & .383 & .110 \\
\hline \multirow[t]{2}{*}{ Age } & $\begin{array}{l}\text { Pearson } \\
\text { Correlation }\end{array}$ & .144 & -.045 & .043 & .062 & -.065 & .025 & $.377(* *)$ & .066 & 1 & .160 & .037 & .025 & .127 & .017 \\
\hline & Sig. (2-tailed) & .144 & .651 & .668 & .543 & .517 & .806 & .000 & .507 & & .132 & .706 & .803 & .201 & .868 \\
\hline \multirow[t]{2}{*}{ Employment } & $\begin{array}{l}\text { Pearson } \\
\text { Correlation }\end{array}$ & $.190^{-}$ & $.246\left(^{*}\right)$ & -.100 & $\begin{array}{r}- \\
.303(* \star\end{array}$ & $-.261\left(^{*}\right)$ & -.116 & .174 & .112 & .160 & 1 & $\left..310{ }^{* *}\right)$ & -.114 & -.168 & .040 \\
\hline & Sig. (2-tailed) & .073 & .019 & .356 & .004 & .015 & .282 & .102 & .295 & .132 & & .003 & .286 & .113 & .706 \\
\hline \multirow[t]{2}{*}{ Income } & $\begin{array}{l}\text { Pearson } \\
\text { Correlation }\end{array}$ & .057 & -.081 & -.045 & .052 & -.148 & .007 & $.208\left(^{*}\right)$ & .035 & .037 & $.310(* \star)$ & 1 & .035 & .033 & .005 \\
\hline & Sig. (2-tailed) & .565 & .416 & .652 & .609 & .143 & .942 & .034 & .724 & .706 & .003 & & .721 & .737 & .961 \\
\hline \multirow{2}{*}{$\begin{array}{l}\text { Number of } \\
\text { Children } \\
\text { given birth to }\end{array}$} & $\begin{array}{l}\text { Pearson } \\
\text { Correlation }\end{array}$ & .037 & .045 & .046 & .081 & $.210\left(^{*}\right)$ & .188 & -.034 & -.192 & .025 & -.114 & .035 & 1 & $.226\left(^{\star}\right)$ & .047 \\
\hline & Sig. (2-tailed) & .706 & .652 & .649 & .424 & .036 & .058 & .732 & .050 & .803 & .286 & .721 & & .021 & .638 \\
\hline \multirow{2}{*}{$\begin{array}{l}\text { Lifetime } \\
\text { History of } \\
\text { Street drug } \\
\text { use }\end{array}$} & $\begin{array}{l}\text { Pearson } \\
\text { Correlation }\end{array}$ & $\begin{array}{r}.324 \\
(* \star)\end{array}$ & -.021 & $.238\left(^{\star}\right)$ & -.003 & .180 & .189 & .160 & -.086 & .127 & -.168 & .033 & $.226\left({ }^{\star}\right)$ & 1 & .015 \\
\hline & Sig. (2-tailed) & .001 & .836 & .017 & .980 & .074 & .058 & .104 & .383 & .201 & .113 & .737 & .021 & & .884 \\
\hline \multirow{2}{*}{$\begin{array}{l}\text { Current Use } \\
\text { of Street } \\
\text { drugs }\end{array}$} & $\begin{array}{l}\text { Pearson } \\
\text { Correlation }\end{array}$ & $.043^{-}$ & -.078 & .043 & -.191 & .041 & .043 & -.091 & -.158 & .017 & .040 & .005 & .047 & .015 & 1 \\
\hline & Sig. (2-tailed) & .667 & .432 & .670 & .056 & .688 & .667 & .356 & .110 & .868 & .706 & .961 & .638 & .884 & \\
\hline
\end{tabular}

Longitudinal Correlations for Immune Variables and AIDS-Related Conditions at Time One and Major Study Variables at Time Two

\begin{tabular}{|c|c|c|c|c|c|c|c|c|c|c|c|c|c|c|c|}
\hline & & $\begin{array}{l}\text { PSI } \\
\text { Tim } \\
\text { e } 2\end{array}$ & $\begin{array}{l}\text { Most } \\
\text { Recent } \\
\text { CD4\# }\end{array}$ & $\begin{array}{c}\text { PSI } \\
\text { Time } 1\end{array}$ & $\begin{array}{l}\text { LOT } \\
\text { Time } 1\end{array}$ & $\begin{array}{c}\text { HAM (COG) Time } \\
1\end{array}$ & $\begin{array}{c}\text { BSI } \\
\text { (DEP) } \\
\text { Time } 1\end{array}$ & $\begin{array}{l}\text { Marital } \\
\text { Status }\end{array}$ & $\begin{array}{l}\text { Years of } \\
\text { Schooling }\end{array}$ & Age & Employment & Income & $\begin{array}{l}\text { Number } \\
\text { of } \\
\text { Children } \\
\text { given } \\
\text { birth to }\end{array}$ & $\begin{array}{l}\text { Lifetime } \\
\text { History } \\
\text { of Street } \\
\text { drug } \\
\text { use }\end{array}$ & $\begin{array}{l}\text { Current } \\
\text { Use of } \\
\text { Street } \\
\text { drugs }\end{array}$ \\
\hline PSI Time 2 & Pearson & 1 & & $.567^{(* *)}$ & $218\left(^{*}\right)$ & $4.90(* *)$ & $474^{(*)}$ & .059 & -.121 & .144 & -.190 & .057 & 0.37 & $.324(* \star)$ & -.043 \\
\hline
\end{tabular}


Psychosocial Moderators127

\begin{tabular}{|c|c|c|c|c|c|c|c|c|c|c|c|c|c|c|c|}
\hline & Correlation & & $.194\left(^{*}\right)$ & & & & & & & & & & & & \\
\hline & Sig. (2-tailed) & & .049 & .000 & .029 & .000 & .000 & .552 & .219 & .144 & .073 & .565 & .706 & .001 & .667 \\
\hline \multirow[t]{2}{*}{$\begin{array}{l}\text { Most Recent } \\
\text { CD4\# }\end{array}$} & $\begin{array}{l}\text { Pearson } \\
\text { Correlation }\end{array}$ & $\begin{array}{r}- \\
.194 \\
\left({ }^{*}\right)\end{array}$ & 1 & -.091 & .008 & .051 & .050 & -.023 & .070 & -.045 & $.246\left(^{*}\right)$ & -.081 & .045 & -.021 & -.078 \\
\hline & Sig. (2-tailed) & .09 & & .367 & .936 & .617 & .619 & .814 & .478 & .651 & .019 & .416 & .652 & .836 & .432 \\
\hline \multirow[t]{2}{*}{ PSI Time 1} & $\begin{array}{l}\text { Pearson } \\
\text { Correlation }\end{array}$ & $\begin{array}{r}.567 \\
(* \star)\end{array}$ & -.091 & 1 & .173 & $.522(* \star)$ & $.596(* \star)$ & .030 & -.017 & .043 & -.100 & -.045 & .046 & $.238\left(^{*}\right)$ & .043 \\
\hline & Sig. (2-tailed) & .000 & .367 & & .087 & .000 & .000 & .765 & .869 & .668 & .356 & .652 & .649 & .017 & .670 \\
\hline \multirow[t]{2}{*}{ LOT Time 1} & $\begin{array}{l}\text { Pearson } \\
\text { Correlation }\end{array}$ & $\begin{array}{r}.218 \\
(*)\end{array}$ & .008 & .173 & 1 & .052 & .137 & -.018 & -.035 & .062 & $-.303(\star *)$ & .052 & .081 & -.003 & -.191 \\
\hline & Sig. (2-tailed) & .029 & .936 & .087 & & .611 & .175 & .856 & .730 & .543 & .004 & .609 & .424 & .980 & .056 \\
\hline \multirow[t]{2}{*}{ HAM Time 1} & $\begin{array}{l}\text { Pearson } \\
\text { Correlation }\end{array}$ & $\begin{array}{r}.490 \\
(* *)\end{array}$ & .051 & $.522(\star \star)$ & .052 & 1 & $\left..810^{(\star \star}\right)$ & -.082 & -.082 & -.065 & $-.261\left(^{*}\right)$ & -.148 & $.210\left(^{*}\right)$ & .180 & .041 \\
\hline & Sig. (2-tailed) & .000 & .617 & .000 & .611 & & .000 & .419 & .416 & .517 & .015 & .143 & .036 & .074 & .688 \\
\hline \multirow[t]{2}{*}{ BSI Time 1} & $\begin{array}{l}\text { Pearson } \\
\text { Correlation }\end{array}$ & $\begin{array}{r}.474 \\
(* *)\end{array}$ & .050 & $.596(* \star)$ & .137 & $\left..810^{(\star \star}\right)$ & 1 & -.048 & -.057 & .025 & -.116 & .007 & .188 & .189 & .043 \\
\hline & Sig. (2-tailed) & .000 & .619 & .000 & .175 & .000 & & .633 & .570 & .806 & .282 & .942 & .058 & .058 & .667 \\
\hline \multirow[t]{2}{*}{ Marital Status } & $\begin{array}{l}\text { Pearson } \\
\text { Correlation }\end{array}$ & .059 & -.023 & .030 & -.018 & -.082 & -.048 & 1 & .148 & $.377(* \star)$ & .174 & $.208\left(^{*}\right)$ & -.034 & .160 & -.091 \\
\hline & Sig. (2-tailed) & .552 & .814 & .765 & .856 & .419 & .633 & & .134 & .000 & .102 & .034 & .732 & .104 & .356 \\
\hline \multirow[t]{2}{*}{ Schooling } & \begin{tabular}{|l|} 
Pearson \\
Correlation
\end{tabular} & $.121^{-}$ & .070 & -.017 & -.035 & -.082 & -.057 & .148 & 1 & .066 & .112 & .035 & -.192 & -.086 & -.158 \\
\hline & Sig. (2-tailed) & .219 & .478 & .869 & .730 & .416 & .570 & .134 & & .507 & .295 & .724 & .050 & .383 & .110 \\
\hline \multirow[t]{2}{*}{ Age } & $\begin{array}{l}\text { Pearson } \\
\text { Correlation }\end{array}$ & .144 & -.045 & .043 & .062 & -.065 & .025 & $.377(* \star)$ & .066 & 1 & .160 & .037 & .025 & .127 & .017 \\
\hline & Sig. (2-tailed) & .144 & .651 & .668 & .543 & .517 & .806 & .000 & .507 & & .132 & .706 & .803 & .201 & .868 \\
\hline \multirow[t]{2}{*}{ Employment } & $\begin{array}{l}\text { Pearson } \\
\text { Correlation }\end{array}$ & $.190^{-}$ & $.246\left(^{*}\right)$ & -.100 & $\left..303^{(* \star}\right)$ & $-.261\left(^{*}\right)$ & -.116 & .174 & .112 & .160 & 1 & $.310(* *)$ & -.114 & -.168 & .040 \\
\hline & Sig. (2-tailed) & .073 & .019 & .356 & .004 & .015 & .282 & .102 & .295 & .132 & & .003 & .286 & .113 & .706 \\
\hline Income & $\begin{array}{l}\text { Pearson } \\
\text { Correlation }\end{array}$ & .057 & -.081 & -.045 & .052 & -.148 & .007 & $.208\left(^{*}\right)$ & .035 & .037 & $\left..310^{\star \star *}\right)$ & 1 & .035 & .033 & .005 \\
\hline
\end{tabular}


Psychosocial Moderators128

\begin{tabular}{|c|c|c|c|c|c|c|c|c|c|c|c|c|c|c|c|}
\hline & Sig. (2-tailed) & .565 & .416 & .652 & .609 & .143 & .942 & .034 & .724 & .706 & .003 & & .721 & .737 & .961 \\
\hline \multirow{2}{*}{$\begin{array}{l}\text { Number of } \\
\text { Children } \\
\text { given birth to }\end{array}$} & $\begin{array}{l}\text { Pearson } \\
\text { Correlation }\end{array}$ & .037 & .045 & .046 & .081 & $.210\left(^{*}\right)$ & .188 & -.034 & -.192 & .025 & -.114 & .035 & 1 & $.226\left(^{*}\right)$ & .047 \\
\hline & Sig. (2-tailed) & .706 & .652 & .649 & .424 & .036 & .058 & .732 & .050 & .803 & .286 & .721 & & .021 & .638 \\
\hline \multirow{2}{*}{$\begin{array}{l}\text { Lifetime } \\
\text { History of } \\
\text { Street drug } \\
\text { use }\end{array}$} & $\begin{array}{l}\text { Pearson } \\
\text { Correlation }\end{array}$ & $\begin{array}{r}.324 \\
(* *)\end{array}$ & -.021 & $.238\left(^{*}\right)$ & -.003 & .180 & .189 & .160 & -.086 & .127 & -.168 & .033 & $.226\left(^{*}\right)$ & 1 & .015 \\
\hline & Sig. (2-tailed) & .001 & .836 & .017 & .980 & .074 & .058 & .104 & .383 & .201 & .113 & .737 & .021 & & .884 \\
\hline \multirow{2}{*}{$\begin{array}{l}\text { Current Use } \\
\text { of Street } \\
\text { drugs }\end{array}$} & $\begin{array}{l}\text { Pearson } \\
\text { Correlation }\end{array}$ & .043 & -.078 & .043 & -.191 & .041 & .043 & -.091 & -.158 & .017 & .040 & .005 & .047 & .015 & 1 \\
\hline & Sig. (2-tailed) & .667 & .432 & .670 & .056 & .688 & .667 & .356 & .110 & .868 & .706 & .961 & .638 & .884 & \\
\hline
\end{tabular}

